

\title{
DISCLAIMER
}

This report was prepared as an acoount of work sponsored by an azency of the United States Government. Neither the United States Government nor any agency thereof, nor any of their employes, make any warranty, express or implied, or astumes any legal liability or ropons;bility for the aceuracy, completeness, or usefulness of any information, apparatus, produch, of process disclosed, or represents that its use would not infringe privately ownod tights. Reference herein to any specific commercial product, process, or service by trade name, tradernark, manufacturer, of otherwise does not necensarily constitute or imply its endorsement, recommendation, or favoring by the Unitad States Government or any agency thereof. The views and opiaions of authors expressed hesein do not necessarily state or reflect those of the United States Government or apy agency thereof.
UCRL-15688

PSA-4312705

\section{HUMAN FACTORS REVIEW PLAN}

\author{
December 1985
}

\author{
Barbara Paramore \\ L. Rolf Peterson \\ Editors
}

\section{Prepared for:}

U.S. Department of Energy

Office of Nuclear Safety

by

Lawrence Livermore National Laboratory

Livermore, California 94550

and

Essex Corporation

Alexandria, Virginia 22314 


\section{EXECUTIVE SUMMARY}

"Human Factors" is concerned with the incorporation of human user considerations into a system in order to maximize human reliability and reduce errors. This Review Plan is intended to assist in the assessment of human factors conditions in existing DOE facilities. In eddition to specifying assessment methodologies, the Plan describes technigues for improving conditions which are found to not adequately support reliable human performance.

The Introduction provides an overview of human factors as a discipline, describes DOE initiatives to improve human factors at DOE nuclear facilities, and describes the objectives and scope of the Review Plan. Section 2.0, Managing a Review, provides guidance to management on structuring and tajloring a human factors review based on the specific characteristics of a particular facility.

The remaining five sections address the following topics:

- Selection of Areas for Review - describes techniques for needs assessment to assist in selecting and prioritizing areas for review

- Human Factors Engineering Review - is concerned with optimizing the interfaces between people and equipment and people and their work environment

- Procedures Review - evaluates completeness and accuracy of procedures, as well as their usability and management

- Organizational Interface Review - is concerned with communication and coordination between all levels of an organizition

- Training Review - evaluates training program criteria such as those involving: trainee selection, qualification of training staff, content and conduct of training, requalification training, and program manegement.

Each of the above sections discuss personnel requirements for the review, presents evaluation criteria and methods, and gives options for problem resolution.

The Appendix, at the end of the Review Plan, has been designed to facilitate access to review aids and references for each of the five review sections. Tables, Figures, and 
Exhibits that are not essential to text comprehension, along with references, have been placed in the associated section of the Appendix, thereby streamlining the text and making reference materials readily available. 


\section{TABLE OF CONTENTS}

\section{PAGE}

EXECUTNE SUMMARY

ii

ACKNOWLEDGEMENTS

iv

1.0 INTRODUCTION

1.1 Overview of Human Factors Goals, Issues, and Applications 1

1.2 Initia tives to Improve Human Factors at Department of Energy 2 Nuclear Facilities

1.3 Objectives and Scope of the Review Plan 4

1.3.1 Applicability 4

1.3.2 Selection Among Review Options 4

1.4 Organization of the Review Plan 5

2.0 MANAGING A HUMAN FACTORS REVIEW 6

2.1 Program Management Structure 6

2.2 Steering Committee Composition ?

2.3 Human Factors Review Program Director

2.4 Review Program Participants 8

2.5 Assessment Team Participants 9

2.6 Nanagement of the Program 9

3.0 SELECTION OF AREAS FOR REVIEW

3.1 Needs Assessment 11

3.1.1 Needs Assessment Personnel 11

3.1.2 Questionnaire Development 12

3.1.3 Selection of Needs Assessment Questionnaire Respondents 14

3.1.4 Questionnaire Distribution and Response 14

$\begin{array}{ll}3.1 .5 \text { Interviews } & 15\end{array}$

3.1.6 Analysis and Interpretation of Questionnaire Date 15

3.1.7 Establishment of Assessment Criteria 16

3.1.8 Assessment Procedure 17 


\section{TABLE OF CONTENTS (continued)}

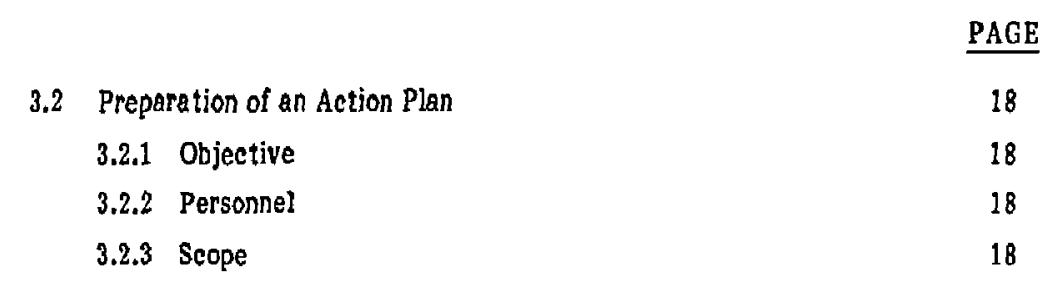

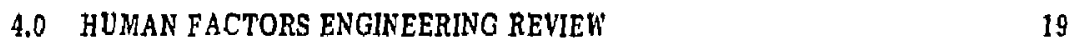

4.1 Review Objectives 20

4,2 Review Criteria 21

4.3 Planning for an HFE Review 22

4.3.1 Selection of Methods 22

4.3.2 Personnel Requirements for an HFE Review 22

4.3.3 Scheduling 23

4.3.4 Preparation of a Facility-Specific Review Plan 23

4.3.5 Preparation of Review Aids 23

4.3.6 Personnel Briefings 24

4.4 Review Methods 24

4.4.1 Operating Experience Review 25

4.4.2 Observation Checklist Survey 32

1.3 Systems Analysis Approach to HFE Review 35

4.4.4 Comparison of HFE Review Methods 41

4.5 Assessment and Resolution of HFE Discrepancies 43

4.5.1 Assessment Team 43

4.5.2 Assessment and Resolution Steps 43

5.0 PROCEDURES REVIEW 48

5.1 Review Objectives 49

5.2 Review Criteria 49

5.3 Trade-Offs in Determining the Scope and Costs of Procedures Review 49 


\section{TABLE OP CONTENTS (continued)}

\section{PAGE}

5.4 Review Methods 50

5.4.1 Verification of the Technical Accuracy and Compieteness of 51 Existing Procedures ("technical verifjcation")

5.4.2 Verification of the Presentation Design Adequacy of Existing 55 Procedures ("procedure design verification")

5.4.3 Validation of the Performance Effectiveness of Existing 58 Procedures

5.4.4 Evaluation of the Procedures Management System 62

5.4.5 Assessment of Needs for Additional Procedures 63

5.5 Assessment and Resolution of Findings from the Procedures Review 67

$\begin{array}{lll}5.5 .1 & \text { Objectives } & 67\end{array}$

$\begin{array}{lll}5.5 .2 & \text { Personnel } & 67\end{array}$

$\begin{array}{ll}5.5 .3 & \text { Preparation } \\ & 67\end{array}$

5.5.4 Assessment Methods 68

$\begin{array}{lll}5.5 .5 & \text { Resolution } & 69\end{array}$

6.0 ORGANIZATIONAL INTE'RFACE REVIEW

6.1 Review Objectives $\quad 72$

6.2 Establishment of Diagnostic Criteria 72

6.2.1 Timeliness : 73

$\begin{array}{lll}6.2 .2 & \text { Redundancy } & 73\end{array}$

6.2.3 Gatekeeping/Withholding Information 74

6.2.4 Feedback

6.2.5 Information Amount $\quad 74$

6.2.6 Quality of Work-Related Documentation 75

$\begin{array}{ll}6.2 .7 & \text { Other Indices }\end{array}$

6.3 Methods of Problem Identification 76

6.3.1 Organizational Interface Review Team 76

6.3.2 Definition of the Organizational/Interface Review Process 77 


\section{TABLE OF CONTENTS (continued)}

\section{PAGE}

6.4 Methods of Problem Solving 82

6.4.1 Quality Circles 83

6.4.2 Interdepartmental Job Coordination Meetings 83

6.4.3 Maintenance Managentent Information Systerns (MIS) 84

6.4.4 Orientation Training 85

6.4.5 Modification of the Organizational Structure 86

6.5 Assessment of Possible Solutions To Improve Organizational Interfaces B6

6.5.1 Criteria 86

6.5.2 Assessment Procedure 87

7.0 TRAINING REVIEW

$\begin{array}{lll}7.1 & \text { Background } & 88\end{array}$

7.2 Application 89

7.2.1 Training Review Objective

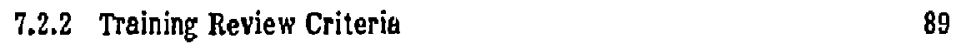

7.2.3 Training Review Method 90

APPENDIX $A-1$

INDEX 


\subsection{RNTRODUCTON}

\subsection{Overview of Human Factors Goals, lsoues, and Applications}

The explosive growth of sophisticated technological systems over the last decades has produced enormous benefits for every aspect of society. Increasing machine power has enabled man to engage in processes and operate on a scale that, until recently, were barely imaginable. Technological advancement has, however, brought its own set of problems. Human endeavors involve hazards of a far greater magnitude than in the past. In many settings it is being realized that the most remarkable technology will be of linited value when it is implemented without proper consideration of jts suitability for people - its users, controllers, and maintainers. Accidents, injury, systems with high failure rates, and even abandoned systems attest to the problems. So does the growth of related legislation, regulation, and litigation.

Many problems can be traced to the interfaces between teahnology and the people who operate and maintain a system. People make errors: errors of omission, commission, precision, timing and sequencing, as they perform the tasks associated with system operations and maintenance. Few of these errors, hcwever, are random. Humans are remarkably reliable if appropriate conditions. Most human error is associated with situational factors that can be removed either during system design or, later, in an operational system, by retrofits of one form or another. Little can be cone to eliminate random human error. Much can be done to eliminate conditions that promote human error and to provide adequate margins of safety where neither human ertor nor equipment malfunetions can be tolerated.

The branch of technology that is concerned with the reduction of human error in system operations and maintenance is called "human factors." Human factors uses the principles, methods, and data of engineering and behavioral science to design systems that maximize human reliability. Human reliability is a function of:

- The physical interface between people and equipment

o The environments in which people work 
- The type and amount of training they receive

- The accuracy and ease of use of the procedures they are given for guidance

- The effectiveness of the organization in which they work.

A human-machine interface that impairs the flow of information between instruments and a person or that impedes control actions can induce erros. A work environment that is noisy, poorly iluminated, or improperly ventilated can induce human error. Training that does not provide all necessary skills and knowledge and does not provide opportunity to learn and practice job tasks can induce error. Procedures that are incomplete, poorly formatted, and difficult to use can induce error. When more than one of these conditions exist, the combination has a conpounding effect that further increases the probability of human error.

\subsection{Initiatives to Improve Human Factors at Department of Bnergy Nuclear Paeilities}

The Department of Energy (DOE) is committed to the goal of maintaining at each DOE nuclear facility a level of safety assurance that is adequate to protect the public and facility personnel. This goal necessitates consideration of human factors. It does not, however, require that all facilities adhere to a single set of requirements for human factors applications. The diversity of DOE facilities missions, activities, sizes, and resources must be taken into account in deciding how the safety goal can best be accomplished at each facility. Each facility should evaiuate its own human factors problems to determine whare improvements may be needed and how they can best be made.

DOE's Office of Nuclear Safety has established a Human Factors Application Program to assist DOE nuclear facilities in efforts to enhance human factors. Four program elements have been defined:

1. Provide guidance for facility initiatives to assess humen factors applications. 
2. Provide guidance concerning humen factors engineering ariteria ayplicable in the design of human-machine systems for new tucilities, and in the design of new systems or system modifications at existing facilities.

3. Promote coordination of activities related to human factors engineering, procedures, training, and other factors in personnel performance and safety, to achieve an integrgted aprlication of good human factors and facility desisn, operations, maintenance, and safety.

4. Promcte exchange of human factors information throughout DOE headquarters, field offices, and contractor organizations.

Several steps have already been taken towar: meeting these objectives:

c Workshops to develop awareness of human factors technology have been conducted in regional locations. The workshops, astended iy both contractor farility personnel and $\mathrm{DOE}$ fjeld office personnel, provide an orientation to human factors concervis, principles, methods and criteria.

- Guidance for training program development and evaluation has been issued.

- An annotated bibliography of human factors literature has been develoyed as an information resource for DOE and contractor personnel.

- Human factors engineering dosign guidelines for system and equipment maintairability have beun prepared. The maintainability guidelines are app!icable to the design of new systems and equipment and also may be used for review and enhancement of the maintainability of existing systems and equipment.

This Human Factors keview Plan provides guidance for a range of humin facturs application areas. It is offered to assist in the assessment of human factors conditions at existing facilities. The Review Plan describes criteria and methods that may be selectively used to improve human factors as determined to be appropriate at a particular facility. Other sources of criteria and methodological guidance are referenced. The objectives and scope of the Review Plen are discussed in more detail beiow. 


\subsection{Objectives and Scope of the Review Plan}

Nuclear facilities, like other complex systems, have many interfaces with human beings. These interfaces consist of:

0 The human-machine interface
$0 \quad$ The human-environment inter face
- The human-procedures interface
- The human-organizational inter face
- The human training interface.

The principal objective of this Review Plan is to identify practical methods that may be used to evaluate the adequacy of each of these interfaces in existing DOE facilities. The Plan also identifies techniques that can be employed to improve interfaces that have been fcund to be less than adequate supports for reliable human performance.

\subsubsection{Applicability}

Given the large numicer of DOE nuclear facilities already in operation compared with the number being designea, the methods presented here were designed mainly to be applicabl s to existing facilities. Approsches for use in facility design are not presented here.

An effort has been made to provide guidance that will be applicable across the different types of DOE facilities. Thus it can be expected that this Plan may not precisely fit a particular facility. Rather, its goal is to provide a framework within which a facility can plan a human factors improvement program to meet its unique needs.

\subsubsection{Selection Among Review Options}

Since it may not be economically feasible to review all interfaces in detail, this plan provides guidance for selecting the typas of interfaces that should be reviewed. Moreover, within individual areas of review, alternative review methods are described and compared so that choices among them may be made. 
Finelly, this plan provides guidance in deciding which of the humin factors problems identified during a review should be corrected, and in deciding the priority among those to be corrected.

\subsection{Organization of the Review Plan}

Section 2.0 of this Review Plan provides guidance to management on structuring a human factors review program for a facility. The focus is on ensuring that the scope of the review is tailored to the particular needs of the individual facility, that appropriate personnel resources are identified, and that the program is conducted in an integrated manner. The remainder of the Review Plan is organized on the basis of application areas.

First, techricules for needs assessment are described, to assist in the selection and prinritization of areas for review. This material is presented in section 3.0.

Then methods of conducting a review in each area are described in the following sections:

- 4.0 Human Factors Fngineering Review

- 5.0 Procedures Review

- 6.0 Organizational Interface Review

- 7.0 Training Review.

Reference lists and examples of review aids for each applieation area are provided in the Appendix. 


\section{ACRNOWLEDGEMENTS}

A number of people contributed to the development of this Review Plan. Advisors in planning the content of the document were: Charles M. Campbell, of the Office of Nuclear Safety; L. Rolf Peterson and Willian W. Banks, of Lawrence Livermore National Laboratory; and Harold P. Van Cott, of Essex Corporetion. Mr. Peterson and Barbara Paramore, of Essex Corporation, served as content editors.

Chapter authors were:
- 1.0 Introduction: Harold P. Van Cott
- 2.0 Managing a Review: G. Allen Elliff, Jr.
- 3.0 Selection of Areas for Review: Marjorje B. Bauman
- 4.0 Human Factors Engineering Review: Barbara Paramore and Margery Davidson Boulette
- 5.0 Procedures Review: Barbara Paranore
- 6.0 Organizational Interface Review: Marjorie B. Bauman
- 7.0 Training Reviếw: Jeffrey Cochran.

Jennifer Goodson Stewart, of Essex Corporation, served as technical editor.

Misdeline A. Ryaby, of Essex Corporation, served as copy editor.

Venessa Weedon, Karen Wessel, and Bessie Aquino, of Essex Corporation, formatted and produced the document. 


\subsection{MANAGNG A HOMAN FACTORS REVIEW}

Potential benefits to be derived from effective implementation of a human factors review program at a DOE facility include improved safety for facility employees and the public, improved operational and maintenance efficiency and effectiveness, reductions in outagas and process :psets due to humari error, and reduced costs. The extent to which these benefits accrue as a result of a particular facility's implementation of a human factors review plan will depend on the initial structuring and staffing of the program and on the resources committed to it by management.

The emphasis in this section is on providing management with suggestions and guidance to halp ensure the success of the program. The key point to be made is that human error of commission or omission only manifests itself in the activities of maintainers and operators; the key to reducing the incidence of human error is identifying the underlying systematic causes that "set up" the hands-on operator or maintainer to make the error.

\subsection{Program Management Structure}

The organizational structure for management of a human factors review program should be tailored to the organizational structure of the particular DOE facility. It should, however, be designed to ensure that the following are addressed:

- Management representatives of operations, maintenance, engineering, training, and other relevant functional units should be involved as a steering committee. They should ensure that an appropriate review plan scope is defined and that the results of the review are directed at improving overall facility operations.

- The Human Factors Review Program Director should have management experience appropriate for management of a program of this scope. He should have objectivity with respect to any individual functional group within the facility organizational structure, and should have an understanding of the overall facility operation. 
- Appropriate involvement of personnel from the various furictional units within the facility organization should be available.

- Provisions should be made to ensure that the appropriate technical disciplines are available for necessary analyses.

- Representatives of operations, maintenance, engineering, training, and other relevant djsciplines should be involved in the assessment process and in the selection of retrofits to the existing systems, procedures, training program, or other areas to ensure that the most sost-effective solutions are chosen.

\subsection{Steering Committee Composition}

Potential benefits from a properly implemented human factors review will accrue because people will be able to do their jobs more effectively with less error. The data collection methodologies described in this guidebook are designed to identify situations where human factors problems exist and to provide management with sufficient information to identify the appropriate "fix" to improve the situation. Human error can occur because of inadequacies in system dasign, training, procedures, or organizational communication. Since potential solutions to the identified human factors problems can also fall in each of these areas, the steering Committee should include representatives of appropriate functional units as well as the line organizations being reviewed.

The Steering Committee should be given a charter defining its role and its responsibility for conduct of the human factors review. This charter should be approved by facility management at the appropriate level with responsibility for the systems no functions being reviewed, and with authority for implementing identified improvements.

The primary role of the Steering Committee should be to approve the scope of the review, approve the plan for the review, ensure that their respective organizational elements provide the necessary personnel and resources to support the review, and review any recommended changes and improvements recommended by the Assessment Team as a result of the review. 


\subsection{Human Factors Review Program Director}

A Human Factors Feview Program Director (Program Director) should be designated to provide overall coordination of the review and to provide continuity in management of the day to day activities. The Program Director's responsibilities should include coordination with the Steering Committee and with other personnel involved in the review. In addition, the Program Director should provide management direction to Review Team members and serve as Chairman of the Assessment Team.

\subsection{Review Program Participants}

The Review Team, under the direction of the Program Director, actually performs the review. The review teain should therefore include representatives of the organizational elements being reviewed, and should be made up of people with the appropriate technical quelifications.

The Review Team should have a core group of specialists in the fields of human factors, operations, training, organizational communications, and instrument and control engineering. The core team may be supplemented by individuals in oiher specific technical disciplines as necessary depending on the nature of the organizational function.

Recommended qualifications for the human factors specialist include a degree, preferably at the graduate level, in human factors engineering or engineering psychology. However, qualified human factors specialists may have received their formal academic training in other disciplines ranging from behavioral sciences to engineering. Therefore, the pertinent formal training requirements for human factors specialists on the Review Team should include course work in at leas! some of the following areas: human factors engineering, ergonomics, humen performance theory, sensory/perceptual processes, experimental design, quentitative methods/statistics, anthropometry, survey design, and industrial engineering/design. 
Since there is no single academic route, certification, or licensing requirement for qualifying as a human factors specialist, professional experience of prospective human factors specialists should be taken into account. As a guideline, five or more years experience is preferred for at least one human factors specialist on the Review Team. less experienced human factors porsonnel may effectively conduct review activities under the direction of the senior human factors speciaist.

For operations and maintenance personnel, a minimum of two years experience is recommended with the equipment and systems used by the organizations being reviewed. Engineering personnel and other disciplines should have a bachelor's degree or equivalent in a course of study relevant to the specific discipline, plis three years experience with the systems and equipments being used.

\subsection{Assessment Team Participants}

The Assessment Team is the group which reviews the îndings of the review team, determines the significance of the findings, and recommends improvements to the Steering Committee for implementation. The Program Director should serve as the Chairman of the Assessment Team. Other members should include the human factors specialist, the lead individual for each of the individual data collection tasks, and appropriate operations and other representatives from the organizational units being reviewed. Specific methodologies for assessment are described in the appropriate sections of this guidebook.

\subsection{Wanagenent of the Program}

The initial step in management of the review is to develop a Program Plan. The Program Plan silould define the scope of bire review and specify the authority of the review team to carry out its work. The Program Plan should also specify the participants and their roles, 


\subsection{SELECTION OF AREAS FOR REVEY}

Most facilities will not be able to undertake a complete human factors review at any given time, but will choose instead to select the most important issues. Naturally, high priority areas should be addressed first, with areas of less concern being reviewed later as resources permit. This section describes a means of conducting a needs assessment to help establish priorities.

\subsection{Neeđis Assessment}

A needs assessment guestionnaire survey is the easiest and most thorough way to prioritize areas for review. The questionnaire may be seli-administered or administered in an interview.

\subsubsection{Needs Assessment Personnel}

A managor should be assigned responsibility for coordinating the needs assessment. This coordinator should be knowledgeable about the facility's organizational structure and have the authority to schedule activities and obtain cooperation from the nersssary personnel. To achieve obiectivity in the analysis of the survey results, it is desirable for the coordinator to be from outside those departments or functional areas represented in the respondent sample.

Ideally, someone experienced in performing questionnaire surveys and in human factors analysis should prepare the questionnaire, assist in defining the respondent sample, and perform or direat the interviews und the analysis of responses. This person also should be from outside the functional areas represented in the respondent sample.

It is desirable for "outsiders" to perform the data analysis, in which individual responses are combined into a results profile. If there are only a few respondents in each department and if background information is collected, then the identities of respondents 
are likely to be obvious to cr-workers if they review the individual questionnaires, and objectivity may be compromised.

If interviews are conducted, one or two additional personnel should be trained to assist in the interviewing. Interviewers should be from outside the respondents' departments, to assure respondents of anonymity, if that is possible.

The steps in conducting a questionnaire survey for needs assessment are listed and discussed below:

- Develop questionnaire

- Select respondents

- Distribute and collect questionnaires

- Analyze and interpret questionnaire data

- Establish assersment criteria

- Perform the assessment.

\subsubsection{Questionnaire Development}

The key to good questionnaire development for the neeás assessment is the definition of questions that probe for problems in each human factors application area. Topic areas for the questionnaire should include questions on the adequacy of:

- Workspace Layout and Environment

- Panel Design

- Annuneiator Warning Systems

- Computer-Based Systems

- Corrective Maintenance

- Preventive Maintenance, Testing, and Calibration

- Communisation

- Organizational Interfaces

- Procedures

- Training.

Two types of questionnaire items are recommended to assess needs in these areas: "critical incident" items and scalar items. 
Critical Incident Items. "Critical incidents" are specific behavioral examples in which the safety or effectiveness of performance was in jeopardy or was actually impaired. To develop relevant eritical incident questionnaire items both the human factors area of interest and the potential outeomes of problems must be considered. Questions should cue the respondents about the types of situations that should be deseribed, for example, "Describe any incident in which your procedures were of insufficient detail or were unclear and resuited in ineiîective or erroneous performance."

Scalar Items. In addition to critical incident items, scalar items (five-point scale) rating the respondents' perceived satisfaction with each human factors area should be included in the needs assessment questionnaire. Scalar items are easiest to score and provide a convenient way to compare the relative importance of the human factors areas.

Examples of Needs Assessment Questionnaire Items. Exhibits 3-1 and 3-2 in the Appendix at the end of this report show a set of questions that might be used in a needs assessment survey. Many of the questions were adapted from the interview grotocol foind in NUREG-0700.

Respondent Information. It is helpful in the analysis of questionnaire data to have certain information about the respondents. Section 4.4.1.2 lists the most useful items to be. included (page 31).

Respondent's name; should not be written on the questionnaires. Instead, each respondent should be assigned an identification code number. This should be recorded before questionnaire distribution. Letter prefixes to the identification numbers may be used to indicate department/functional area.

Questionnaire Pretest. It is desirable to pretest the questionnaire to ensure that question wording is unambiguous and that questions elicit the kinds of information that are needed. A pretest also allows a more accurate estimate of the time required to complete the questionnaire. It is recommended that questionnaire completion time should not exceed two hours whether the questionnaire is self-administered or administered in an interview.

Two or three people should be chosen as pretest respondents from among the departments/functional areas to be included in the survey. They should complete the 
questionnaire or be interviewed and asked to comment on the questions. Their comments will provide a basis for improving the questionnaire.

\subsubsection{Selection of Needs Assessment Questionuaire Respondents}

The objective in respondent selection is to get a range of input across departments/functional areas and also to obtain perspectives from different levels within the organization. A cross section of the major organizational units involved in safety-related activities is recommended.

The number of respondents in the survey sample will depend on the number of staff within the applicable functional areas. As a rule of thumb, four to five people from each area should be sufficient. For departments/functional areas with a large staff, a $30 \%$ sample should be considered. For areas with a small staff, everyone may be included. Operators, technicians, and craftsmen, and line supervisors should be drawn from $e$ ! least the following areas: Operations, Maintenance, Instrumentation and Control (l\&C), Health and Safety, Quelity Control/Quality Assurance, Training, and Technical Documentation and Procedures. Managers should also be included. Table 3-1 in the Appendix illustrates the type of vertical and horizontal representation that is needed.

\subsubsection{Questionnaire Distribution and Response}

Before questionnaires are distributed, cognizant managers should be briefed about the needs assessment process. They should be told what will be asked of them and their personneh, and the time frame in which the needs assessment will be conducted. It is elso recommended that each manager inform his/her personnel that they may be askcd to participate as respondents in a needs assessment survey and to explain its purpose.

The following materials will be needed in addition to the questionnaires:

- List of respondents with name, functional area/department, location code/mail stop, and telephone number. A code number should be assigned to each respondent. This list should be kept confidential.

- A memo to be distributed with the questionnaire which explains the objective of the needs assessment and encourages candid, thoughtful responses. Anonymity of responses should be guaranteed. This memo should be signed by an appropriate top-level manager.

- Copy of questionnaire for each respondent with instructions for completing it, including due date, where to return it, and the name and telephone number of a point of contact to call in case of any 
questions. An addressed return envelope should be provided with the questionnaire.

One to two weeks should be allowed for completion of questionnaires. After that time, the needs assessment coordinator should follow up by memo or telephone call, allowing an additional week if necessary for completion of the questionnaire.

\subsubsection{Interviews}

Preparation for interviews is similar to the preparation for a self-administered questionnaire survey. Managers and other personnel who may be involved should be briefed as described at the beginning of Section 3.1.3, above. A list of respondents as described in that section siould be prepared. A memo to respondents should be prepared and given to the respondent at the beginning of each intervjew. This ensures that the neads assessment is explained to each respondent in the same way.

In addition, other steps will be necessary if the needs assessment survey is to be conducted by meens of intervicws:

- If item explanations and probes are to be allowed, a written instruction that defines acceptable statements for these purooses should be prepared. ("Probes" are sometimes used to draw out more complete responses or to redirect a respondent whose answer is not well targeted on the question asked.) As an alternative, interviewers may be instructed to reed the questionnaire items as written, and offer no further explanation or encouragement to respondents.

o. Train and/or instruct the interviewer(s), depending on their experience.

- Arrange for private space in which to conduct interviews.

- Contact respondents to schedule their interviews. The schedule should be planned to allow interviewers time after each interview to review their recording of responses and ensure that it is clear and complete.

\subsubsection{Analysis and Interpretation of questionnaire Data}

After collection of completed questionnaires, they should be reviewed to ensure that they were properly completed. After the initial review, two types of analysis will be needed. One type will be directed at the qualitative critical incident questionnaire items. The other type will focus on the quantitative scalar items. Each type of analysis is described below. 
Critical Incident Items. Responses to each critical incident question should be categorized and separate tallies made for each functional area (e.g., Operations, Maintenance). Because these questions are open-ended, there may be many multiple responses. Each type of response should be treated equally in the data reduction process.

Once response tallies for each item have been obtained, the number of responses per category should be converted into a percentage of total responses for each item. Percentages make it easier to interpret what the data suggest in terms of identifying specific problems areas for a given group of respondents (e.g., functional area, job level, experience level), or response patterns across all groups, it should be recognized, however that individual responses may be most useful, even if unique. A particular respondent may have more in-depth knowledge of a topic then other respondents.

Scalar ltems. Frequency data for each item sho!id be computed. Measures of central tendency (e.g., mean and mode), and variability (e.g., standard deviation), should be calculated for the total group and for subgroups of respondents (e.g., functicnal area on job level groups). The response distributions, measures of central tendency, and variability may then be compared for groups of respondents (e.g., by functional area. job level, experience level). Comparisons between the total set of responses and those mace by particular groups may also be of interest.

Once the response categories and calculations have been made, the needs assessment team should be augmented by one or two individials who are knowleogeable about the overall work and organization of the facility and about the specific functional areas that were included in the questionnaire survey. This expanded team should review and interpret the results to identify those human factors areas regarded as most important by the facility's personnel. A prioritized list of problem areas should be prepared based on the questionnaire response data.

\subsubsection{Establishment of Assessment Criteria}

After identification and prioritization of the human factors problem areas, the nature and scope of the formalized human factors review can be decided. To assist in this process, a set of assessment criteria can be used to determine the suitability of each potential human factors review area. Assessment criteria include: relevance to organizationa] 
issues, peyoff to facility, safety considerations, and ease of implementation. Each eriterion is briefly described below.

- Relevance to Organizational Issues, This criterion estimates the degree to which the candidate human factors review area addresses the improvement of real organizational issues. High relevance ratings are preferred.

- Payoff to Facility. This criterion estimates the relative benefits of the candidate review areas in terms of improving cost efficiency or productivity. High pstential payolfs are preferred.

- Safety Considerations. This criterion estimates the extent to which salety, either to facility personnel or the public, plays a role in cefining the issues related to the candidate human factors review area. High safety consideration ratings warrant most immediate attention.

- Ease and Cost of Implementation. This criterion assesses the level of required involvement on the part of the facility's management and technical personnel necessary to ensure an objective in-depth evaluation of the candidate human factors area. Reviews requiring a large allocation of resources would receive a low ease-of-implementation rating. High ratings are preferred.

\subsubsection{Assessment Procedure}

The definitions provided above provide a basis for selecting among candidate review areas, A five-noint scale ( $1=10 \mathrm{w} ; 5=h i g h)$ can be used $b$; each member of the needs assessment team to rate the areas on each criterion. Once individual ratir.gs heve becn obtained, mean ratings for the g - up can be calculated to determine the best estimate of the desirability of each option. These ratings should be ineluded in recommendr-ions to the facility's managentent as part of the rationale for selecting specific areas ur the human factors review over other options. Trade-offs will have to be made based on the relevanee of the candidate review areas to the most important issues facing a lacility, the potential gains to be made in each area, and the personnel and financial resources required to support each review. 


\subsection{Preparation of an Action Plan}

\subsubsection{Objective}

Based on the assessment criteria tratings, the final selection of the human factor areas to be reviewed should be made, and a plan should be prepared to guide the performance of these reviews.

\subsubsection{Personnel}

It is desirable to establish a steering committee to prepare the action plan. This committee should include key managers and resource personnel as appropriate. The needs assessment team may be involved in this committee. The steering committee should serve throughout the review to help resolve any issues that may arise, periodically assess progress, and make decisions about implementing recommendations that result from the reviews.

\subsubsection{Scope}

The action plan should be the working-level document that defines the "what, where, when, who, why, and how" of the human factors reviews to be conducted. For each review area, a set of technical and personnel requirements should be generated from the guidance provided by Sections 4 through 7 of this Review Plan. This should include the definition of skill and knowledge reguirements necessary to perform each type of review. In some cases the same individuals may be suitable for several review areas; in other review areas individuals who have specialized skills will be required. 


\subsection{HOMAN FACTORS ENGIEERING REVIEW}

Human factors engineering is concerned with optimizing the interfaces between people and equipment and between people and their work environment. Equipment that is not compatible with human capabilities and limitations may contribute to human error. These errors may be due to poorly designed displays, controls, or equipment groupings and labelling. Equipment refers to tools as well as to control panels. Environmental conditions may also contribute to human error. Excessive noise, heat, poor illumination and glare are examples.

The purpose of a Human Factors Engineering (HFE) Review is to evaluate the humanequipment and human-environment interfaces at a facility, to identify features of these interfaces that may contribute to human error, and to develop cost-effective solutions for these human factors engineering problems. An HFE Review may address the human factors engineering design of an operational control room, an experiment station, or another facility area such as design for maintainability.

An HFE review has three phases: (1) planning; (2) performance of the review; and (3) assessment and resolution of findings. These phases are summarized below and discussed in de tail in Sections 4.3-4.5.

The planning phase is important to ensure proper consideration of requirements, personnel acceptance and support, and efficient performance. Knowledge of facility operations and knowledge of HFE review methodology is needed for planning.

Performance of the review involves comparing the characteristics of work areas and equipment to human engineering design criteria. Some HFE criteria are applicable regarcless of a specific task. Other HFE criteria refer to the suitability of the work area and equipment for specific tasks. These criteria are concerned not only with individual components but also with the relationships and layout of components to support the integrated flow of tasks. To apply criteria of this kind it is necessary to have knowledge of a system's operating characteristics and of the specific tasks requireo of personnel Examples of both types of criteria are to be found in the Appendix (Exhibits 4-1 and 4-2). 
In the course of an HFE Review, any equipment design characteristics or environmentul conditions that are inconsistent with one or more HFE criteria is called a "Human Engineering Discrepaney" or HED. Some, but not all, HEDs have the potential to degrade human perfornance and to cause human error. Some HEDs may not have any significant effect on performance or contribute to error. Therefore, once identified, each HED should be assessed for its significance: that is, for its potential to degrade performance and cause error. When an HED has been assessed and found to have the potential to contribute to human error it may be called a Human Engineering Deficiency rather than discrepancy or HED. This is why the assessment and resolution of HEDs is an important part of an HFE Review.

Assessment involves identifying the possible effects of discrepancies on performance (e.g., delay, misinterpretation of information, ignorance of a critical condition, incorrect control action) and the possible system consequences. Then ways of correcting significant discrepancies may be defined, and the costs of corrention may be compared to the costs of performance degradation. This provides a basis for deciding on the resolution of discrepancies - i.e., it provides a basis for selecting and prioritizing corrective actions.

\subsection{Review Objectives}

A thorough HFE review should accomplish the following objectives:

1. Evaluate environmental conditions that may affect human performance (e.g., HVAC, lighting, noise)

2. Evaluate workspace layout and arrangement of instrumentation, controls, and other equipment, tools, and materials

3. Evaluate the characteristics of instrumentation, contrcls, annunciators, communications equipment, and other equipment

4. Determine if adequate system status and advisory/warning information is provided

5. Determine if adeguate control capabilities exist

6. Determine the availability of necessary feedback and analytic aids

7. Determine if adequate communication capabilities exist

8. Evaluate panel arrangements to verify appropriate integration cf components 
9. Evaluate design adequacy with respect to how well it facilitates the
work to be done in a performance context.

The applicability of these objectives depends on the depth of review that is desired. The first three objectives address characteristics that can be evaluated without in-depth knowledge of task performance requirements. Objectives 4-9 require consideration of the use of the equipment in performing tasks. This distinction will be discussed in more detail in Section 4.4, Review Methods.

\subsection{Review Criteria}

The human factors engineering literature provides sources of criteria applicable to HFE reviews at DOE nuclear facilities. Some of the most widely used sources are listed below. Additional sources are referenced at the end of this chapter.

- Bongarra, J.P., Jr. (1983). Human factors design guidelines for maintainability of Department of Energy (DOE) nuclear facilities (draft). Livermore, California: Lawrence Livermore National Laboratory, Nuclear Systems Safety Program.

- Department of the Army. (1975). Human factors engineering desigh for Army materiel (MIL-HDBK-759). Washington, DC: Author.

- Department of Defense. (1981). Human engineering design criteria for military systems; equipment, and facilities (MIL-STD 1472-C). Washington, DC: Author.

- Department of Defense. (1966). Maintainability program requirements (MIL-STD-470). Washington, DC: Author.

- Kinkade, R.G. \& Anderson, J. (Eds). (1984). Human factors guide for nuclear power plant controi room development (EPRI-NP-3659). Palo Alto, CA: Electric Power Research Institute.

- McCormick, E.J. \& Sanders, M.S. (Eds.). (1982). Human factors engineering and design (5th edition). New York: McGraw-Hill

- Seminara, J.L., Gonzalez, W.R., \& Parsons, S.O. (1981). Human factors review of nuclear power plant maintainability (EP $\bar{R} \bar{I}-\overline{N P}-$ 1567). Palo Alto, CA: Electric Power Research Institute,

- U.S. Nuclear Regulatory Commission. (1981). Guidelines for control room design reviews (NUREG-0700). Washing ton, DC: Author. 
- Van Cott, H.P. \& Kinkade, R.G. (Eds.). (1972). Humar engineering gujde to equipment design. Washington, DC: U.S. Government Printing office.

- Woodson, W.E. (1981). Human factors design handbook. New York: MeGraw-Hill.

Industry and facility-specific standards end conventions may also be a source of criteria. In addition, the expert judgment of HFE specialists may be drawn upon, especially in interpreting the applicability of criteria.

\subsection{Planning for an HPE Revien}

The planning phase should include:

- Selection of methods

- Selection of personnel

- Scheduling

- Preparation of a facility-specific review plan

- Preparation of review aids such es criterion checklists, data forms, and an HFE review questionsaire.

- Briefing of participants and others affected by the review.

\subsubsection{Selection of Methods}

HFE review methods differ in the types and completeness of information they generate and in the resources they reguire (e.g., personnel mix time, and funding). These methods are described in Section 4.4. At the end of that section, trade-offs in the selection of methods are discussed.

\subsubsection{Personnel Requirements for an HFE Review}

Personnel requirements for an HFE review will vary, depending on the methods selected. In most reviews a combination of people will be needed with expertise in:

- Human factors engineering and analysis

- System/equipment design engineering 
- Facility operations, maintenance, or other functional areas.

Management responsibility for the review should be specified. It is recommended that a single individual be assigned to serve as the HFE review coordinator. The coordinator should be very familiar with the facility organizational structure and the work done by the functional areas or departments considered in the review. The coordinator should have management skills and the authority to secure persornel participation and maintain the schedule.

The coordinator should thoroughly understand the objectives and tasks of the HFE review and be willing to take on the respansibilities of the coordinator role. It is recommended that the coordinator be assisted by a human factors specialist. An assistant should also be provided to maintain review documentation and pronide clerical support.

More detailed recommendations concerning personnel requirements for specific review tasks are made in the discussion of each method (Section 4.4).

\subsubsection{Scheduling}

A schedule of review tasks should be prepared. The schedule for other review activities (e.g., a procedures review) should also be considered. It may be possible for some tasks to contribute to more than one review.

The schedule should include all phases of the review, from planning through assessment and resolution of findings.

\subsubsection{Preparation of a Pacility-Specific Review Plan}

It is usually desirable to prepare a written HFE review plan tailored to the review objectives of a particular facility. Such a plan will serve as guidance for all persons involved in a review.

\subsubsection{Preparation of Review Aids}

Review aids should be sclected or prepared in advance, according to the methods chosen by a facility. Other review aids are discussed in more detail in the descriptions of methods in Section 4.4. An HED report form should be prepared for use in documenting 
discrepencies found by any of the review methods used. (See Exhibits 4-3 and 4-4, in the Appendix, for examples of HED report formats.)

\subsubsection{Personnel Briefings}

It is important to aequaint participants, and others who may be affected by the review, with its objectives, schedule and the tasks to be performed. This is necessary to establish acceptance and support for the effort. It is recommended that a general briefing be provided during the planning phase. Other briefings should be given to the appropriate personnel at the beginning of each specific task. Management should be apprised of the progress of the review as it proceeds.

\subsection{Review Methods}

Three basic methods are typically used in performing HFE reviews:

- Operating experience review

- Observation checklist surveys

- Systems analysis approach.

An operating experience review will provide information applicable to all of the objectives of an HFE Review. It may include an analysis of historical records (e.g., Unusual Occurrence Reports) and/or an HFE questionnejre or interview survey. Although an operating experience review will provide useful information, it will not provide all of the ir ormation needed for a thorough HFE Review. Its principal value is to identify desir, , characteristics that have contributed to human error in the past or that are perceived as human engineering diserepancies, deficiencies, or problems by personnel.

An observation checklist survey may be used to meet the first three objectives listed in Section 4.1. Those objectives ariress directly observable or measurable characteristics of the workspace and equipment such as desk/console height, spacing requirements between rows or items of equipment, illumination levels, labeling, control coding, scale divisions on displays, etc. Characteristics of these kinds can be evaluated on the basis of generically 
applicable human engineering criteria, without in-depth knowledge of the specific work performed.

The systems analysis approach can be used to meet Objectives $4-9$ in Section 4.1 . These objectives address the adequacy of workspace and equipment design to enable personnel to perform their required tasks effectively. The systems approach involves system function and ask analysis to specify the human performance requirements and the equipment characteristics required to support them. Actual equipment characteristics are compared to these data to identify design diserepancies. The systems approach may identify discrepancies such as lack of displayed information about a parameter, poor location of a source of information so that it cannot be accessed when needed, and insufficient means of communication with others who must be involved in performing an activity.

These methods of HFE review are described in more detail in the following sections.

\subsubsection{Operating Experience Review}

An HFE review of operating experience may include a review of a facility's documentation, a personnel questionnaire/interview survey, or both.

\subsubsection{Documentation Review}

This review method may be used to identify equipment design characteristics that have had a negative effect on facility personnel performance in the past. If a documentation review is also performed for other areas of review (e.g., procedures review) it should not be done more than once. This requires that the data collected include items pertirent to all human factors applications areas to be addressed by the documentation review.

Selection of Records. Probable sources of useful information include:

- Facility performance records

- Unusual Occurrence Reports (UORs)

- Unusual Incident Reports (UiRs)

- Operating and maintenance logs

- Triennial Management Review (per DOE Order 5480.1A, Ch. 6)

- QA/QC deta anc audits. 
It is recommended that reports going back one to five years be reviewed, depending on the volume of records per year. Different approaches to report sampling may be used. For example, all UORs and UIRs from a 3 to 5 year period might be reviewed, while operating and maintenance logs over a 1 or 2 year period might be sampled (e.g., 1 week per month, rotating the week drawn each month).

Personnel Requirements. Documentation reviewers must be able to interpret the reports and relate apparent problems to specific human engineering criteria. Therefore, expertise in facility functions and expertise in HFE evaluation will be needed. It may be necessary to involve more than one facility expert if the review addresses the human engineering design of more than one functional area. Technical specialists (e.g., I $\mathrm{IC}$ or system engineers, radiation protection technicians) may also be needed to answer particular questions.

Preparation of a Data Form. A data form should be prepared so that the data are collected in a consistent manner and can be easily collated to develop a profile of HFE problem areas. A two-part form (or two separate forms) will be needed: one for initial screening of the reports and one for detailed analysis of the reports identified as pe:tinent to the HFE review. An example of a documentation review data form is included in the Appendix (Exhibit 4-5).

Performance of the Documentation Review. The first step is to examine report files to select those to be analyzed. Reports of equipment failures resulting frcm material defects/stress, or from improper design, fabrication, or installation of equipment, may be ruled out immediately. Human errors may have contributed to such failures but they are assumed not to be operating facility errors.

Ideally, all documents involving reports of human error should be analyzed for their HFE implications and classified as to type of error and the consequence of error.

The screening documents should be based on the functional areas to be addressed in the HFE review. For example, a review may be limited to documents related to operations or to maintenance. However, care must be taken not to eliminate cases where error in a fune tional area not under review contributed to error in the target functional area. 
The following types of information shnuld be seasched for in the analysis of facility documents:

- The work area/unit involved

- The results of the error (effect on the facility, equipment, personnel)

- The type of error

- The HFE diserepencies that appear to have contributed to the error

- Immedjate actions and follow-up corrective actions

- The effectiveness of the immediate and corrective actions

Descriptions of discrepancies should (1) explain the equipment/environmental characteristics that are not in accordance with good HFE practice and (2) specify equipment or components involved by function, identification number, and location. An entire category of equipment or components may be involved or only an individual component. In the former ease it is not necessary to identify each item in the class, but any exceptions from the discrepancy should be noted.

\subsubsection{HFE Questionnaires/nterviews}

HFE questionnaires/interviews can provide both quantitative and qualitative cata based on personnel experience in interfacing with the design. Different questionnaires may be needed if more than one functional area is being addressed in the review (e.g., chemical processing operations and corrective maintenance).

Ejther a self-administered questionnaire or an interview approach may be used. If the former is chosen, it is desirable to plan on follow-up intervjews with selected personnel to answer questions concerning their written responses and to cbtain additional information about key areas of concern.

Personnel Requirements. Respondents should be selected from each functional area being revieved (e.g., operations or subdivisions of operations, preventive and corrective maintenance). The most useful information will be provided by those who do the actual work and by their line supervisors.

The sample size will depend on the number of staff in the applicable functional areas. As a rule of thumb, four to five respondents from each area may be sufficient. For areas 
with a large staff, a $30 \%$ sample should be considered. For areas with a very small staff, all may be included.

Personnel will also be needed to develop or select the HFE questionnaire, administer it, and analyze resforises. At least one individual who is experienced in work of this kind will be needed. One or more others as needed may be trained and supervised by the specialist to assist in conducting interviews, analyzing data, and performing other tasks. Ideally, any personnel involved in interviewing or in questionnaire response analysis should be from outside the functional areas being addressed in the review to ensure objectivity and preserve respondent anonymity.

The HFE review coordinator will be needed to facilitate selection of respondents and scheduling.

Preparation of a Questionnaire. In designing questionnaires, a number of steps are necessary:

1. Decide on the topics to be covered in the questionnaire.

2. Develop a preliminary pool of questions for each topic.

3. Decide on the format( $\$$ ) appropriate for the questions.

4. Write and edit the questioniaire items.

5. Group and sequence the items.

6. Prepare instructions for self-administration and instructions for the conduct of intervjews.

7. Test the questionnaire on a small number of respondents (2 to 3 ), evaluate, and revise as necessary to clarify questions and ensure responses will be on target.

The way questions and instructions are stated can affect the quality of data obtained. References on questionnaire/interview design may be corisulted for discussion of issues such as item wording and sequencing, question ambiguity and bias, instructions for responding to questions, and instructions for interviews.

To develop an item pool, HFE criterion topics should be identified that are applicable to the functional areas being addressed in the review. Examples of topics are listed below:

- Work station dimensions (i.e., anthropometrics) 


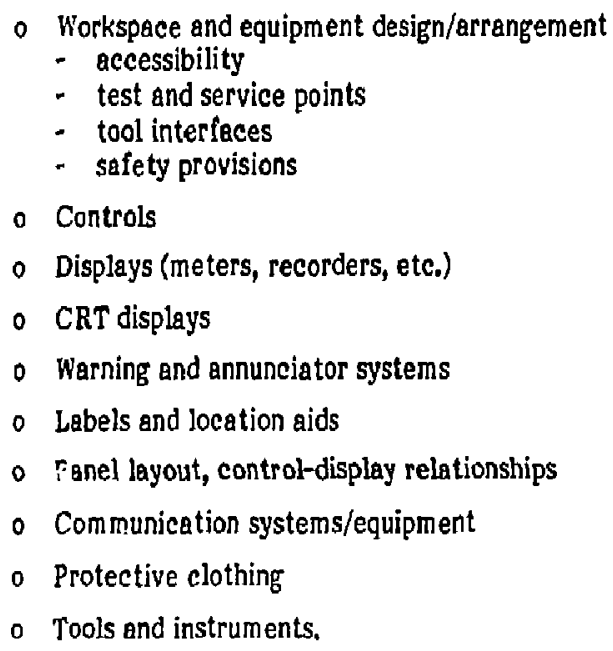

When relevant topics have been identified, specific criteria to be covered by questions should be selected from the criterion source documents identified in Section 4.2 and in the reference list at the end of this chapter. Criteria that require personnel input should be selected. Criteria that can be applied by direct observation, without familiarity with the work performed, may be omitted if an observation checklist survey is to be used as an additional method of HFE review.

It is not appropriate to include criteria in \& questionnaire or interview that require measurements to be made or the detailed comparisons of equipment characteristics to specifications. However, the principles underlying such criteria may be addressed in a general way. For example, it would not be appropriate to ask if all displays are located within the recommended upper and lower limits for display height. However, personnel might be asked if all displays are located at a height that makes them easy to read.

An HFE questionnaire may be complete in its coverage of HFE criteria. This is particularly appropriate when it is the only method selected for use in the HFE review. However, it is recommended that a questionnaire require no more than 2 hours to complete, whether it is self-administered or administered in an interview. Completion time can be determined in the pretest. If observation checklist surveys will also be used, then the questionnaire may be less detailed and questions may be written in more general terms to address major criterion topic areas. 
A YES/NO questionnaire response format is recommended. There are two approaches to writing this kind of item. One approach is to write all items so that a YES response or a NO response always indicates that the eriterion is met (there is no HED related to the criterion). Exhibit 4-6 (in the Appendix) shows example items written in this way. This approach simplifies questionnaire analysis. A drawback is that it invites respondents not to read and answer questions earefully. A second approach is to vary item wordin; so that response choices are sometimes YES (no discrepancy) and sometir es NO (diserepancy). This approach increases analysis time but demands careful reading of each question.

Space in the questionnaire should be provided for including an explanation when a response indicates a discrepancy, and a "not applicable" response may also be allowed for.

Criterion references should be included after each item of a questionnaire. This facilitates the analysis and grouping of responses by the criteria to which they are related.

Other types of item formats may also be used. The following format was used in a survey of communications systems in nuzlear power plants:

"Raie on a scale of 1-7 the effectiveness of the emergency alert or warning system $(\mathrm{s})$ in your plant $(1=$ never works, $7=$ system perfect)."

System:

\begin{tabular}{llllll}
\hline 1 & 2 & 3 & 4 & 5 & 6
\end{tabular}

One or more open-ended items should be included to allow respondents to identify any discrepancies not brought out by structured items. An open-ended item might be written for each criterion topic, or a single, general request for any additional remarks can be put at the end of the questionnaire.

It is often helpful in the analysis of questionnaire/interview data to have, information about the background of respondents, The following ty: $=$ of information are pertinent:

- Department/functional area

- Typical duties

- Years of experience performing that type of work at the facility

- Related experience. 
Examples of HFE questionnaires are provided in the review aids in the Appendix (Exhibits $4-7$ and 4-8).

Questionnaire Distribution and Collection. Before questionnaires are distributed, managers, supervisors, and staff in the functional al'eas add! essed by the review should be briefed about the objectives of the HFE questionnaire/interview. Personnel should be informed that they may be asked to participate. They should be assurad of the anonymity of their responses and encouraged to answer thoughtfully and condidly. Examples of the types of questions asked should be reviewed.

The following materials will be needed in addition to the questionnaires:

- A list of respondents with name, functional area/department, location code/mail stop, and telephone number. A code number should be assigned to each respondent. This list should be kept confidential.

- A memo to be distributed with the questionnaire which explains the objective of the needs assessment and encourages candid, thoughtrul response. Anonymity of responses should be guaranteed. This memo should be signed by an appropriate top-level manager.

- A copy of the questionnaire for each respondent with instructions for completing it. Inelude due date, where to return it, and the name and telephone number of a point of contact to call in case of any questions. An addressed return envelope shculd be provided with the questionhaire.

One to two weeks should be allowed for completion of questionnaires, After that time, the HFE review coordinator should follow up by memo or telephone call, allowi-g an additional week if necessary for completion of the questionnaire.

Interviews. Administration of interviews is Jiscussed in Section 3.6. The in iormation given there is also applicable if an HFE questionnaire is to be administered in interviews.

See, specifically, Section 3.1.4.

Analysis of Questionnaire Responses. The following steps are recommended:

1. Inspect each questionnaire to ensure completeness and clarity of responses. It may be necessary to follow up with a respondent or an interviewer concerning certain items. 
2. Prepare a table showing the frequency and percentage distribution of responses to each item (see Exhibit $4 \mathbf{4}$, in the Appendix).

3. Review all responses that indicate a discrepancy for each item. Prepare an HED report for each item. Identify the item, state the number and percentage of respondents who indicated a discrepancy in relation to the item, and summarize the discrepancy information given by all respondents. Be sure to provide clear identification of equipment, components, or environmental characteristics involved, including their location. (See Exhibits $4-3$ and 4-4, in the Appendix for examples of HED report formats.)

\subsubsection{Observation Checklist Survey}

An observation checklist survey is performed by systematically comparing workspace, equipment, and environmental characteristics to HFE criteria. Direct observations and measurements of specific characteristics will be required. In some cases it may be necessary to look at documentation such as equipment/system specifications or administrative procedures to determine whether criteria are met.

An observation cinecklist survey may be performed in the actual work setting, in a simulator, or from photomosaic mockups. If the survey is done in a simulator, it is necessary to identify any differences between the simulator and the actual work setting. If the survey is done from a mockup, it will be necessary to go to the work setting to evalua te environmental criteria and certain other criteria that cannot be evaluated with a mockup alone.

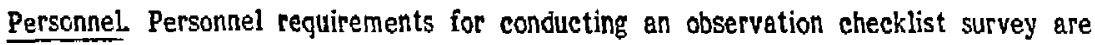
suggested below:

- An experienced human factors engineering specialist to prepare checklists, train other personnel in performing checklist surveys, direct mockup construction if applicable, and participate in and oversee the performance of the surveys

- Tw additional survey personnel. More may be desirable, depending on the time allotted to complete the surveys. Preferably, one will have expert knowledge of the equipment and the work perfor wed, and the other will have HFE training and experience.

Preparation of Checklists. Since criteria for design for operability and design for maintainability are not the same, different checklists will be needed for each to be reviewed. 
In addition, checklists should be divided according to uES criterion topics. Examples of potential topics are:

- Workspace (e.g., general layout, availability and accessibility of equipment, tools, and materials, feasibility of coordination between personnel as required, work station/panel anthropometries)

- Environmental factors (e.g., lighting adequacy, climate control, auditory environment)

- Communications systems/equipment (e.g., access, susceptibility to interference, audibility at different locations, provision for communications when wearing protective clothing or breathing apparatus, opereting condition of equipment)

- Marning systems (e.g., audibility and discriminability of auditory alerts, readability/discriminabillty of visual alarms, prioritization of alarms, first-out information, personnel response subsystems)

- Controls (e.g., position indication, activation feedback, protection, coding, design specifications for usabjlity)

- Displays (e.g., readability, printing, markings/scales, coding)

- Computer-based systems (e.g., software security, command language usability, keyboard design, CRT display and printer (ormats)

- Labels and location aids (e.g., label subordination, placement in relation to components, readability, needs for demarcation, use of color coding and mimics)

D Panel layout (e.g., spacing and arrangement of components).

Criterion topies and criteria to be included under each topic should be selected on the basis of review of HFE guidelines in the literature. Then existing checklists may be modified as necessary or checklists may be prepared to cover the selected criteria.

Care should be taken to word checklist items clearly, so that they will be interpreted in the same way by all users. It is desirable for two or three personnel to review checklists before they are used so that ambiguous items can be detected and corrected.

Checklist items should be worded positively, so that items checked YES indicate that the criterion is met and items checked NO indicate that an HFE diserepancy exists. Provision should be made for indicating that a criterion is not applicable. A criterion reference should be given for each item. Space should also be provided for notes to ijentily the equipment/componenis and loeations where discrepancies are found. Exhibit 4-10 (in the Appendix) is a typical format for an HFE observation checklist. 
Major sources of HFE criteria are listed in Section 4.2. Additional sources are included in the list of references at the end of the chapter. Examples of observation checklists are included in the review aids in the Appendix (Exhibits 4-1 and 4-2).

Other Materials/Equipment Needed. Measurement equipment will be needed (e,g., tape measure, angle finder, push-pull gauge, torque gauge, caliper).

Specialized equipment and expertise are needed to measure and evaluate climate control, lighting adequacy, and sound, If problems in these areas are indicated by observations and personnel comments, it is recommended that the appropriate technical specialists be brought in to perform messurements.

Performance of Observation Checklist Surveys. To determine whether a work area is fully consistent with an HFE criterion, it is usually secessary to inspect a number of components or take a number of measurements. For example, a criterion for meter scales is that there should be no more than nine graduation marks between numerals. All meters should be checked to make sure the criterion is met.

In many cases, however, a criterion can be applied to only one of each different type of a component. For example, there may be three or four different types of meters, but meters of any given type may be identical

Some observation checklist topics will require a panel-by-panel review (e.g., panel layout for control system operations, test, and calibration). Other topics address special equipment, such as operator consoles and CRT formats for graphic display systems. Still other topics should be reviewed from the perspective of the sverall work area, such as workspece errangement and communicetions.

Observation checklist survey team members should perform their assigned surveys, completing their checklists to indicate whether each criterion is met and, if not, to ident.fy discrepancies. A diserepancy report should be written to describe and locate each discrepancy. This information should be given to the HFE review coordinator for consideration in the assessment and resolution of HFE review findings. 


\subsubsection{Systems Analysis Approach to HPE Review}

The objective of the systems analysis approach to HFE review is (1) to establish the input tiris output reguirements of personnel tesks, and $(2)$ to evaluate the adeguacy of the existing equipment design and configuration against those input and output reguirements.

Personnel Requirements. To implement a systems analysis approach, a team is needed that has the following combination of capabilities:

- Expertise in performing the work being analyzed

- Expert knowledge of equipment design and operating characteristics

- Human factors expertise - specifically, experience in performing function and task analyses for HFE applications.

A human factors specialist should develop the methodology to be used with input and concurrence from the review coordinator and other facility personnel, and should oversee its application.

Material Requirements. The following materiels should be assembled or prepared in advance:

- System/equipment documentation (e.g., system descriptions, panel front drawings, technical specifications, safety analyses, procedures)

- A task-descriptive data collection form.

Summary of the Methodology. A systems analysis for HFE review is complex. While it is not possible to describe here the methodology in detail, four major steps in the systems analysis approach to HFE review include:

1. Review system functions.

2. Identify and analyze personnel tasks.

3. Verify that task input and output requirements are met by the design.

4. Validate the performance effectiveness of the integrated "man-machine system".

Definitions of key terms in these steps are given in Figure 4-1. The steps are described in the following paragraphs. 
System Function Review. This effort begins with a review of the organizational context of which the system is a part. The output gools of the system are specified, including any criteria and corstraints associated with them. The analysis then identifies the system functions necessary to accomplish these output goals. Functions may need to be subdivided depending on their complexity.

The next step is to r.view the engineering design to determine how equjpment subsystems and major components are used to accomplish system functions. The analysis contintes by describing the process of function implementation, including human and equipment roles, by reference to the system design. Specific criteria for function performance should be identified.

With the functions and function allocation established in general, the analysis proceeds to look at the performance sequences, or procedures, and the relationships of functions and humen and equipment actions in time. The preliminary analysis of system functions provides a basis for selecting performance sequences or procedures to ensure that the full range of functional reguirements is addressed, without necessarily analyzing all possible sequences or risking omission of a major aspect of performance. The analysis should address the requirements of procedures, but should not be derived from the procedures. That is, the analysis should look independently and objectively at the task input and output requirements represented by procedures, and should use other data sources in establishing or verifying those requirements.

Steps of performanee sequence analysis are summarized velow:

- Develop a narrative description of the sequence, or a "scenario." This defines initiating and final conditions, the major events or phases, the functions invoked by the events or phases, and the major human and automatic actions. Exhibit 4-11 (in the Appendix) is an example of a scenario for control system operations (nuclear power).

- Develop functional flow diagrams. These depict the interrelationships between functions and the sequencing of performance requirements. Such diagrams are developed at levels of increasing detail until a level suitable foi identification of human behavioral functions and tasks is reached. Figure 4-2, in the Appendix, is an example diagram from a functional flow analysis of an aircraft system mission.

- Develop action-decision diagrams. Diagrams of this kind may be prepared instead of or in addition to functional flows. 
If used in conjuriction with functional flows, action-decision diagrams may pick up where the former leave off. The funetional flows would provide an overall integrated picture of operations over time. The action/decision diagrams would further break out the human action requirements and show the data which govern decisions and the points at which decisions must be made.

Figure 4-3, in the Appendix, illustrates the nature of a decisionaction diagram.

At this point, a task list can be developed and task-descriptive information gathered to document the specifics of the input and output requirements for each task.

A Note About System Function Review for Maintenance, Test, and Calibration Activities and for Primarily Manual Operations. The preceding discussion of system function review is most applicable to complex control systems in which personnel interact with equipment and software to perform system functions. In other activities, the man-machine dynamics characteristic of control system operations are not present. The functions belong to personnel. In maintenance task analyses, for example, a system review is performed to identify and categorize the equipment to be maintained and the types of equipment and tools to be used. Behavioral functions are defined, which represent categories of human actions performed on the various types of equipment (e.g., checking, servicing, salibration, troubleshooting, etc.). Performance sequenees and a task list may then be generated by integrating and further analyzing equipment types and behavioral functions.

Task Analysis. The first step recommended is to prepare a task list for each performance sequence from the results of the system function review. The task list indicates the scope and sequencing of the total array of human performance requirements in the sequence.

- Sequence jdentification: an alphanumeric codo and/or title.

- System function identification: an alphanumeric code and/or title.

- Behavioral function identification: an alphanumeric code nnd/or tit.e.

- Task sequence number, based on time of task initiation relative to initiation of other tasks. Task sequeneing may not be absolute; an acceptable sequence should be established.

- Task title: a summary statement of the human performance requirement.

- Task purpose/objective: the immediate reason for performing the task, or the output expected from the task. 
Each task may then be described in terms of a predetermined set of information items. The following is a list of items commonly included in task deseription for HFE applications:

o Work-area Iocation: where task is accomplished.

- Task cue(s): What causes task to be initiated.

- Task action description: detailed, sequential description of each task action element or step.

- Display and control needs (for cue, task action input information, task uction feedback information).

- Needs for tools, equipment, materials, aids, pratective gear, etc.

- Frequency of performance: once, twice, etc., per shift, daily, weekly, monthly.

- Performance time: estimated hours and minutes task will take/ maximum permissible time.

- Performance criteria/standards: criteria for successful task executios.

- Hazards inherent in the task/environmerit.

- Potential errors.

- Err or likelihood (usually a relative rating).

- Potential consequences of error.

- Error severity (usually a relative rating).

- Task difficulty (usually a relative ranking).

- Skills and knowledge: types of skills or knowledge pertinent to the selection and training of individuals for the job or tasks.

- Physical characteristics: special physical requirements necessary for effective task performance (e.g., body size, strength, dexterity, cocrdination, physiological tolerance to stressors).

A variety of cormats are used for recording task-descriptive data. Figures 4-8 and 4-9 (in the Appendix) are two examples.

Verification of Design Adequacy To Support Task Performance Requirements. The objective of verification is to ensure that personnel have ready access to all the information and controls and other tools, equipment, and materials they need to perform each task in accordance with the specified performance standards. 
For instrumentation, this includes verification that all necessary parameters are displayed, in a suitable form (e.g., status indication, specific value or band, trend). It also includes verification of specific instrumentation characteristics, such as appropriate units, range and precision. Similariy, the suitability of control characteristics such as precision, range of control, and response time should be verified.

Verification may also address issues such as design safeguards against hazards in the use of tools and equipment, or desigit provisions to minimize the likelihood of error.

Verification may be partly performed by comparing design specifications to the taskdescriptive data. It should also, however, include examination of equipment characteristics in the actual work location, with reference to the requirements identified in the taskdescriptive data.

An HED report should be prepared for each case in which it appears that the design does not adequately meet task input and output requirements. This information should be submitted to the HFE review coordinator for consideration in the assessment and resolution of findings.

Validation of the Integrated "Man-Machine System" Design. The objective of validation is to ensure that the functions allocated to personnel can be performed effectively given the existing work area, equipment configuration, staffing, and procedures. The recommended approach to validation is to conduct performance exercises. Performance exercises allow design characteristics to be evaluated in the context of the performance of procedures. Experienced persannel are asked to perform procedures step by step. Normal staffing should be used to perform these exercises.

Exercises should be observed by a team consisting of an HFE specialist, an expert in the work being performed, and a systems/equipment technical expert. Preferably, the observers will have already participated in the system function review, task analysis, and verification.

Performance exercises may be conducted in the actual work location, in a simulator, or in mockup if available. A mockup used for this purpose should be a full-scale replica of the 
panels and other equjpment used. The work setting should be represented as realistically as possible.

Procedures should be selected for performance exercises to allow all major interfaces to be used and all key personnel performance requirements to be observed. All or parts of several different procedures may be selected to provide this coverage.

Scenarios are helpful to guide the performance exercises. Scenarios indicate the paths through procedures that personnel will take during performance exercises. This is essential in the case of multi-path or multi-contingency procedures. Scenarios developed in the system function review may be used (see Exhibit 4-11, in the Appendix, for an example) for this purpose.

If performance exercises will be conducted in a real-time simulator, it will be necessary to review the scenarios with a simulator operator to ensure that they are feasible and provide sufficient information to program the simulator.

A guideline or checklist for observers should be prepared. It should identify the base set of eriteria to be applied in performance observation (although observations will not necessarily be limited to predefined criterial. Among the areas that may be addressed are equipment layout in relation to task action sequencing, feasibility of time-constrained actions, coordination of actions when more than one person is involved, communications, and effects on task performance of requirements to wear protective clothing and ureathing apparatus. Performance observation checklists should be tailored to the type of work being observed.

The objectives and activities involved in performance exercises should be discussed with all participants before each exercise. The scenario and/or procedure should be reviewed with participants. Questions should be resolved and roles specified if more than one person is involved in perfoming a procedure. Observers should be assigned to observe individual personnel.

Personnel performing a procedure exercise should then conduct the procedure in real time including all necessary face-to-face and telecommunicutions. Observers should make notes about potential problem areas in accordance with the observer guidelines/checklist. 
Performing personnel should repeat the procedure again, this time in a slow walk-through. They should point out and explain all of their actions. If a team is performing the procedure, this will require phasing of the actions of each participant. Observers should ask questions as they arise and make notes accordingly to their checklists. After its completion, participarıts should discuss the exercise to further define any problems. An HED report should be prepared to document each problem.

Performaree exercises may be conducted for review of procedures as well as for review of design adequacy. If both areas are included in a facility review, it is desirable to conduct one set of exercises for both to save time.

\subsubsection{Comparison of HFE Review Methods}

The methods described in the preceding sections may be used together for a comprehensive review, or a more modest effort using selected methods may be sufficient. The advantages and limitations of each method are diseussed below.

Documentation Review. Reviewing facility docunentntion enables reviewers to identify a sample of problems that have had a tangible, substantive effect on operations.

The merits of reviewing facility documentation to uncover human engineering problems depend on the clarity and completeness of the records. If records are not well kept and standardized in format, then interpretation may be difficult. Another drawback is that past experience cannot predict the future problems that may occur due to human engineering discrepancies. Therefore, a documentation review may reveal valuable information regarding actual problems and provide direction for future evaluations, but it should be performed in conjunction with one or more other methods for a more complete HFE review.

HFE Questionnaires/Interviews. This method provides the opportunity to obtain user input concerning the functional adequacy of the design. Questionnaire items can also be written to address the types of criteria covered in an observation checklist.

This method will identify design problems that are of the greatest concern to personnel. It will not, however, provide the best context for systematic identification of every type of discrepancy or every occurrence of a particular type of discrepancy. 
The HFE questionnaire/interview method can be expected to yield incomplete data. However, it will provide more complete data than a documentation review.

Observation Checklist Survey. This method can provide a complete and detailed evaluation of the HFE acceptability of the face characteristics of components, of anthropometrics, labeling, and environmental conditions. It is not, however, a good way to evaluate design adequacy with respect to specific task performance requirements. It will, for example, jdentify display scales which are not well designed for readability. It will no: indicate whether all necessary parameters are displayed in appropriate units over required ranges. Personnel questionnaire/interviews and the systems analysis approach are better methods for making these kinds of evaluation of the functional adequacy of the design.

Systems Analysis Approach. This is the best method to ensure the functional adeguacy of a design. It also provides some opportunity in the verification step to identify discrepancies from generic criteria for characteristics of types of components. However, the systems approach is not as effective and complete for the latter purpose as an observation checklist survey.

The main drawback of the systems analysis approach is that it is time-consuming and conceptually demanding when used in the review of complex control system operations, and it may be unnecessary unless there is reason to guestion the functional effectiveness of the design. For example, if there is any question about whether all emergency response requirements can be met, the systems analysis approach should be applied to verify and validate the design for its emergency response capability.

Appropriate Combinations of Methods, If it is decided to use only selected methods, either of the following two combinations can provide a relatively thorough review. The first combination can be expected to reguire a lower level of effort, but will also yield less complete and in-depth information:

1. HFE questionnaires/interviews and observation checklist survey.

2. Observation checklist survey and systems analysis approach.

Documentation review may be added to either combination. 


\subsection{Assessment and Resolution of HFE Discrepancies}

An organized method is needed in order to assess the safety significance of each discrepancy, for developing feasible solutions, and for estimating solution costs. This information may be used to decide which alternative solutions represent cost-effective improvements.

\subsubsection{Assessment Team}

An assessment team should include at least one individual representing each of the following specialities:

1. A qualified human factors specialist.

2. An individual trained and experienced in performing the work of functional area being addressed.

3. A technical specialist familiar with system/equipment engineering design.

4. Other design specialties, as appropriate, may be added. An instrumentation and controls engineer may be needed in some cases.

The assessment team should perform the ussessment and resolution of discrepancies as a team, and not independently as individuals.

\subsubsection{Assessment and Resolution Steps}

1. Screen and organize discrepancy reports.

2. Assess the relative significance of discrepancies, identify those which will be analyzed for solutions.

3. Identify alternative solutions.

4. Evalua te alternative solution costs.

5. Decide on solutions to be implemented.

Sereening and Organization of Discrepancy Reports. A preliminary screening and organization of discrepancy reports will increase the efficiency of the subsequent steps in the assessment and resolution process, Several screening and organizational issues should be considered. Examples are described below. The assessment team may identify other factors that provide a basis for sorting and organizing discrepancy reports before the assessment of safety significance and solution development is undertaken. 
Some HFE discrepancies identified in the review may not represent true design deficiencies. This situation may arise when human engineering principles are inappropriately applied or when special circumstances are not taken into account. For example, there may be cases where a discrepancy represents a minor inconvenience but clearly would not impede personnel performance. These discrepancies may be eliminated from further consideration.

In other cases a discrepancy may call for increased personnel awareness through training, or through administrative procedures or other documentation. Discrepancies of this type should be handieci separately with appropriate mankigers.

The assessment team should establish a consensus opinion regarding the question of design deficiency. If a discrepancy is judged not to represent a design deficiency, the reasons for this decision should be documented.

Screening can also be expected to identify duplicate discrepancy reports, especially if more than one review inethod is used. In addition, some uscrepancy reports may cescribe a small part of a larger problem covered in another report. All information crincerning a common problem should be grouped together.

It may also be desirable to group discrepancies for which a surface enhanceri - nt is the best solution. A surface enhancement uses peint, labels or tape to solve a problem, and requires no engineering change. It may be decided to correct such discrepancies without assessment of their signif cance. In any case, grouping tinem will help to ensure that all of them are treated in a consistent manner.

lemaining discrepancies should be gro'ped in ways that will facilitate integrated assessment and development of solutions. Appropriate groupings may be by panels, work areas or equipment systems under review. In the case of control systems, for example, grouping of discrepancies by panel is recommended.

Assessment of Discrepancy Significance. The significance of a discrepancy can be expressed as the ratio of the potential that it will induce human error to the potential for error detection and recovery, multiplied by the consequence (assuming that an error is made and not recevered). Expressed functionally: 


\section{Significance $=\frac{\text { Potential for Error }}{\text { Potential for Recovery }} \times$ Consequence of Error.}

The significance value derived from this assessment may be used as a measure of the relative benefit of correcting a discrepancy and thus as basis for prioritization. Although the potential error consequence associated with a given discrepancy must be undesirable, if the potential of making the error is low and/or potential for detection and restoration is high, the oiscrupancy will have a relatively low significance. Thus the benefit of correcting it may be relatively low.

The significance terms identified above may be rated on the basis of expert judgment using a scale of 1 to 5 , low to high (e.g., $1=$ lowest potential for error and $5=$ highest potential for error).

Another approach is to define factors to be colsidered in arriving at ratings, For example, factors that affect potential for error inducement me! 'sclude:

- The time within which an action must be taken

- Frequency of use of the equipment or component involved

- Degree of skill/attention necessary for use of the component

- Locatability of component (Is it in a logical, accessible place?)

- Identifiability of component (Is it well labeled?).

Factors that may affect detection and recovery of an error may include:

- Is the action in which the error may occur normally verified?

o Is direct information available to verify whether an error condition exists, or must this be inferred from indirect information?

- Is there a time limit for recovering the error (e.g., How fast will conditions degrade? Is there a point of nu return")

- How difficult is it to recover from an error so that it has no consequence on safety?

Consequence assessments may be done in different ways. For complex control systems, an assessment may be based on weights assigned to the functions of the systems and subsyst. " that could be impaired. Exhibit 4-14 (in the Appendix) shows an example list of nuclear power systems grouped by function. The functions are prioritized (high to low) 
on the basis of their importance to safety. Numerical weights mey be assigned to each function.

Exhibit 4-15 (in the Appendix) illustrates a scheme that has been used for the assessment of error consequenees in a decontamination and decommissioning operation of a DOE nuclear facility.

Identification of Solutions. Many human engineering problems can be improved relatively simply by surface enhancement techniques (e.g., chenging control and display labels, changing recorder paper supplies, adding demarcation tines to enclose functionally-related controls and displays). Design of appropriate enhancement solutions should be performed by human factors engineers with input from plant personnel who have first-hand knowledge of the equipment and the associated human engineering problem(s). In identifying candidate solutions, the assessment team must consider whether the enhaneement may conflict with other proposed changes or existing facility conditions and conventions.

If discrepancies cannot be corrected by surface enhancements, they may require design modifications. Design modifications may include the relocation of panel components, the addition or removal of panel components; system modifications (e.g., addition of limit switches, rerouting of sensing lines); rearrangement of a workspace; or modifications to the lighting or HVAC systems.

Desigı modifications should be developed by specialists with the required expertise. They should be iniormed about the problefn to be solved. Potential solutions may be suggested. The design specialists should be asked to define alternatives and associated costs that will solve a problem.

It is important to cross checl: all proposed changes to ensure that no new problems are created in the process of correcting discrepancies.

Estimation of Solution Costs. The cost of implementing a soluition to a diserepancy can be determined by estimating the resources required for each solution. 
and the methodologies to be used. The Program Plan, following review and approval by the Steering Committee, should be the guiding document for the conduct of the review.

Once the Program Plan has been accepted and adopted by the Steering Committee, and the participants have been selected, it is recommended that an orientation for the participants in the review be conducted. This orientation should cover human fectors engineering objectives and methodology, general plant design and operation, and the scope of work defined in the Program Plan. The purpose of this review is to provide all participants with a common framework and understanding of the scope and intent of the review and their respective roles in its successful completion. 
Estimates should include engineering and construction labor and materials. In addition, procedures revision costs and training costs that may be associated with correcting diserepancies should be considered. Although generally less than physical change costs, these other costs can be signifjeant. For example, recurrent training over the life of a facility as a solution can represent a substantial cost. If a solution requires significant procedure changes or additional training, an estimate of these costs should be made.

It may be desirable to devise an ordinal cost classification scheme so that the relative costs of different solutions can be more easily compared.

Decisions on Solutions to be Recommended for Implementation. The significance and cost information described above should be weighad to make final recommendations to facility management for the implementation of solutions. The assessment team should arrive at a consensus. If this cannot be reached, then the problem should be brought to management for a decision. 


\subsection{PROCEDURES REVIEW}

In studies of safety-related incidents at commercial nuclear power plants it has been found that:

- About $40 \%$ of incidents involving human error in operations were procedure-related. ${ }^{1}$

- About 75\% of incidents inyolving humen error in maintenance, test, and calibration activities were procedure-related. ${ }^{2}$

These were cases in which it could be determined that a procedure was available for the activity being performed, but was not used, was used improperly, or was incompie ie, incorrect, out-of-date, or deficient in some other way. Exhibit 5-1, in the Appendix, gives some examples of procedure-related errors recently circulated by the U.S. Nuclear Regulatory Commission's office of Inspection and Enforcement.

In a major project for the Air Force Systems Command a $92 \%-100 \%$ reduction in errors was found to occur witi improved maintenance and troubleshooting procedures. ${ }^{3}$ These data suggest that review and improvement of procedures can significantly reduce the risks and costs of human error.

This chapter includes objectives, methods, and criteria for a complete review of procedures, It can represent a large scope of work depending on the number of functional areas (e.g., processing operations, maintenance) and procedures involved. Facilities may decide to select from the objectives, methods, and criteria presented here according to their particular needs and resources.

Both technical and operational issues are included in the scope of : $\because$ 's chapter. That is, the procedures review addresses issues that require technical/operational data and knowledge to evaluate. They are nevertheless human factors issues. If, for example, procedures are incomplete, or contain incorrect or imprecise information, those are critical human factors concerns. With such deficiencies, procedures cannot be counted on to support reliable human performance, as they are intended to do. 
Thus it was decided not to limit the guidance to mattere of information presentation only. Guidance is offered for technical verification and for validation of the performance effectiveness of procedures as well.

\subsection{Review Objectives}

Five objectives of procedures review are treated in this chapter:

1. Verification of the technical accuracy and completeness of existing procedures.

2. Verification of the presentation design acieguacy of existing procedures.

3. Validation of the performance effectiveness of existing procedures.

4. Evaluation of the procedures management system.

5. Assessment of the need for additional procedures.

\subsection{Review Criteria}

Detailed criteria under each of the potential review objectives are discussed in the individual sections on review methods (Sections 5.4.1 through 5.4.5). Criterion checklists are provided in the Appendix (Exhibits 5-2, 5-3, 5-4).

\subsection{Trade-Offs in Determinirg the Scope and Costs of Procectures Review}

The scope and costs of a procedures review depend on the review objectives to be addressed, the number and complexity of procedures to be reviewed, and the review methods selected. It may be decided, for example, to address only the first objective - to 
verify the technical accuracy and completeness of existing frocedures, $O_{t}$ it moy be decided that procedures are technically accurate and complete, but there are questions about clarity of presentation. In that case, the review might be limited to the second objective - to verify the presentation design adequacy of existing procedures. If it is decided to address either of these objectives in the review and if problems cre found, then it is advisable to conduct validation exercises (Objective 3 ) to further develop the findings or to validate revisions made on the basis of those findings. The latter is especially important. It is also advisable to look at the procedures management system (Objective 4) to identify underlying reasons for problems.

Another approach to limiting the review might be to begin with validation of performance effectiveness and conduct verification activities only to follow up on problems identified in the validation. This would be a less thorough strategy but should identify major problems.

The review may also be limited to procedures in one functional area (e.g., maintenance) or to a subset of procedures within one functionel area. Many combinations are possible.

There may be no question about priorities for procedure review. If there are questions about where the needs are greatest, they may be resolved based on a preliminary needs assessment. Suggestions for conducting such an assessment are given in Section 3.0.

\subsection{Review Methods}

Methods that may be used to meet each of the three major review objectives are described in Sections 5.4.1 through 5.4.5. Before the specifics of the methods are described, general personnel requirements, applicable across all of the objectives and methods, will be identified.

A single individual should be assigned to coordinate all activicies of the procedures review. The procedures review coordinator should:

- Have thorough knowledge of facility organization, operations, and support functions 
- Have lines to facility management which provide him/her authority to involve personnel in review activities, control the review schedule, and otherwise meet review requirements

- Have a commitment to the quality of procedures and an understanding of the objectives and criteria of procedures review

- Have management skills and be willing to take on the responsibilities of the assignment.

The coordinator should monitor performance of review activities (this may be on a sampling basis) as well as interface with management, handle scheduling, ensure clear and complete documentation of findings, assist in resolution of questions, and perform other cnordination functions as required.

The coordinator should be assisted by a human factors specialist or someone else who is experienced in the procedures design and review. The human factors specialist should select or prepare all review aids such as criterion checklists and forms for recording findings.

An individual should aiso be assigned to assist the coordinator in maintenance and control of review documentation. This individual should have appropriate administrative and clerical skills.

Additional personnel requirements specific to each method are identified in the methods sections. Often a combination of facility technical expertise and human factors expertise will be needed. To the extent possible, however, these requirements have been separated to allow the most efficient possible use of personnel time.

\subsubsection{Verification of the Technical Accuracy and Completeness of Existing Procedures ("rechnical verification")}

Technical verification is a "tabletop" activity in which procedures are systematically compared to technical documentation and expert knowledge of the bases for procedural requirements. This may be done to answer the following major questions about the technical adequacy of a procedure:

- Are all action and information requirements covered without error?

a Is the procedure written at an approptiate level of detail? (i.e., is the guidance complete enough for all users to perform the instructional steps, without cluttering the procedure with unnecessary detail?) 
0 Are user checkoffs and independent verifications of correct performance specified at the proper points to guard against significant error?

Sources of Information. Listed below are examples of the types of documentation that may contribute to the technical bases for procedures:

- System/equipment design specifications provided by vendors

- Instructions for system/equipment operation, test, calibration, maintenance

- Safety analyses and pisk assejsments

- System function and task analyses

- Technical Specifications, including Limiting Conditions of Operations and Safety Limits (for Category-A reactors)

- Regulatory anu facility specifications for radiological protection and contamination control

- Procedures for equivalent activities at other facilities.

Documentation of the technical design bases for emergency response requirementr has been prepared specifically for use in the development of emergency operating procedures at the commercial nuclear utilities. Generic teehnical guidelines were prepared by the nuclear steam supply system (NSSS) owner's groups and then made plant-specific and incorporated into Procedures Generation Packages by the individual facilities. This documentation incorporates and integrates data from sources of the kinds listed above. Analogous documentation has been prepared by a number of DOE nuclear facilities. Where available, it should provide the principal reference for the teclinical verification of procedures.

Where the documented technical design bases for procedural requirements are incomplete, technical experts will be needed to provide information. Depending on the activity addressed by the procedure, expertise may be needed in system/equipment engineering, instrumentation and control system engineering, radiological protection, industrial safety, system safety analysis, or other areas.

If the documented bases for procedural requirements are incomplete or not well integrated, it would be desirable to pull together the necessary information in the course of performing this review. This would provide a record which could be maintained as a reference for future use in procedures managenient. 
Personnel Requirements. The core personnel who perform the technical verification should te theroughly trained and experienced in performing the procedures under review. In addition to being master performers, they should have knowledge of the skill range of personnel who may use the procedures. They will be referred to as "technical evaluators." Preferably, a team of two technical evaluators will work together on each procedure. If procedures in more than one functional area are to be reviewed, then a different team of technical evaluators with different skills may be needed for each area.

Material Reguirements. The following materials will be needed for technical verification:

- A copy of each procedure to be reviewed

- A copy of each procedure referred to in the procedures to be reviewed

- Copies of technical documentation that provides the bases for the procedures to be reviewed

- Copies of pertinent regulatory guidance/requirements

- List of standard terminology, acronyms, and abbreviations if available

- Sehematic drawings as applicable (e.g., equipment/system diagrams, P\&IDs, panel front drawings)

o Review aids such as checklist and forms for recording findings and recommendations

- Copies of schedule.

Preparation of Checklist. It is recommended that a criterion checklist be used to structure the evaluation. The following dre examples of specific eriteria that should be covered in the checklist. Some tailoring may be necessary for different types of procedures:

- Descriptiveness of title and stated purpose of procedure

- Accuracy and completeness of entry conditions or symptoms and prerequisites

- Accuracy and completeness of procedure steps

- Specification of required communications

- Appropriateness of order of steps; correct identification of steps that must be performed in a particular order

- Specification of time requirements where applicable

- Correctness and sufficiency of component identification, including location when there couid be uncertainty 
- Correctness and consistency of nomenclature, acronyms, and abbrevi. ations

- Correctness and completeness of parameter identification

- Clear and accurate identification of values and conditions which represent operating or safety limits

- Clear and accurate specification of values and trends which provide cues to step initiation, step completion, and decisions as to subsequent steps

- Inclusion of all applicable cautions and warnings

- Correctness of logic statements

- Complete and clear identification of significant contingencies that could oceur in procedure exectition, and clear instructions as to how to proceed under contingency conditions.

- Correctness of "GO TO" instructions within a procedure and instructions to enter another procedure; provision of clear instructions about whether, when, and where to return

- Need for aids such as flow diagrams and references; accuracy and clarity of aids provided

- Sufficiency of procedural guidance for personnel who have completed training but do not have substantial experience in performing the activity.

- Sufficiency of guidance in procedures that are not used of ten

- Potential consequences of incorrect execution of a step; need for a formal checkoff or verification by the procedure user or by another person.

An example checklist for technical verification of procedures is included in the review aids in the Appendix (Exhibit 5-2).

Other Preparation Steps. The procedures review coordinater should aljo enzire that the following additional preparation steps are completed before the techinical verification begins:

- Schedule the verificatioll; obtain agreement of managfrs/line supervisors whose staff may be involved, as well as parthipants themselves,

- Assemble materials.

- Assure availability of suitable workspace.

- Brief participants on the objectives and steps of the technical veriflcation, including criteria, aids, documentation of findings, and schedule. (It is also desirable to describe in this briefing the entire 
scope of the procedures review, so that participants will have a clear understanding of the division of wark.)

Performance of the Technical Verification. The technical evaluators should consider each criterion identified in the checklist, making comparisons to technical documentation and drawing information from their own knowledge to decide on the adequacy of the procedure with respect to the criterion. It may be necessary to draw upon the expertise of other personnel to resolve questions.

The disposition of checklist items should be noted on the checklist. Notes should also be made on a copy of the procedure itself to identify any problems in individual instructional steps and attachments. From these notes, an evaluation report should be prepared. Any problems should be defined clearly, keyed to the appropriate criteria, and keyed to the parts or steps of the procedure to which they apply. If additional inquiry/analysis is necessary to resolve a question or evaluate a potential problem, tiis should be stated. Recommendations for correcting problems may be included. They should be considered in the assessment and resolution of review findings when a plan for making improvements is established (see section 5.5). It is important, however, to ensure that considerations about the effort required to correct a problem are not allowed to bias assessment of the significance of the problem.

\subsubsection{Verification of the Presentation Design Adequacy of Existing Procedures ("procedure design verification")}

Procedure design verification, like the technical verification, is a tabletop activity. It is done by comparing procedure characteristics to human factors criteria and to facility guidelines/directives concerning the organization, format, style, and wording of procedures.

Personnel Requirements. The core personnel for this evaluation should include at least one human factors specialist or other person with applicable experience in procedure design/evaluation. (This person will be referred to as the "procedures design specialist.") Others may be involved as needed for the number of procedures to be reviewed. They should have above-average writing/editorial skills and ability to attend to detail. They shoula be familiarized with the criteria and supervised by the procedures design specialist. 
Material'Requirements. The following materials will be needed for the procedure design verification:

- A copy of each procedure to be reviewed

- A copy of each procedure referred to in the procedures to be reviewed

- If technical verification has been performed (as described in Section 5.4.1), copies of the findings and recommendations

- Facility administrative directives/guidelines pertinent to procedure design

- A checklist of procedure design criteria representing principles in the literature and facility-specific directives and guidelines (an example checklist is provided in Exhibit 5-3 in the Appendix)

- A data format for recording findings and recommendations

- List of standard terminology, acronyms, and abbreviations, if available

- Copies of schedule.

Preparation of Checklist. A checklist approach is recommended for this evaluation as for the tabletop technical evaluation. Listed below are examples of eriteria that should be included in a procedure design evaluation checklist:

- Completeness of procedure identification information (e.g., title, number, revision number, date of issue, number of pages in procedure)

- Conformance to facility guidance concerning organization into sections (e.g., objective, jnitial conditions, immediate actions, subsequent actions, diagnostic aids)

- Clarity of responsibilities and provisions for coordination when a procedure is performed by more than one person

- Placement of Notes, Warnings, and Cautions

- Discriminability of Notes, Warnings, and Cautions from Instructiona] Steps

- Complete separation of action instructions from information that belongs in Notes, Karnings, and Cautions (e.g., action instructions should not be imbedded in Warnings, and vice versa)

- Clarity of instructional steps

1

- Conciseness and clarity of wording; readability

- Conformance to facility standard nomenclature, acronyms, and abbreviations

o Correct spelling, grammar, and punctuation 
- Correct use of capitalization

- Consistency and clarity of logic statemients

- Clarity and c.apleteness of internal branching instructions and instruetions for branching to other procedures

- Need for internal or external branching to other procedures (could the relevant instructions more effectively be incorporated in the step serjes under review?)

- Readabiity/clarity of aids such as graphs, flow diagrams, tables

- Provision for required calculations (e.g, for recording input data, caleulations, and results).

An example checklist for verification of procedure cesign is included in the review aids in the Appendix (Exhibit 5-3). If the facility has a procedure writers guide, it should he the primary source of checklist items. Items suggested herein that are not addres $d$ in the writers guide might be added. If the facility does not have a procedure writers guide, it would be highly desirable tc riepare one as part of this effort.

Other Preparation Steps. These are as stated for the technical verification (see Section 5.3).

Performance of the Procedure Design Verification. The design evaluators should consider each eriterion in the checklist. If the facility has a procedure writers guide, $t$ ' evaluators should refer to it as necessary to ensure that the procedure conforms to its specifications.

The disposition of each checklist item should be noted on the checklist. Notes should also be made on a copy of the procedure itself to identify any problems in individual instruetional steps and attachments. From these notes, an evaluation report should be prepared. Any problems should be defined clearly, keyed to the appropriate criteria, and keyed to the parts or steps of the procedure to which they apply. Recommendations for correcting problems may be included for consideration during the assessment and resolution of review findings (see Section 5.5). However, it is important to ensure that these recommendations not be allowed to bias the assessment and resolution process. 


\subsubsection{Validation of the Performance Effectiveness of Existing Procedures}

Validation is concerned with the effectiveness of procedures in actual use. Can a procedure be followid without difficulty by the individual or team expected to use it? If the procedure is followed, does successful performance result? Is the procedure consistent with actual system/equipr ent characteristics, symptoms, and responses'

Performance exercises are necessary to valichate procedures. The exercise! may be conducted as walk-throughs in which procedural steps are acted out but not executed. If a real-time simulator is available, the procedural steps can be executed. Then it is possibie to fully assess the consistency of the procedure with actual system/equipment conditions and responses, the effects of personnel actions, and coordination and timing factors. In some cases it may be possible to validate procedures in the course of real operations, maintenance, or other activities.

Personnel Requirements. Normal staifing should be assigned to perform the procedure. The personne: selected should be the least experienced personnel available who may rurform the procedure. A technjeal evaluator and a procedures design specialist should observe the exercises and record the findings. If the procedure is executed by a team and involves a large number of steps, additional observers may be needed to track the performance of each member of the team that is executing the procedure.

Material Requirements. The following materials will be needed for performance exercires:

- Copies of procedures to be performed (observer copies should be annotated with personnel and location codes as applicable)

- Copies of findings and recommencations from previous review activities (e.g., technical verification)

- Scenarios that define the paths to be followed in multiple-path procedures. A scenario will also be needed if only part of a procedure is to be performed or a segment is to be skipped.

- Copies of all reference materials/aids that may be used in performing the procedure

- All tools, supplies, equipment used in performing the procedure

- Protective clothing, breaıning apparatus or other protective equipment that should be used in actually performing th.: procedure

- Validation checklist

- Copies of schedule. 
Preparation of Validation Checklist. A checklist should be prepared for use by each observer. It should identify the base set of criteria to be watched for as exercises are performed. Discussions with performing personnel typically lead to findings beyond the base set of observation criteria. However, use of a checklist will ensure that major issues are watched for consistently.

It is recommended that the checklist identify a fairly small number of criteria. It should include criteria that cannot be evaluated fully in the tabletop situation of technical verification and procedure a.sign verification (as discussed in Sections 5.4 .1 and 5.4.2, respectively). The number of eriteria should be limited because it is difficult to attend to performance dynamics when concerned with numerous detailed criterion statements. Examples of criteria that are appropriate for use in performance exercises are listed below.

- Can the instructional steps be performed in the sequence indicated by the procedure?

- Can personnel readily locate and identify all components referred to in the instructional steps?

- Do the symptoms and equipment/system responses observable in the work situation agree with what is said in the procedure?

- Do personnel perform steps that are not in the procedure? Do they omit steps specified in the procedure?

A complete example of a validation checklist is included in the review aids in the Appendix (Exhibit 5-4).

Comparison of Procedure Nomenclature/Terms to Eguipment Labeling. An additional task included in this evaluation is to compere the component and parameter references given in the procedures to the labeling of the actual equipment used in executing the procedures to ensure that they match. This must be done in the work location.

System and component names and identification numbers, units of meesure, control positions, etc., should not only be referred to consistently and sccurately within the procedures; they should match the labels and location aids which personnel refer to in the work locations. Examples of differences which may be found include:

- Different panel/cabinet identifier - the procedure gives the facility alphanumeric identifier while the panel is labeled with the vendor identifier 
- Different anits of measure - the procedure tells the operator to verify level less than "X inches," but the displey reads "percent."

Diserepancies should be noted on copies of the procedures. $\Lambda$ technical evaluator will be needed to make the comparison and identify discrepancies. This information should be shown on the procedure copies used by observers of the verformance exercises, so they may watch for the effects of discrepancies on performance.

Determination of Personnel Tasks and Locations. For procedures that are performed by more than one person, it is recommended that the allocation of procedural tasks be noted before performance exercises begin. If tasks are performed at several panels/work stations, then task locations should be noted as well. Personnel and location codes should be established for these purposes. An individual who is experienced in using the procedure should record the personnel and locetion code by each step or substep on a copy of the procedure. It may or may not be necessary to go to the work area to do this, Each observer of the performance exercises should have a copy of the procedure annotated with personnel and location codes.

Preparation of Scenarios. A brief narrative statement should be written to specify the conditions under which the procedure or procedure segment is assumed to be performed and the path to be followed. Scenarios are also used in performance exercises to validate the human factors engineering of design. The preparation of scenarios is discussed in Section 4.0 of this Review Plan, concerning human factors engineering review. An example scenario is provided in that section of the Appendix, Exhibit 4-11.

Other Preparation Steps. The procedures review coordinator should see that the fellowing additional preparation steps are completed:

- Obtain use of facilities in which the exercises are to be conducted, This may involve:

- scheduling of time in the actual work area

- arranging for use of a simulator and the services of a simulator operator

- arranging for construction of a mockup of work area and equipment

- arranging for use of actual equipment and space for testing.

- Schedule personnel time, obtaining agreement of managers/line supervisors and participants. 
- Assemble required materials.

- If exercises are to be conducted in a simula tor, review scenarios with simulator operator. Ensure that each scenario is feasible in the simulator. Plan start and stop points and time slicing, as appropriate.

- Brief participants on the objectives and steps of the performance exercises, including criteria, aids, documentation of findings, and schedule. It is important to emphasize that the exercises are not intended to evaluate those who perform the exercises, but rather to jdentify needs for procedural improvements (or other human factors improvements).

Observers should review the findings and recommendations from any previous review activities. They also should become thoroughly familiar with the validation checklist.

Conduct of Performance Exercises. The steps involved in conducting performance exercises include the following, for each procedure or procedure segment to be performed:

1. The procedures review coordinator should lead a discussion of the scenario (if applicable) and procedure. Questions should be resolved, and roles should be specified if more then one person is involved in performing the procedure. Observers should be assigned to observe the personitel performing the procedure.

2. Perforrning personnel should then conduct the procedure in real-time, or an approximation of real-time, including all necessary communications. Observers should make notes about any questions they inay have concerning guideline criteria. It is ustally easiest to do this on a copy of the procedure.

3. Performing personnel should agtain conduct the procedure, this time in a slow walk-tirough. They should point out and explain all of their actions. If a team is performing the procedure, this will require phasing of the actions of each participant. Observers should ask questions as they arise and make notes.

4. All participants and observers should discuss the procedure, with reference to each criterion in the validation checklist. Any other problem areas or questions that may have arisen about the usability and performance effectiveness of the procedure should also be discussed.

5. One observer should assemble all documentation from the exercise and prepare a statement of findings for submission to the procedures review coordinator. Any problems should be defined clearly, keyed to the validation guideline as applicable, and keyed to the parts or steps of the procedures to which they apply. Recommendations for correcting problems may be included for consideration in the assessment and resolution of procedures review findings (see Section 5.5 ) 


\subsubsection{Evaluation of the Procedures Management System}

This evaluation addresses the system for developing, controlling, maintaining, and updating or revising procedures.

Personnel Requirements. One evaluator should be sufficient. The evaluator should have a background in procedure design and management, and should be detached enough from the existing system to maintain objectivity. The evaluator will need to talk with procedure users and other personnel with responsibilities in the procedure management system.

Material Requirements. The following materials will be needed to review the procedure management system:

- Copies of all documentation which defines how procedures are to be developed, reviewed, updated/revised, and controlled at the facility

- A list of personnel who mey be contacted for information concerning the procedure management system.

Preparation of Guidelines for the Evaluation. This is an exploratory evaluation. It should be open to identification of any problems that may exist and to recommending solutions $t o$. fit the organizational structure and administrative practices of the particular facility. Generally applicable characteristics of effective procedures management systems may, however, be identified as guidance. Major characteristics are stated below in the form of guestions that should be considered during the evaluation:

0 Is there clear and specific written guidance for procedure writers?

- Does the guidance provide for review of new procedures and revisions, by experienced user personnel? Does the guidance specify a performance test before a new procedure or major revision is approved for use?

- Is there an established schedulc for periodic review of procedures?

- Is there a written directive to define the steps necessary to update or revise a procedure?

- Is there a written directive to define what should be done if a need for procedure change is identified between periodic reviews?

o In all such directives/guidance, are personnel responsibilities clearly specifjed?

- Are there appropriate, designated areas where procedures and other documentation referenced in procedures are kept? 
- Are the conditions under which procedures may be removed from the designated areas specified and enforced?

- Are personnel prevented from making unauthorized personal copies of procedures?

- Is responsibility assigned for making sure procedures are in good condition for use (e.E.s legible, clean, complete copies)?

Other Preparation Steps. 'The procedures review coordinator should ensure that all relevant documentation is assembled. The coordinator should briel the evaluator (or arrange for briefing) on the system for procedure development, review, updating/revision and control. The coordinator should also identify personnel to provide additional information. Those personnel should be informed about the objective and major steps of the evaluation, the contribution expected from them, and the schedule.

Performance of Procedure Management System Evaluation. The resommended evaluation steps are summarized below.

1. Review the available documentation pertinent to the procedure management system.

2. Go into the work locations to look at the status of procedures in use and provisions for maintaining procedures in good condition and for controlling access. Talk informally with personnel to answer questions. (This must be arrenged through the procedures review coordinator.)

3. Review results of needs assessment, if available (see Section 3.0).

4. Conduct interviews with selected personnel to get their views on actual practices and needs related to procedure manegement. (Needs assessment results may make additional interviews unnecessary.) If interviews are conducted, they should address questions and findings from preceding steps. They should also solicit undirected input from the respondents.

5. Write a statement of findings if no problems are identified, or formulate problem statements and possible solutions.

6. Discuss problems and solutions with selected personnel and refine ts necessary (This may be unnecessery if interviews are conducted in step 4.)

7. Prepare findings and recommendations.

\subsubsection{Assessment of Needs for Additional Procedures}

This assessment can be performed by one or a combination of several methods, depending on the thoroughness considered appropriate: 
- A check may be made to ensure that the intent of applicable reguiatory guidance has been met.

- Documentation of performance history may be reviewed for indications of error in activities not covered by existing procedures.

- Personnel may be asked to identify activities which they believe should be covered by procedures.*

- Personnel may be asked to demonstrate and/or explain the steps involved in activities not covered by written procedures.

Personnel Requirements. At least one person will be needed with expertise in each functional area included in the review. A human factors specialist should be available to work with the technical expert on matters of methods and criteria.

Material Reguirements. The following materials will be needed:

- A list of all existing procedures and manuals for each functional area included in the review

- Copies of the procedures and manuals or ready access to them

- Job/task analysis date if available

- Documentation of incidents, outages, etc., if performance history is to be reviewed

- A questionnaire if the personnel survey method is to be used

- A list of respondents (at least two technicians/operators from each applicable functionel area) if the personnel survey method is to be used

- Criteria for assessing needs for procedures.

Establishment of Criteria, Regulatory guidance can provide a baseline set of criteria for assessing whether needs for procedures have been covered completely. Guidance concerning procedures coverage may be gives for specific facilities in Field office Supplements to DOE Orders. General guidance is given in a number of documents, including the Code of Federal Regulations, DOE Orders, and industry standards, A summary of the general guidance is provided in the review aids in the Appendix (Exhibit 5-5). As part of the preparation for the assessment it will be necessary to identify the

* An overall, preliminary assessment of review needs is suggested in Section 3.0. A questionnaire/interview survey conducted for that purpose could provide information specific to the assessment of needs for additional procedures. 
guidance applicable to the functional areas to be included in the review at the particular facility.

The above sources tend to identify major categories of activities for which procedures are required or recommended. To decide which specific activities within a category should be governed by written procedures, four main issues should be considered:

- The memory load imposed by the activity and situational factors that may affect recall.

- The extent of cues as to action requirements and sequence evident from the equipment itself.

- The recoverability of error and potential consequences of unrecovered error.

- The proficiency levels of personnel who may perform the activity.

- Supervision of the activity or verification of correct performance.

Criteria related to each of these issues may be used to aid decision-making. An example set of eriteria is provided in the Appendix (Exhibit 5-6).

Preparation of a Questionnaire to Identify Needs for Additional Procedures, If the personnel survey method is to be used, a questionnaire will have to be prepared. The following are examples of questions that would be appropriate:

- We do not have a written procedure for Review of records indicates that there has been some difficulty in performing that activity. What is your opinion about the need for a written procedure? Please explain.

- Do you know of any cases when you or others have been uncertain or made errors because there was no procedure specifying requirements?

- Do you have any recommendations about additional procedures in your area of work?

Other Preparation Steps. The procedures review coordinator should ensure that the necessary materials are available, schedule personnel time, and brief the participating personnel.

Performance of the Assessment. The following steps may be taken to assess needs for additional procedures. A selection may be made from these options: 
1. Outline the task content of the activities performed by personnel in each funetional area. (If job-task analysis has been performed as a basis for training in a functional area, jt may be meet this need.)

2. Compare the results of step 1 to the list of procedures/manuals for each functional area. Check the latter as necessary to determine what is covered. Flag any activities that are not fully covered by the existing procedures/manuals.

3. Review applicable regula tory guidance and industry standards concerning provision of written procedures and compare to the results of step 2. Note where gaps in procedure coverage represent omissions in areas where procedures are recommended.

4. Review unusual occurrence/incident reports, operating loss, maintenance recurds, etc., as applicable:*

- Identify occurrences that involved human error.

- Determine whether a procedure existed to guide the activity being performed.

- For cases in which there was no procedure, evaluate whether the use of a procedure could have prevented the error.

5. Distribute questionnaires or interview personnel for their opinions as to needs for additional procedures.

6. Evaluate potential needs identified in previous steps by analyzing the activity with reference to human factors criteria used to determine needs îor procedural guidance.

Where questions remain about need for a procedure it may be helpful to get personnel to demonstrate and/or explain their understanding of the required steps and contingencies. This should be done with reference to a scenario for the activity and a detailed list of performance requirements to define the success path(s). These materials should be prepared by the technical expert. The personnel asked to demonstrate/explain the activity should be briefed on the scenario but not shown the detailed list of performance requirements. At least two individuals should independently demonstrate/explain the activity. At least one should have minimal experience.

A statement of findings and recommendations should be prepared based on the results of all assessment steps performed.

* Additional guidence concerning documentation review is provided in Section 4.4.1.1. 


\subsection{Assessment and Resolution of Pindings from the Procedures Beviaw}

This section applies to findings from technical verification, presentation design verification, and validation of existing procedures, as discussed in Sections 5.4.1 and 5.4.3. It may also be applied to findings concerning necds for new procedures (Section 5.4.5), although assessment of the significance of such needs will be accomplished largely if not entirely in the course of the review per se. This section does not apply to findings concerning the procedures management system. Assessment and resolution of findings in that area involve factors specific to the individual facilities.

\subsubsection{Objectives}

The objectives of the assessment and resolution process are:

- To assess the significence of discrepancies that may be identified in the review, to decide which discrepancies should be corrected, and to decide their priority

- To plan and schedule corrective actions.

\subsubsection{Personnel}

It is recommended that a team be formed to conduct the assessment and resolution of procedures review findings. Team recommendations may then be submitted to facility management or to the human factors review steering cunmittee if one has been established (as suggested in Section 3.2.2).

Team cumposition is suggested below:

- The procedures review coordinator

- At least one person with key responsibilities for procedures management

- A maneger from each functional area/department that is involved

- Technical and human factors personnel who conducted review activities. ‘ applicable.

\subsubsection{Preparation}

If more than one review method has been used (e.g., buth technical verification and presentation design verification), the findings applicable to each procedure from each 
review miethod will need to be assembled, The procedures review coordinator should also ensure that any questions remaining from each review method have been answered.

\subsubsection{Assessment Methods}

A facility may decide to correct any or all of the diserepancies that are identified in a procedures review without formal assessment of their significance. Priorities for performing corrective actions may also be decided informally, based on knowledge of the criticality and frequency of use of different procedures and on other consiserations of needs and schedules within the functional areas/departments affected. Suggestions for a more formal approach are provided here for use when resources dictate limited rorrective action or when priorities are not clearly evident.

Two methods for assessment of review findings are discussed elsewhere in this Review Plan. Either can be applied to the assessment of procedures review findings,

General Criterion Ratings. The first method, described in Sections 3.2.5 and 3.2.6 is more general. It involves rating discrepancies according to a set of assessment criteria. The ratings may then be averaged to obtain single values that can be used to rank the discrepancies. The applicable criteria are listed below. Their wording has been modified to be more appropriate for procedures review findings.

- Relevance of the discrepancy to issues of real concern to procedure users.

- Safety impact: the potential of the diserepancy to degrade safety; i.e., how likely it is that this discrepancy will contribute to an error that could affect the safety of facility personnel or the public.

- Potential payoff in terms of improved efficiency if the discrepancy is corrected.

Each criterion should be rated on a 1 to 5 scale. The averages will also range from 1 to 5. High ratings most warrant follow-up attention. A facility may decide, for example to correct all discrepancies that receive ratings of 3 or higher. The ratings may also be used to establish the priority for corrective action even if it is decided that all will be corrected. 
Safety-Significance Algorithm. The second assessment method is discussed in Section 4.0. This method involves consideration of the following:

- The potential for error arising from the discrepancy

- The potential for error detection and recovery

- The potential conseguence of the error.

Values are assigned to these parameters based on analysis of underlying factors. Significance may then be expressed as the ratio of the patential that the discrepancy will induce error to the potential for recovery, multiplied by the consequence if the error is not recovered;

$$
\text { Signifieance }=\frac{\text { Potential for Error }}{\text { Potential Ior Recovery }} \times \text { Consequence of Error }
$$

The resulting signifieance values may be used to rank discrepancies and decide which will be corrected.

The details of this method are explained in Section 4.5 concerning assessment of human engineering design review findings. Some modifications will be necessary if this method is to be used for assessment of procedures review findings. The concepts are applicable, however.

\subsubsection{Resolution}

The remaining task is to recommend the actions needed to correct discrepancies and to prepare a projected schedule for making improvements. This material will provide input for final decisions by management.

The recommendations may range from minor ccrrections of technical or presentation discrepancies that occur in individual instructional steps, to complete editing and reformatting, to full-scale technical revision.

If substantial changes are made in organization, wording, and format of procedures, it is recommended that they be checked over lor techrical accuracy after this is done. Conversely, if a major techni ? revision is made, it should be checked for conformance to eriteria for elfective presentation design. 


\subsection{ORGANEATIONAL DNTERPACE REVIEW}

Defining organizational interfaces as the communication links between different functional groups or departments within an oryanization provides the basis for evaluating the adequacy of the vertical and horizontal communication of an organization. Studies performed for nuclear and many other industries underscore the effects of vertical and horizontal organizational communication on the effectiveness of an organization's operations. Many of the communication problems identified by this research are generalizable to DOE facilities,

A survey of nuclear power plant maintenance found that communication and coordination problems are responsible for major delays in completing maintenance tasks. ${ }^{1}$ Another study of nuclear power plant maintenance identified six problems responsible for inraeasing maintenance time and extending outages, all of which involved a communication component. ${ }^{2}$ These included: (a) lack of materials (parts and tools), (b) worker attitude, (c) cooperation and coordination, (d) inadequate supervision, (e) red tape, and (f) poor planning. In a more recent study of ten nuclear power plants, three categories of conmunication-related problems were revealed. ${ }^{3}$ The most frequently cited was difficulty in interacting horizontally with other departments. Another was insufficient lead time to provide for advanced planning, which limits departments' abilities to organize, schedule, and perform work efficiently. A third was insufficient sharing of "big pieture" information about plant issues (scheduling, workload, etc.) with lower level employees, resulting in uncleer lines of responsibility, confusion, and resentment.

Based on this experience, the major issues in organizational communication that may impact the effectiveness of an organization are defined in this section. In addition, a set of evaluation eriteria and measurement tools that may be used by DOE facilities to review coordination patterns end organizational interfaces in their organizations is presented. 


\subsection{Review Objectives}

Within the domain of DOE nuclear facility contractors, many types and sizes of organizational structure may be found. Despite their diversity, comron objectives can be stated for evaluation of organizational interfaces. The first objective is to ensure the adequacy of vertical communication within a contractor organization, between it and its cognizant DOE field office, and between the contractor organization and its own corporate management structure. The second objective is to ensure effective horizontal coordination among the various functional areas within a contractor facility (e.g., Operations, Maintenance, Health and Safety, Quality Control).

A third objective of this section is to provide DOE facility managers with a framework for evaluating the effectiveness of their organizational communication and to identify problem areas as perceived by personnel from various functional and or -anizational levels.

\subsection{Establishment of Diagnostic Criteria}

A comprehensive evaluation of the organizational interfaces found in a DOE facility must address criteria or standards necessary to assess the dimensions that impact organizational communication within a facility. These standards are referred to as diagnostic criteria and provide the framework for identifying problem areas in the organizational interface review. The Organizational Communication Questionnaire 4,5 was developed as a diagnostic tool, and covers a wide spectrum of communication issues applicable to most types of organizations. The benefit of using it for assessing orgenizational communication issues is that it provides indices that have already been tested on a variety of organizations and found to have both high reliability and high validity ratings.

The Organizational Communication Questionnaire contains items covering 18 communication indic ss. Each communication index represents a set of individual questionnaire items that are related to a particular aspect of communication (e.g., timelines of information). Exhibit 6-1, in the Appendix, contains a list of these communication indices and their 
related questionnaire items. The questionnaire is provided as Exhibit 6-2 in the Appendix. Some modifications have been made to tailor the questionnaire for use by DOE nuclear facilities.

Administration of the Organizational Communication Questionnaire in commercial nuclear power plants 6 revealed six communication indices with lower than average ratings:

1. Timeliness of information

2. Redundancy of information and requirements to pruvyide information

3. Gatekeeping/withholding information

4. Feedback

5. Information anount

6. Quality of work-related documentation.

These six indices represent problem areas that are most likely to be pertinent to the DOE farinities, Each problem area is described below.

\subsubsection{Timeliness}

This index represents the perceived satisfactic of personnel with the timeliness of the information they receive from different departments or job levels. Persistent lack of planning leads to crisis management and a "brush fire" approach to prioritizing and scheduling jobs. The higher the information source in the organization, the more time it takes for information to be transmitted drwnward. Information of ten becomes distorted as it is passed down through many management levels. As a result, supervisors resort to circumventing official lines of communication in oros to convey information in a more timely and acer ate manner.

\subsubsection{Redundancy}

This index represents how frequently information, including directives, statements of policy, changes in regulations, and requests for reports, is received more than once. Redundancy of information may be characterized in terms of the paperwork overload created by multiple layers of documentation requirements. Requirements for documentation may be both internally generated (facility, QC, QA, etc.) and externally generatec (e.g., DOE, corporate management). This may result in supervisors' feeling overburdened 
with paperwork that minimizes the time they spend interacting with their subordinates and the staffs of other departments about important issues. A related priviern is the amount of time spent in preparing documentation that is never used. Communication about work requests is so poor at some plants that technicians often waste time p'anning twice for the same job, restlting in the inefficient use of persontel.

\subsubsection{Gatekeeping/Withholding Information}

This index refers to information not being transferred beyond a particular point in the communication flow. Gatekeeping is more of a problem among supervisory and upper job levels than among lower job levels. Information tends to flow freely among peers in the work group, but too little information is made available by upper levels to the personnel who actually perform the work. Gatekeeping tends to start at the very top of the communication flow. This results in a lack of trust between supervisors and management - an attitude that has a cascading effect through the organization. This phenomenon can result in barriers between departments and rival "empire building."

\subsubsection{Feedback}

This index measures the degree of satisfaction with feedback from various job levels and departments within the arganization. In some facilities, upward communication is often considered a futile effort, since follow-up actions, or even acknowledgements, by management in response to upward suggestions or requests are rare. The need for more complete documentation and feedback from other departments is also required.

Lack of feedback regarding work performed by maintenance appears to be the most common problem. Maintenance often does not provide enough feedback to requestors regarding completed work and job histories.

\subsubsection{Information Amount}

This index measures satisfaction with the amount of information produced and transmitted by plant personnel for purposes of documenting work, relaying job-related information, reporting poor working conditions, and requesting clarification of work requests. Problems with not receiving enough job-related information to meet job requirements are cornmon. 
Judging the amount of information lor different types of people is also difficult. For example, lower level employees may feel they do not get enough "big picture" information to understand the context of their work, or department heads may not have enough accurate information when attending meetings in which work priorities are set and work schedules are defined.

\subsubsection{Quality of Fork-Related Documentation}

This index refers to the perceived quality of technical material related to guidelines and procedures for the performance of work. These include work requests, job orders, policies, and procedures. Several problems with work procedures may arise. One problem involves the updating of procedure files. So much time may be required to incorporate updates and char:ges into the working files that new procedures are not always flagged, making it difficult for personnel to recognize and follow designated changes,

\subsubsection{Other Indices}

Other indices deveioped from the Organizational Communication Questionnaire may also be pertinent to different facilities. The areas addressed by the other indices are outlined below:

- Trust refers to the sense of openness and confidence that personnel feel in relationship to their supervisors.

- Influence refers to personnel perceptions of the extent to which their career development can be furthered by their supervisors.

- Mobility refers to personnel interest in advancing to higher positions within the organization.

- Upward Directionality, Downward Directionality, and Lateral Directonality indicate mobility tendency based on patterns of communicetion with higher level personnel, subordinates, and peers.

- Accuracy refers to personnel perceptions of the reliability of information received from athers at different levels within the organization,

- Summarization refers to the extent to which personnel take responsibility for identifying important aspects and minimizing unimportant aspects when transmitting information within their own departments and to other departments.

- Expansion refers to the extent to which personnel take responsibility for providing additional detail when transmitting information within their own departments and to other departments.

- Desire for Interaction refers to the importance personnel place on interaction with higher level personnel, subordinates, and peers. 
- Changing information refers to the extent to which personnel must transform intormation before passing it on to others within their own departments or in other departments.

- Satisfaction refers to overall satisfaction with organizational communications.

Exhibit 6-1 in the Appendix identifies the questionnaire items that make up all of the indices described above.

\subsection{Methods of Problem Identification}

This section describes what is entailed in an organizational communication survey. It provides guidelines for: selecting those who should participate in the respondent sample, conducting the survey, and analyzing the survey responses. Requirements for the review team are also discussed.

\subsubsection{Organizational Interface Review Team}

Most work in the area of organizational communication has been conducted by trained professionals working as internal or external consultants to an organization. However, in the case of DOE facility reviews, this review is being suggested as part of a larger human factors program review. If consultents can be used, the assistance of one or two organizational/industrial psychologists would increase the efficiency of the review without excessive time demands on facility staff. Professional consultants are also in the best position to develop survey instruments, evaluate the survey data, and protect the confidentiality of the survey participants.

If the use of consultants is not a viable option, an internal team of two to three professionals with relevant skills and knowledge will be needed. The team should include someone with experience in designing and conducting surveys and in analyzing survey data. Basic statistical and computer skills may be needed for the data analysis effort. 
Strong interpersonal skills are also needed for this type of assessment. Survey respondents must trust the members of the evaluation team if they are going to be candid about their true feelings regarding interface problems. The importance of confidentiality of responses cannot be overemphasized. For this reason, members of the review team should not be selected from the target functional areas (see Table 6-1, in the Appendix).

\subsubsection{Definition of the Organizational/Interfuce Keview Process}

A minimum of three months should be allocated for the entire organizational interface review process, which includes seven major steps:

1. Formulation of questionnaire items

2. Selection of respondents

3. Distribution and collection of questionnaires

4. A -lysis and interpretation of questionnaire data

5. Development and administration of interviews

6. Analysis and interpretation of interview data

7. Development of recommendations to facility management.

Each step of the review process will be described in the paragraphs below.

Questionnaire Item Formulation, Candidate organizational communication issues or problem areas must be broken down into component parts or characteristics that tescribe each issue. This type of review will provide the topics or areas that specific questions need to address.

Before creating questions to tap each characteristic, several guidelines are useful when developing a questionnaire:

- Each question should ask for a response in terms of behavior or performance.

4. Descriptive questions should be kept to a minimum so that as much questionnaire time as possible can be devoted to evaluative questions.

- Multiple-choice items should be used where possible to minimize completion time.

- Time to complete the questionnaire should be limited to 30 minutes.

- Respondent anonymity must be guaranteed. 
Questions should be developed by reviewing each communisation issue and its component characteristics. Where a question or group of questions can be identified from an existing survey or questionnaire (see Exhibit 6-2 in the Appendix), it should be modified as necessary to suit the DOE facility situation.

An initial list of questions should be reviewed for wording consistency, readability, content overlep, and elarity. These questions must then be formatted into a questionnaire and sent to subject matter experts for review. Also, a pretest using a small group of three to five employees from the functional areas listed in Table 6-1 should be conducted. The purpose of the pretest and review is to identify any additional problems in question wording and comprehension and to determine whether the questionnaire can be completed within 30 minutes. Based on pretest and reviews, questions should be modified and the questionneire shortened as necessary. (A sample questionnaire is included in the Appendix es Exhibit 6-2.

Selection of Respondents. Where facility size permits, it is recommended that a minimum of 25 people be selected to complete the questionnaires. The sample should be chosen to represent all functional areas and job levels. Operators, technicians, craftsman, line supervisors, and depariment managers should be drawn from the following areas: Operations, Maintenance, Instrumentation and Control (I\&C), Health and Safety, and Quality Assurance/Quality Control (QA/QC). The top-level manager at the facility should also participate. Since Operations and Maintenance typically have more staff than the other functiona! reas, twice as many questionnaires may be obtained from personnel in those areas. Table 6-1, in the Appendix, summarizes the type of vertical and horizontal representation that is needed.

Questionnaire Distribution and Collection. Each facility should name a point of contact who selects the individuals to participate in the survey and distributes and receives the questionnaires. The point of contact will need:

o Instructions for distributing questionnaires (e.E., categories of employees to select, when to distribute, when to follow up), answers to anticipated questions, and the name and phone number of an evaluation team member to call in case of problems

- Sets of questionnaires and instructions and the name and phone number of the on-site point of contact for distribution to participants 
- Follow-up memos for the point of contact to issue once, and again two weeks after initial questionnaire distribution

- Returi envelopes to be used by employees to return completed questionnaires to the review team. Each participant must be given a guarantee of complete anonymity.

Analysis and Interpretation of Questionnaire Data. After the completed questionnaires are collected they must be reviewed to ensure that they were properly completed (e.g., one response per questionnaire item unless specified as a multiple response item). After the initial review of the questionnaires, frequency data for each item should be computed. In this way, items of paw data become meaningful when they are grouped in a frequency distribution by type of respondent (e.g., department or job level). To analyze the frequency distribution of the scores, a measure of the central tendency or central point around which the scores scatter must be computed. The simplest measure, the mean, which is the same as the familiar arithmetic average, should be computed for the total group and for each functional group of respondents. Total and group means for each set of questionnaire jtems dealing with a specific type of communication (e.g., feedback or timelines) should be calculated to provide an easy comparison of group responses. More information about a distribution than can be obtained from the mean scores ic :eeded to tell whether scores cluster closely around their average or whether they scatter widely. The most common measure of the dispersion of scores around the average is called the standard deviation.

Mean and standard deviation scores should be caleulated for the total group, and also by type of respondent (each functional area or job level), depending on the number of respondents. For those items that are components of communication indices (see Exhibit 6-1 of the Appentix), index scores should also be calculated. Index scores for each questionnaire are deter ined by summing the individual item component scores, and then dividing the sum by the number of component items. Looking at the index scores pross functional departments or job levels gives the review team a way of measuring the degree of onsensus across groups regarding the existence of organizational communication probleins. Thus, comparing index scores across functional areas or job levels may provide the best way to evaluate the data. Since the majority of questionnaire items are rated on a 1 (low) to 7 (high) scale the mean scores can be used to profile individual facility responses. Table 6-2 presents a summary of the major departmental communication 
problems identified in three commercial nuclear power facilities using the questionnaire provided in the Appendix. A quick glance at Table 6-2 reveais that some departments perceive more communication problems within their organization than others. Contingency tables may also be generated for the index scores, and the chi-square test may be used to estimate the statistical significance of differences between functional areas and job categories.

Once the calculations have been made, the review team must examine the summary statistics and interpret the results in terms of how they may be applied to interaction patterns within the facility. A list of candidate problem areas may be defined and used to formulate the topic areas to be addressed in the follow-up interviews.

Interview Development and Administration. Follow-up interviews should be held with personnel from each of the functional areas included in the questionnaire sample in order to:

- Ask plant personnel about key topies and problems that emerged from the questionnaire data

- Expand on the definition of problem areas identified from the questionnaire data and other sources

- Identify and verify problem areas and illustrate them with real-world behavioral examples or critical incidents that illustrate the role and importance of organizational communication factors.

To define specific questions to be used in the interviews, a set of guidelines similar to those used in the development of the questionnaires should be followed, with one notable exception. For the questionnaire, a multiple-choice format was suggested to keep questionnaire completion time to a minimum. Since there is no way to define what types of responses may be given in the interviews, open-ended questions must be used.

Using a critical-incident interview technique7 that focuses on real world examples of communication problems, interviewees should be asked to describe specific events that had or might have had efferts on functional effectiveness and safety. This approach tocuses on salient success, failure, near-miss, and delay situations that would provide insight into critical factors in performance effectiveness. Personnel should be asked about communication problem areas such as completeness of work requests, advanced planning, and interdepartmental coordination. Following is an example of the type of 
question used: "Please describe a situation in which the facility's productivity and operation have had problems due to conflicting priorities." Suggested interview questions are provided in the Appendix (Exhibit 6-3).

Within each facility, the same type of cross section of personnel used in the questionnaire survey should be used for the verification interviews (see Table 6-1 in the Appendix). Adjustments may be made in the numbers of operators, technicians, and craftsmen for the interviews to minimize the burden on personnel. Included in the sample should be represeniatives of various organizational levels of Operations, Maintenance, I\&C, QA/QC, and Health and Safety or other major functional areas.

Interview Analysis and Interpretation. Responses to each interview question must be analyzed and categorized. Exhibit 6-4, in the Appendix, illustrates the type of interview response tally sheet that may be used to summarize responses to the interview questions. Separate tallies should be made for each facility interviewed. Bec se the interview questions are open-ended, there may be many multiple responses to an item. Each type of response must be treated equally in the data summarization process.

Once the response tallies for each interview item have been obtained, the number of responses per category should be converted into a percentage of total responses for each item. By using percentages, it is easier to interpret what the data is suggesting in terms of identifying specific problem areas for a given group of respondents (functional area or job level) or response patterns across all groups. For example, Figure 6-1 (in the Appendix) illustrates how ratings for Operations, Maintenance, and Management differ widely depending on the job category of the respondents. Only 20 percent of respondents who were operators, mechanics, or technicians had problems dealing with the Operations and Maintenance departments; whereas, 34 percent to 40 percent of top level managers had interaction problems with the same Operations departments, and 40 percent of the top level managers reported problems with interfacing with their Maintenance departments. In contrast, the graph to the right shows that top level managers have far fewer problems interacting with their peers in management (22 percent) than the operators and maintenence personnel in their organizations have interacting with them (48 percent).

Integration of Findings. Interview and questionnaire results should be compared. Then a problem statement should be written that integrates results from the two sources and 
describes the nature and extent of organizational interface problems that have been indicated.

Development of Recommendations to Facility Management. For development of recommendations, the review team should be augmented by additional personnel who have indepth knowledge of the facility and the activities performed in the different functional areas. At this point, personnel in the areas from which questionnaire and interview rarticipants were drawn need to become involved in the process of evaluating the findings and developing recommendations.

Translating the problem statements into recommendations for management to act on is not an easy undertaking. Some techniques and guidelines that may be used to formulate recommendations are suggested below:

- Brainstorm alternative solutions to the problem (see Section 6.4).

o Discuss the "what," "where," "when," "who," "why," and "how" of each alternative.

0 Invite subject matter experts from outside the facility to contribute.

- Visit similar frcilities to gain insight into what solutions may have worked elsewhere.

- Prepare a cost-benefit analysi; of the alternatives to select the best one.

- Develop an action plan outiining the problem statement, impact of problem, solution, implementation strategy, schedule, and benefits.

- Anticipate and plan for any objections or questions regarding the action plan.

- Use adequate documentation: charts, graphs, and refercnces.

\subsection{Methods of Problem Solving}

nnce the problem definition or diagnostic phase of the organizational interface review is complete, the focus of the evaluation team must shift to concentrate on defining the best approach to solve or resolve the interface issues, Therefore, to ensure that the evaluation team's recommendations for change are tailored to the important issues and take into account resource availability, a review of candidate solutions is warrented. 
Five solutions thought to be the most effective for dealing with organizational interfaces inciude quality circles, interdepartmental job coordination meetings, maintenance management information systems, orientation training, and policies and procedures. In the paragraphs below, each solution strategy will be defined in terms of its methodological approach and resource requirements.

\subsubsection{Quality Circles}

Stemming froin the Japanese efforts to improve the quality control of their products, quality circles (sometimes referred to as pride circles) have developed in many U.S. organizations and taken on a broader focus. ${ }^{8}$ Quality circles may be defined as small groups of employees (approximately 10 ) who do similar or related work and meet regularly (usually one hour a week) on company time to identify, analyze, and solve work-rolated problems. The decision to implement quality eircles as a vehicle for improving organizational interfaces involves a significant commitment by the organization's management. Eight to ten training sessions are required to familiarize circle participants with the quality circle process, problem-solving skills, and participative managament strategics. Each circle has a facilitator to guide the group interactions; facilitators reguire additional front-end training to prepare them for their unique roles.

The decision to implement quality circles in an organization is a big one. It involves the long-term commitment of many personnel resources to bring such a program to fruition. The development, treining, and implementation process may take one to two years. Many large manufacturing organizations have been impressed with the positive recommendations and more participative atmosphere that have resulted from the quality circles. However, no organization should consider implementing quality circles for short-term gains.

\subsubsection{Interdepartmental Job Coordination Meetings}

in contrast to guality circles, described above, regular (e.g., dajly, interdepartmental job coordination meetirgs for supervisors fosus on the shering of information between departments which is crucial to the efficicn: operation of the facility. During job coordination meetings, participants review specific work requirements in order to detarmine prioritics and to resolve scheduling conflicts between departinents. In these meetings, representatives from the different departments discuss the status of ongoing work orders, plan upcoming work, and review completed work. The purpose of such 
meetings is to improve the quality, timeliness, and amount of information transmitied beiween departments and to encourage better feedback between dijartments and between upper management and the lower levels.

Daily interdepartmental job coordination meetings should last approximately 15 minutes and should fcllow a standard agenda similar to thet shown in Table 6-3 (in the Appendix). This structure actually serves two purposes in the job coordination meeting: it provides guidelines for the meeting and serves as an information collection form to characterize specific communieation problems. Participants discuss and resolve work problems, plan fuititie work, and provide feedback to one another.

Tre advantage of the job coordination meetings ovet the more formal quality circle concept is that it institutionalizes daily interdepartmental contact to address interface issues while minimizing the tir.ci and training requirements associated with the intergetion.

\subsubsection{Maintenance Manapement Information Systems (HIS)}

With the rapidly increasing high technology systems needed to operate the DOE facilities, naintenance management information requirements are also growing. Automated systems for handling both corrective and prevontive maincenance have been introduced at a number of DOE facilities as well as at commercial nuclear plants. The organizational unterface aspects of these systems emphosize the availability of timely and accurate information to a broad spectrum of system users. These systems would reduce the need for face-to-face corroboration prior to the initiation of work. A maintenance MIS, whether automated or not, should provide for the timely notification of functional areas regarding work requirements, schedules, and status, as well as provide feedback beiween affected departments.

The design of an automated maintenance MIS can require a significant investment of resources. Facilities have spent as much as two years in defining and coding their equipment inventories and performing needs assessments, which are keys to the system's success. A dedicated design team is needed for the effort. Some hardware/software packagus are commercially available to minimize design costs; hawever, these packages have limited flexibility to tailor the system for a specialized application. The user of canned programs often becomes bound to their structure, rather than having the system serve as a tool for the user. 


\subsubsection{Orientat on Training}

Another approach to improvirg arganizational interfaces is to develop a set of orientation training modules that address lines of authority, areas of responsibility, and other coordination issue, iailored to the structure of each facility. Training modules $r$ ay be designed to provide new personnel with the following:

1. An understanding of how the system works

2. Identification of roles and required authorizations

3. Explanation of time/performance requirements for each responsible individual

4. Encouragement toward's interdepartmental information exchange and feedback

5. Know]edge of how to prepare required forms, including the formulation. of problem descriptions and the accurate identification and location of equipment.

Tne approach for developing orientation modules on organizaticnal communication and the work request proces; is to first define specific training objectives. In conjunction with the definition of training objectives, skill and knowledge requirements or enabling skills must be identified to ensure that the objectives are met. It often is necessary to tailor such training modules for different functional areas/departments and for different job levels.

Members of the organizational interface review team should meet with subject matter experts to establisl, the training requirements. The available documentation of interface requirements will be needed as reference data for the preparation of the training modules. If training personnel are available to develop the training modules, they inould work in conjunction with the review team and subject matter experts to ensure that the communication issues identified in the organizational interjace review are adiressed in the modules. To optimize the usefulness of the modules, is job-performance-aid (JPA) format is suggested, JPA formats involve the integration of graphics and text and could be l'sed to provide procedural guidance as well as descriptive information about specific functions or interfaces to be covered.

Representatives from the facility's major functional areas should be asked to review each module to verify jts technical accuracy. In addition, comments on the modules should be requested from the first set of recipients for evaluation purposes, Modifications to the modules should be made on the basis of such input. 


\subsubsection{Modification of the Organizational Siructure}

The organizational structure itself can promote or deter effective communications. A recent study of the organizational effectiveness and safety performance of commercial nuelear power plants lound that the plants with more vertical ranks and brobder spans of control were poorer performers. 9 It found that coordination among the functional areas was a key to successful meration. Orgarizational structures can be modified by a concerted effort on the part of the organization's management to optimize, clearly delineate, and document the lines of authority, span of control, and interaction patterns for its personnel. Often, the organizational strurture is influenced by the personalities of the job incumbents or by conformity to known stereotypes rather than objectively designed to optimize the effectiveness of the organization.

Management can make significant changes in organizational interfaces by rearranging the organizational structure and mandating specific interaction procedures to accommodate routine and problem conditions. However, maximum gains in this area are only the product of: careful analysis of the problems, definition of organizational changes to address them, and distribution of the information and euthority necessary to institutionalize the changes. Management's commitment to and support of such efforts are essential to their success. Ir acdition, input from those funetiona] areas or job levels must affected by the changes should be incorporated into the development of any policy or guide' ine documentation.

6.5 Assessment of Possible Solutions To Improve Organizational Interfaces

\subsubsection{Criteria}

Just as diagnostic criteria were needed to help identíy organizational interface problems, assessment criteria are necessary to weigh or rate the relative desirability of eech strategy for solving the organizational interface problems. A set of assessment crituria is suggested below for use in each facility in making the decision of which solution, or combination of solutiens, to implement. 
- Rejevance to Organizational Interface Issues. This criterion estimates the degree to which the candidate solution addresses the improvement of real-world organizational communication issues identified at the facility. High relevence ratings are optimum.

- Payoff to Facility. This criterion estimates the relative amount of inprovement in coordination and organizational effectiveness that can be expected if the solution is implemented. High potential payoffs are most desisable.

- Evidence of Effectiveness. This eriterion assesses whether or not the proposed soiution has been used in analogous organizations to improve the internal communications and effectiveness of their operations. High ratings regarding the perceived appropriateness of the techniques are desirable.

- Ease of implementation. This criterion assesses the level of involvement on the part of the facility's management and technical personnel that will be necessary to implement candidate solution. The greater the involvement that is required, the lower the rating for ease of implementation. High ratings are preferred.

\subsubsection{Assessment Procedure}

$T: \cdots$ ganizational isterface review team may use the criteria definitions provided above lermine the suitability of the potential solutions. A five-point rating scale (1=low;

ch) can be used by each member of the evaluation team to rate the interventions on each criterion. Exhibit 6-5, in the Appendix, presents a sample form to be used for completion of the assessment criteria ratings. Once individual ratings have been obtained, mean ratings for the group can be calculated to determine the best estimate of the desirability of each option. These ratings should be addressed in the preparation of recommendations to the facility's management as part of the rationale for selecting one type of solution over other options. Trade-offs will have to be made if one technique seems mast preierable in terms of one criterion (e.g., relevance) but is less desirable in terms of others (e.g., ease of implementation). 


\subsection{Application}

Training problem identification is the "trigger" for a training program review. Problem identification can come from a variety of sources, such as:
- Accident/Incident Reports
- Human Factors Engineering Review
- Procedures Review
- Organizational Interface Review.

In any case, once a training problem has been identified, certain steps should be taken in order to correct it. These steps are referred to as a Training Review.

\subsubsection{Training Review Objectiye}

The objective of a Trainine Review is two-fold:

1. Validate that the training problem identified is in fact a training problem, and

2. Once validated, correct the problem.

During the training review process, other problems related to the identified training problem may surface. For example, the cperation or maintenance procedure used to perform the function may be inadequate. These should be dealt with separately, using appropriate DOE guidance.

\subsubsection{Training Review Criteria}

Several types of eriteria may be used in a training review. The guidance developed to date for DOE nuclear facilities includes the following:

- Program organization and management

- Qualificetion of training staff

- Trainee selection

- Content and conduct of training (includes initial training and periodic update/requalification training)

- Trainee examinations and subsequent on-the-job competency checks

- Program supporting resources. 


\section{APPENDIX}


It is advisable to conduct a thorough training review in order to ensure that all facets of the problem are identiried and corrective action taken.

\subsubsection{Training Review Method}

The training review should always be done using training staff personnel as well as technical, operations, or maintenance personnel as appropriate. This will ensure that the corrective actions taken will be appropriate and that all parties affected concur in the action.

In most cases the starting point is to review all course materials that relate to the training problem identiried. The training staff will be most helpful since they will be familiar with course conduct and content.

Once the problem is isolated within a course, a decision can be made concerning what corrective getion is to be taken. This decision must be careflily made as it may have far reaching consequences on other facets of the training process. For example, changing course content in the affected cuurse may affect materials taught in a related course. In other words, fixing the problem in one course may very well require changes to be made in one or more related courses, or even the crsation on deletion of a course.

It is stressed that training development and evaluation efforts should be coordinated with other human factors applications to achieve integrated, mutually reinforcing results. Equipment design, procedures, communication processes, and training combine to produce the total human factors environment. They should compliment and be consistent with each other. As changes are made in any one of these areas, corresponding changes me: be needed in others to maintain human factors integration. 
3.0 SELECTION OF AREAS POR REVIEW

REVIEW AIDS 
The resolution of review findings should not necessarily specify the details of each change to be made. It should identify the types of changes needed and classify procedures accordingly. It should also identify the types of personnel needed to develop the changes. A projected schedule can be prepared based on the types of changes. 


\section{EXHLBT 3-1}

\section{EXAMPLE CRITICAJ, INCIDENT \\ QUESTIONNAIRE TTEMS \\ FOR A NEEDS ASSESSMENT}

\section{Workspace Layout and Environment}

"Describe at least three aspects of the workspace, furniture, equipment layout, or environmental conditions that you find particularly bothersome. Deseribe specific incidents or ways in which these have been ineffective and have interfered with job performance."

\section{Panel Design}

"Can you think of any occurrences when someone has activated the wrong control, activated a control inadvertently, or activated a control incorrectly?" (Probes: Why did this happen? What system and panel were involved? How and when was the mistake discovered? What was the consequence?)

"Describe any changes to the facility that you feel would improve worker's capability to recognize and control normal and abnormal plant operating conditions."

"What do you consider to be the three most confusing or difficult systems to work on and why? Give an example of an incident in which there was difficulty with the system."

\section{Annunciator Warning System}

"Describe any features of your annunciator warning system that you feel have resulted in inefficient or erroneous fault isolation,"

\section{Computer-Based Systems}

"Describe at least three characteristics of your computer-based systems that you consider awkward or difficult to use under normal, abnorral, and emergency conditions."

\section{Corrective Maintenance}

"Can you think of incidents in which a defect of the corrective maintenance program caused an operational problem? If so, please deseribe what happened and explain the problems with the maintenance program."

"Can you think of any situations in which characteristies of the maintenance program caused delay or difficulty in performing corrective maintenance? If so, please explain." 
"Can you think of any situations when equipment design or characteristics of the workspace contributed to error, difficulty, or delay in performing corrective mainten- ance? If so, please explain."

\section{Preventive Maintenunce, Testing, and Calibration}

Note: repeat questions stated under the heading Corrective Maintenance, but replace "corrective maintenance" with "Preventive Maintenance, Testing, and Calibration."

\section{Communicatiens}

"Describe any problems with the facility communications systems (phones, page phones, loudspeakers, radios, etc.) that have prevented or interfered with yous ability to communicate with other personneL"

\section{Organizational Interface} ments."

"Describe any problems with receiving inadequate information from other depart-

"Describe any work delays that are caused by poor communications between departments/functional areas."

\section{Procedures}

"Deseribe at least three incidents in which your procedures did not provide clear guidance and resulted in ineffective or erroneous performance."

\section{Training}

"Describe at least three characteristics of your training (elassroom, OJ'r, self-study, or other) that you feel were inadequate in preparing you for your job responsibilities." 


\section{EXHEIT 3-2}

\section{EXAMPLE SCALAR QUESHIONNAIRE \\ JTEMS POR A NEEDS ASBESSMENT}

Please answer all of the questions from the perspective of gour funetional area.

How satisfied are you with the following aspects of your facility?

\begin{tabular}{ccccc}
\multicolumn{5}{c}{$\begin{array}{c}\text { Neither } \\
\text { Setisfied }\end{array}$} \\
Very & Somewhat & Nor & Fairly & Very \\
Dissatisfied & Dissatisfied & Dissatisfied & Satisfied & Satisfied \\
1 & 2 & 3 & 4 & 5
\end{tabular}

Workspece Layout

Environment

Equipment Design for Operability

Equipment Design for Maintainability

Annunciator Warning System

Computer-Based Systems

Corrective Maintenance

Preventive Maintenance, Test, and Calibration

Safety-Radiological

Safety-Industrial

Communication Systems

Organizational Interfaces
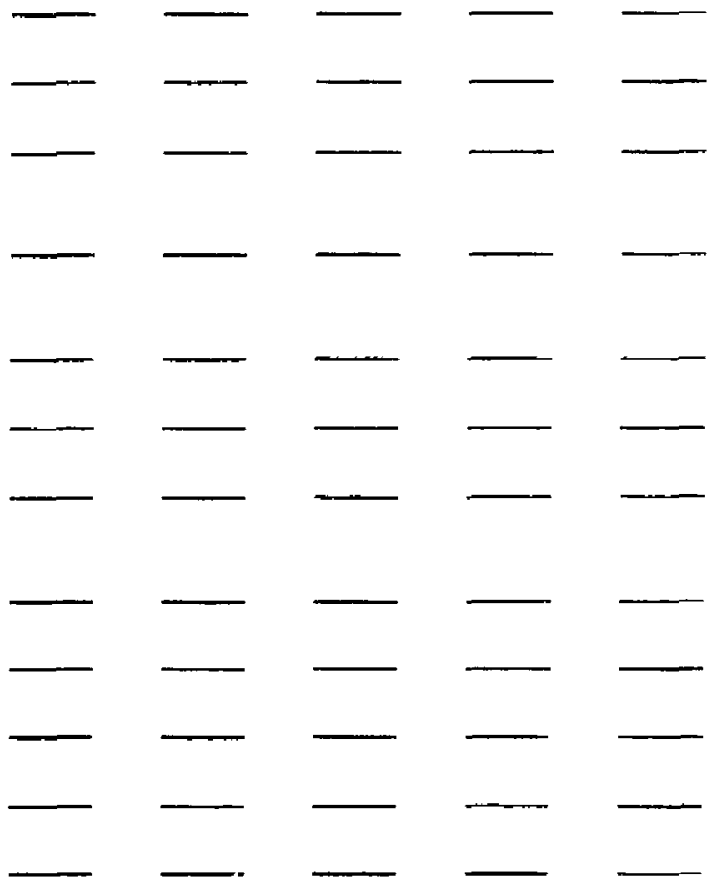


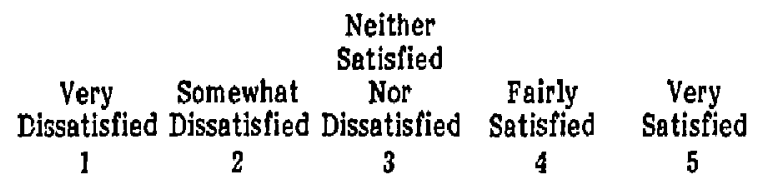

Procedures

Opereting

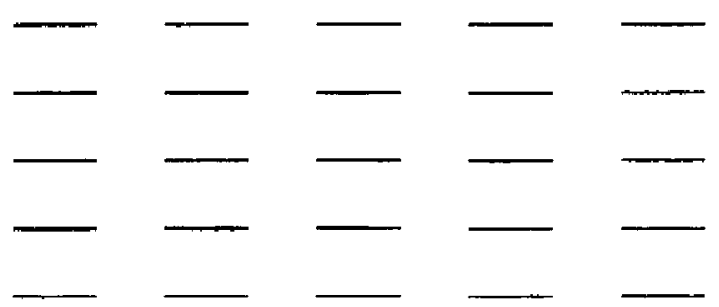

Training

Comments: 


\section{TABLE 3-1}

TYPICAL CROSS SECTION OF DOE FACILTTY PERSONHEL SELECTED FOR A NEEDS ASSESSMENT SURVEY

\begin{tabular}{|c|c|c|c|c|}
\hline Functional Area & $\begin{array}{c}\text { Operators/ } \\
\text { Technicians/ } \\
\text { Craftsman }\end{array}$ & $\begin{array}{c}\text { Line } \\
\text { Supervisors }\end{array}$ & $\begin{array}{l}\text { Department } \\
\text { Managers }\end{array}$ & $\begin{array}{l}\text { Facility } \\
\text { Manager }\end{array}$ \\
\hline Operations & 3 & 1 & 1 & \\
\hline Maintenance & 3 & 1 & 1 & 1 \\
\hline $1 \& \mathrm{C}$ & 3 & 1 & 1 & \\
\hline Health and Safety & 2 & 1 & 1 & \\
\hline $\begin{array}{l}\text { Quality Control/ } \\
\text { Quality Assurance }\end{array}$ & 2 & 1 & 1 & \\
\hline Training & 2 & I & 1 & \\
\hline $\begin{array}{l}\text { Technical } \\
\text { Documentation } \\
\text { and Procedures }\end{array}$ & 2 & 1 & $\underline{1}$ & - \\
\hline Subtotals & 17 & 7 & 7 & 1 \\
\hline
\end{tabular}

Totali 32 personnel per facility receiving questionnaires out of a staff of 96 . 


\subsection{SELECTION OF AREAS FOR REVIEW}

\section{REPERENCES}

1. Flannagan, J. The critical incident technique. Psychological Bulletin, 1954, 51, 327358.

2. Guidelines for control room design reviews (NUREG-0700). Division of Human Factors Safety, Office of Nuclear Reactor Regulation, U.S. Nuclear Regulatory Commission, Washington, D.C., 1981. 


\subsection{HOMAN FACTORS ENGNNERING REVIEW}

REVIEW AIDS 


\section{EXHIBIT 4-1}

\section{EXAMPLE OF AN OBSERVATTON CHECKLIST POR \\ HPE REVIEW OF OPERABILITY (partial)}

(Source: Essex Corporation, Systems Operability and Design Group, 1983.)

This checklist inclures a comprehensive set of HFE criteria that are appropriate for an observation survey of displays (excluding CRT displays). The criterion source is NUREG0700 (reference 18).

Similar checklists are needed to address other HFE topics. Because of the number of criteria involved and length limitations of this Review Plan, a full set of checklists to cover each topic is not given. 


\section{ALL DISPLAYS}

1. For highest contrast, visual displays should have black markings on a white scalel; however, this does not mean that color should not te used as long as the colors used provide cood contrast 6.5.1.3c(2)\&(2).

2. The calos used for coding any display should contrast well with the panel background 6.5.1.6e(2).

3. Any given color used for display coding should be recognizable from all other display codte colors for all illumination conditions 6.5.1.6e. 3 ).

\section{ALL DDICATOR LIGHTS}

4. Ambient lighting should not be so bright nr reflective that it couses indicator lights to eppear on when they are off, or off when they are on 6.5.3.15.

\section{SIMPLE INDICATOR LIGHTS}

5. Colors used for indicator lights should be clearly jdentifiable - 6.5.3.2a'3; ,

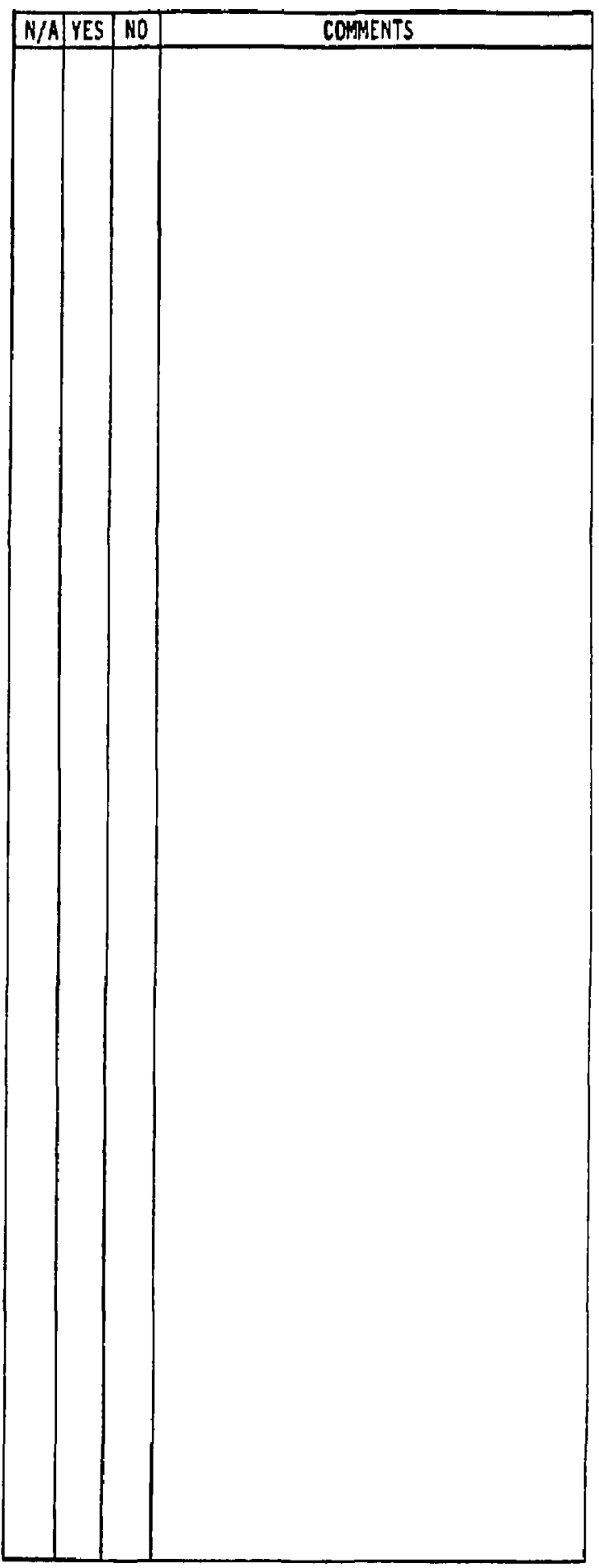


6. Where meaning is not apparent, message label should be located in close proximity to the indicator light 6.5.3.28(1).

\section{LECEND LIGHTS}

7. Legends should be legible under ambient lighting with indicator lights off 6.5.3.3a $(2)$.

8. Legend lettering should contrast well with background under both ambient and transilluminated lighting 6.5.3.39(3).

9. General design of legend light indicators should be consistent throughout the control room - 6.5.3.3b(1).

10. Legend symbols should be clear end unambiguous as to their mesning $-6.5 .3 .3 \mathrm{~b}(3)$. 
11. Legend text should be short, concise, end unambiguous 6.5.3.3b(4).

12. Legend messages should cortain no more than three lines of text $-6.5 .3 .3 \mathrm{~b}(5)$.

13. Nomenclature and abbreviations on legend light indicators shoult be standard, and consistent with usage throughout the control room and in the procedures $-6.5 .3 .3 \mathrm{~b}(6)$.

14. The wording in a legend ahould only signify the stated condition when the light is illuminated ( $e . g$. in $D F F$ legend that means off when the light is out is incorrect) $6.5 .3 .3 \mathrm{~b}(7)$.

\section{METERS AND RECORDERS}

15. When scale multipliers are used, they can be clearly geen and they use the powers-aften to indicate multiplication or division - 6.5.1.2e, 6.5.1.49 \& 6.5.4.1c.

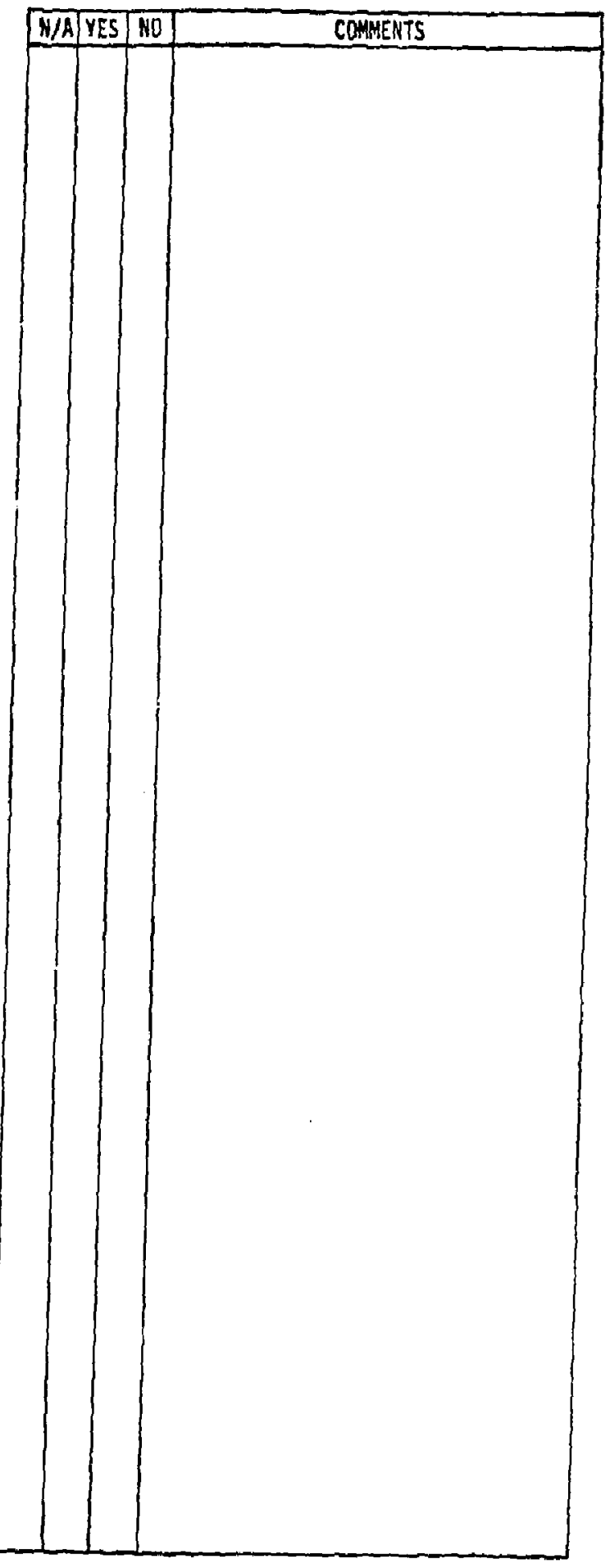


16. Character atyle used on any display should be simple block style with no verifs or embellishments, upper-case only, and be consistent 6.5.1.3b \& 6.5.3.3b(2).

17. If information is required to use $a$ scale, the message should be placed in close proximity to the scale (i.e., printed on the dislay face or adjacent to it) 6.5.1.4a(1)\&(2)\&6.5.4.1c.

18. Information not needed in using a display should not be printed on the display face (i.e., patent notices, manufacturer's trademark, etc.) 6.5.1.4b \& 6.5.4.2c.

19. Messages printed on display faces should be as brief as clarity permits - 6.5.1.4c \& 6.5.4.1c.

20. Individual numerals on any type of fixed scale (i.e., circular, linear) ghould be vertical - 6.5.2.4a.

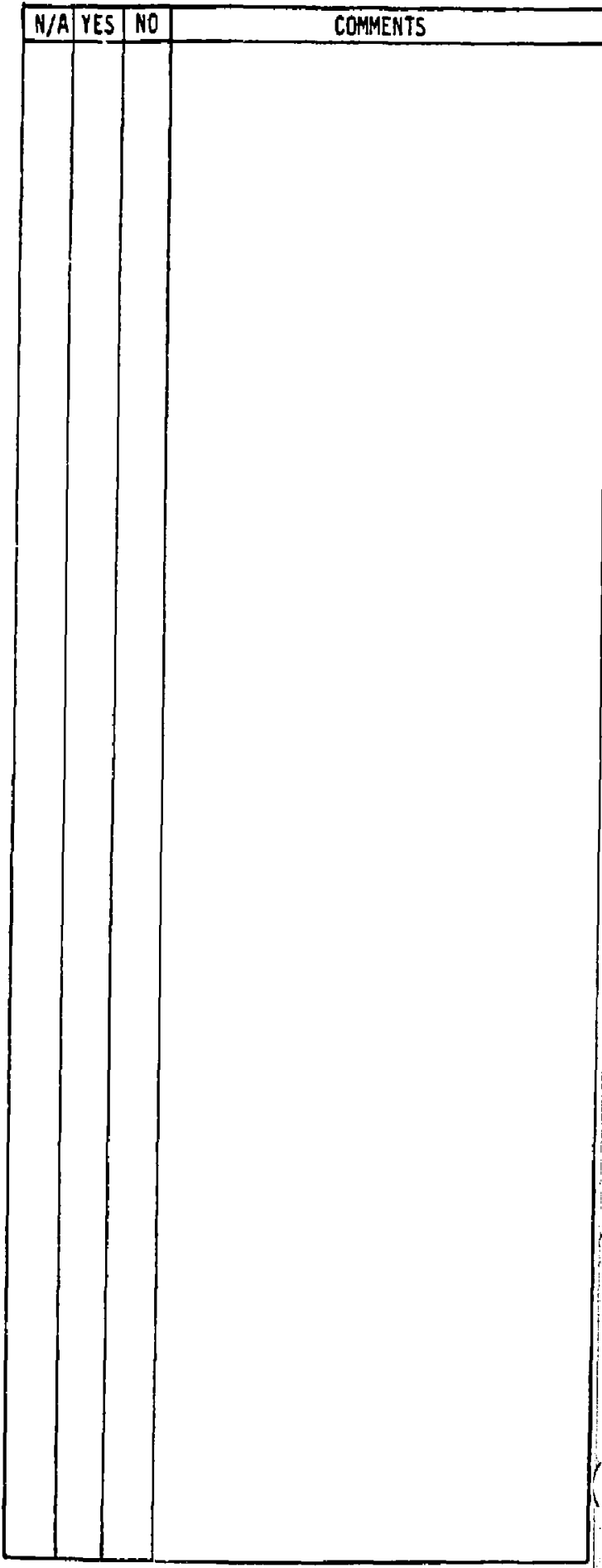


21. Scales for quantitative reading ohould be provided with graduations consistent with the progression of their numerals -6.5 .1 .58 \& $6.5,4.1 \mathrm{c}$.

22. No mote than nine graduations should reparate numerals on scales - 6.5.1.5a(1) \& 6.5.4.1c.

23. Major and minor graudation thould be used if there are up to four graduations between numerals on scales 6.5.1.58(2) \& 6.5.4.1c.

24. Major, intermediate, and minor graduations should be used if there are five or more graduations between numerals on scales - 6.5.1.5a(3) \& 6.5.4.1c.

25. Values indicated by unit greduations should progress by j, 5 , or 10 , or those values multiplied by some power of 10, or at least progress by 2 or 2 multiplied by some power of 10 - 6.5.1.5a(3) \& 6.5.4.1c.

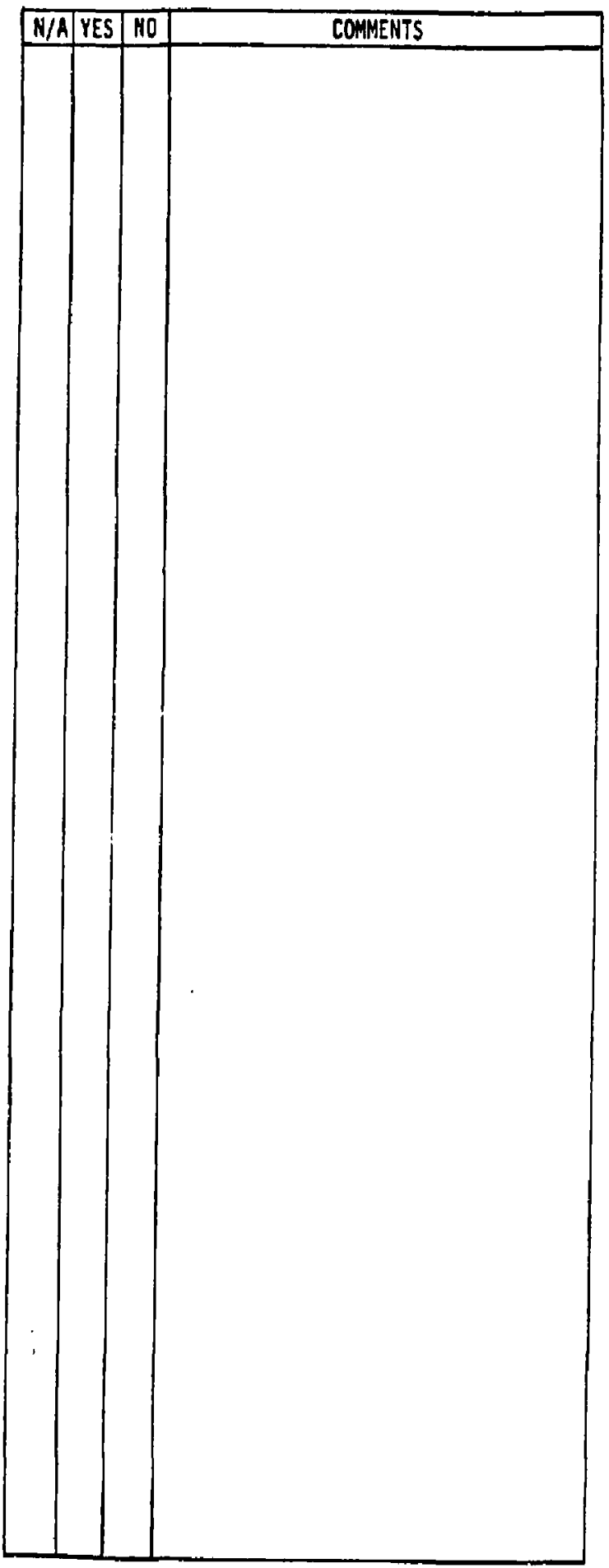




\section{EXHBBIT 4-1 (continued)}

\section{METERS}

26. Circular scale values should increase with clockwise movement of the pointer 6.5.2.1a.

27. Vertical straight scale values should increase with upward movement of the pointer 6.5.2.1b.

28. Horizontal straight scale values should increase with pointer movement to the right $-6.5 .2 .1 \mathrm{c}$.

29. Pointer tips should be simple (e.g., arrow-head, triangular, or blunt-tipped needle) 6.5.2.2a(1).

30. Pointer tips ghould be selected to minimize concealment of acale graduation marks or numerals $-6.5 .2 .2 \mathrm{a}(2)$.

31. Pointers should be nounted close to the scale to avaid parallax $-6.5 .2 .2 \mathrm{~b}(2)$.

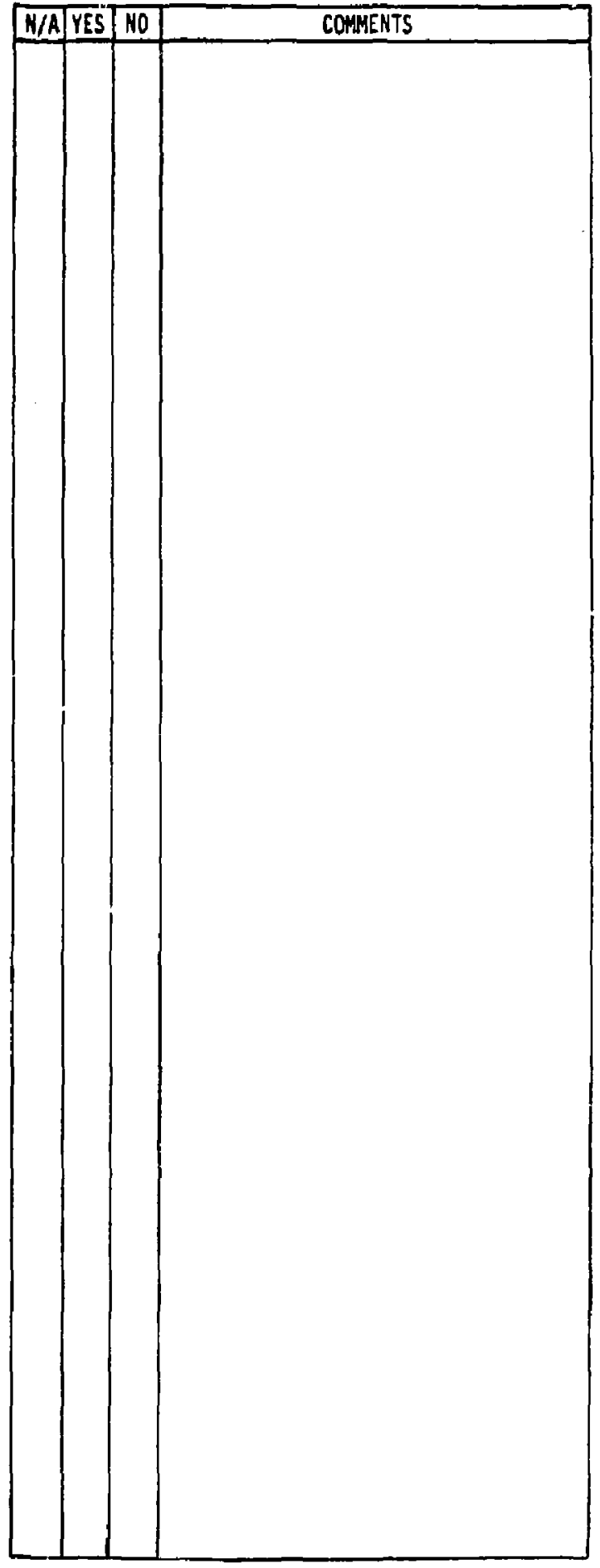


32. Pointer/background cuntrast

- and pointer size should be - dequate to permil rapid recognition of pointer position - 6.5.2.2c.

33. Zone markings should be conspicuous and distinetively different for different zones -6.5 .2 .30 .

34. Zone marking should not interfere with reading of quentitative markings $-6.5 .2 .3 \mathrm{~b}$.

35. If colored zones are used:

a. Red should mean unsafe, danger, or out of tolerance.

b. Green should mean safe, or in Lolerance.

c. Amber (yellow) should mean hazard, coution, potentially unsafe or marginal value -

$6.5 .1 .6 \mathrm{e}(2) \& 6.5 .2 .3 \mathrm{r}$

36. Where pointer movement is more than $360^{\circ}$, the zero point should be foceted at the 12 o'clock position - 6.5.2,46il).

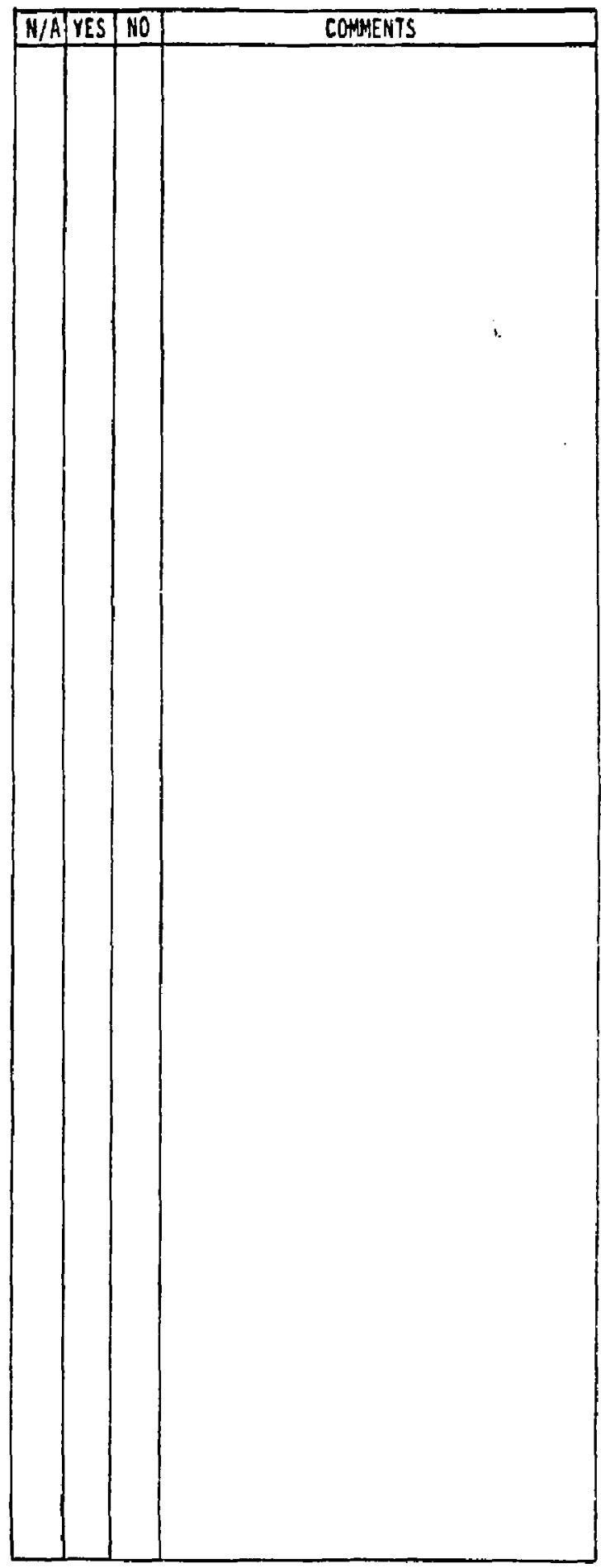


37. Where positive and negative values are diaplayed around a zero of null position, the zero or null point should be located ot the 12 o'clock position 6.5.2.4b(2).

38. Where the scale covers less than a full rotation of the pointer, scale end-points thould be indicated by a break in scale $-6.5 .2 .4 \mathrm{c}(1)$.

39. Scale end-point breaks should be at Jeast one numbered interva! in length $6.5 .2 .4 \mathrm{c}(2)$.

40. Scale end-point breaks should be oriented at the 6 o'clock position - $6.5 .2 .4 \mathrm{c}(3)$.

\section{ALL CHART RECORDERS}

41. Pens, inks, and paper used in chart recorders should be of a quality to provide clear, distinct, and reliable marking (i.e., ink does not clog pens or omudge an paper) - 6.5.4.10.

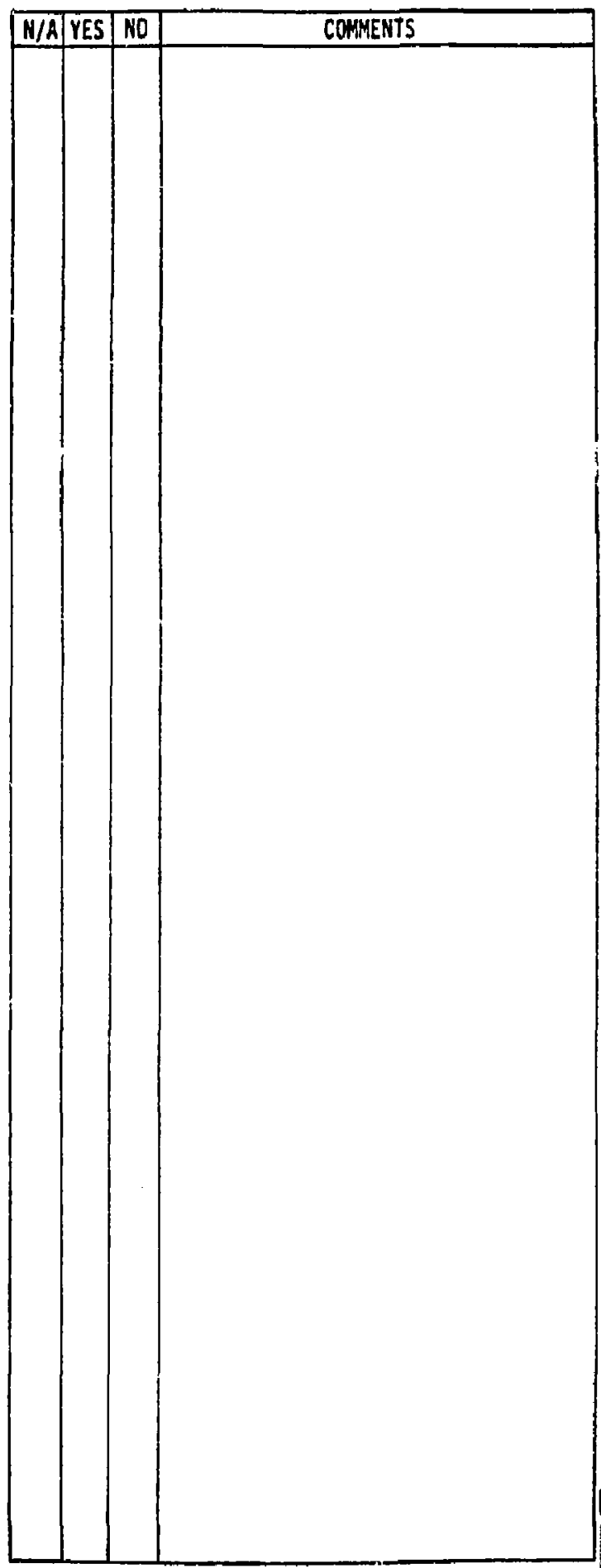




\section{Scales printed on the} recording paper should be the tame as scales shown on the recorder - 6.5.4.1b.

43. Chart recorders which must be monitored by the operator shoulo be lcosted within the primary operating ares 6.5.4.1 h.

44. All data should be visible through the window of the chart recorder and not require an operator to open the door $=$ 6.5.4.1k.

\section{PENRECORDERS}

45. Labels should identify the parameters on all multiple-pen recorders, and the parameters should be listed in the order of the associated scales 6.5.4.2a $\{1)$.

46. Dn multiple-pen recorders, each pen should use a different colored ink - 6.5.4.28(2).

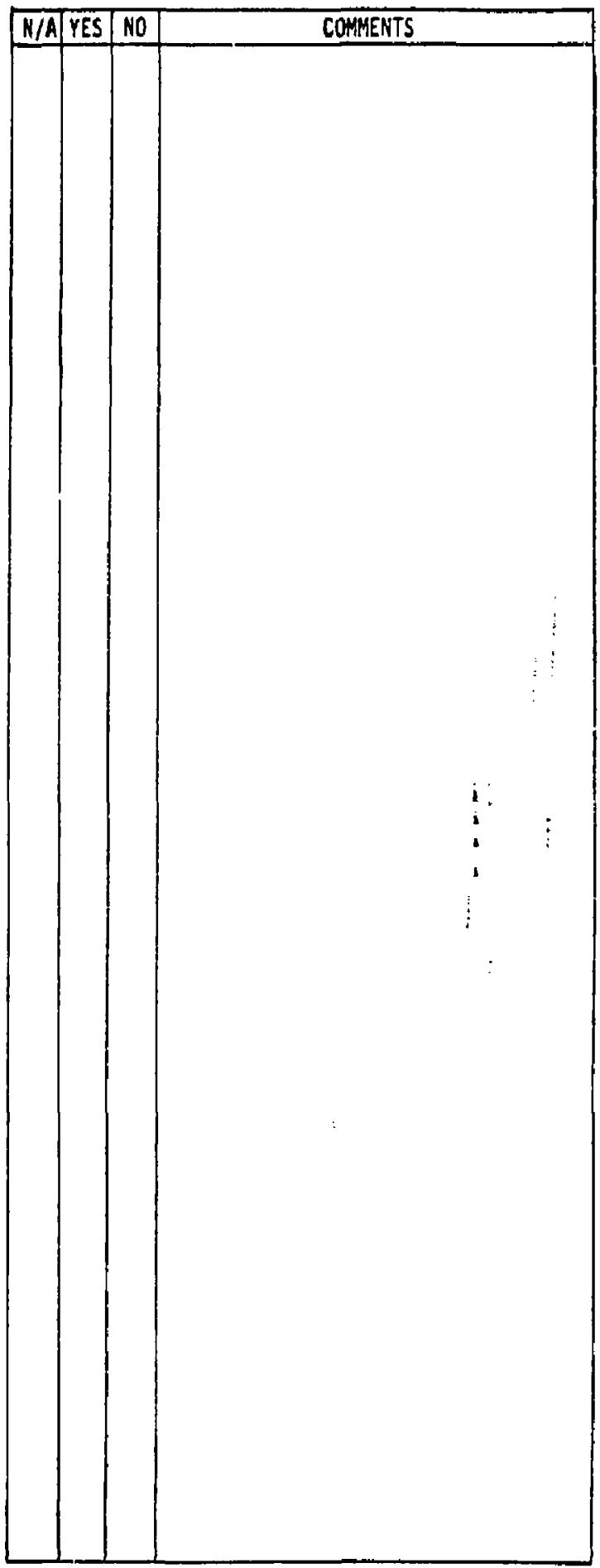


47. Colors used on multiple-pen recorders should be distinctly different and should afford good contrast with the papar $-6.5 .4 .2 \mathrm{~g}(2)$.

\section{MPACT RECORDERS}

48. Imprint heads on impact fecorders should be easy to view. Odd and inconvenient viewing angles should be avoided $-6.5 .4 .2 \mathrm{~b}(2)$.

49. The number-printing mechanism on impact recorders should be designed and maintained to provide clear, sharp, and small numbering to avoid crowding of data $-6.5 .4 .2 \mathrm{~b}(3)$.

\section{DRUM STYLE COUNTERS}

50. Multidigit numbers formed by several counter drums should be oriented horizontally from left to right $-6.5 .5 .18(1)$.

31. If muse than fous digits are required on drum-type countera, they ahould be grouped and the grouping aeparated as appropriate by commas, by a decimal point, of by additional space 6.5.5.18(3).

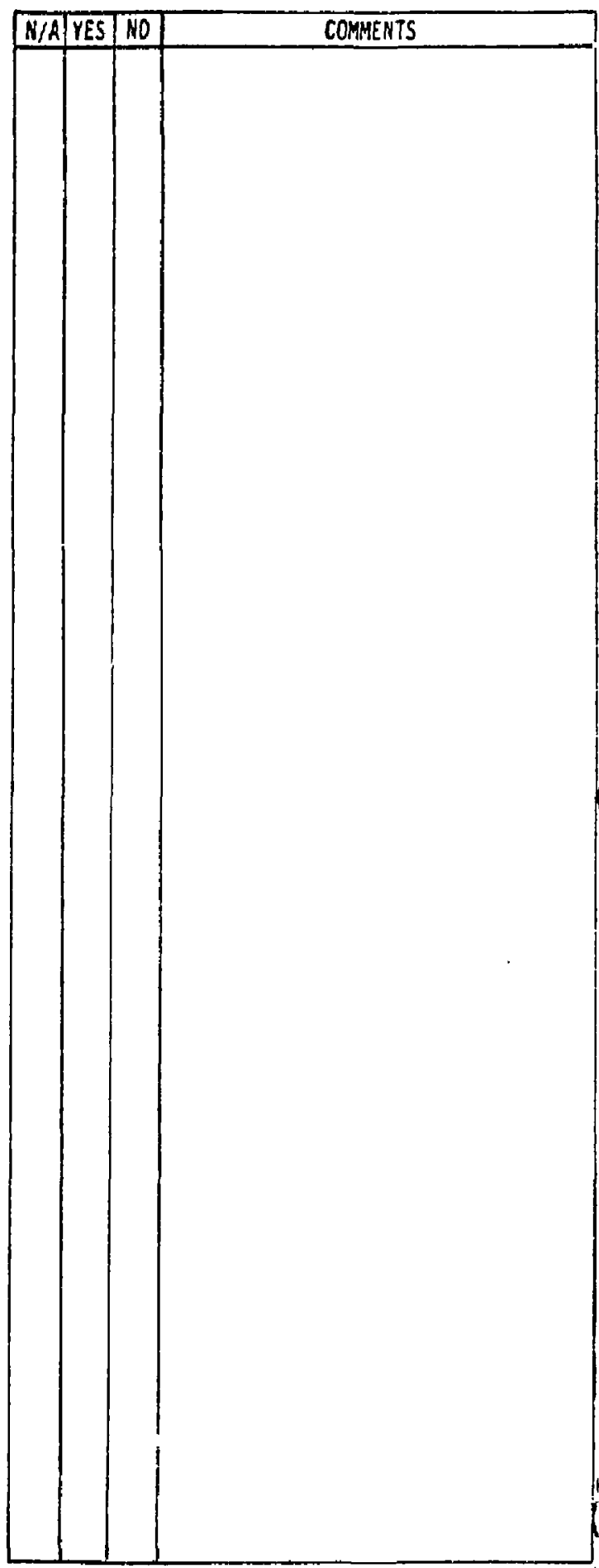


52. For high contrast, black numerals on $a$ white drum surface is recommended 6.5.5.1日(4).

53. Drum surfaces and surrounding areas shouid have a ma"te finish to minimize glare 6.5.5.1a(5).

54. Drum-type counters should be mounted perpendicular to the operetor's line of sight 6.5.5.10,1).

55. Drum-type counters should be mounted as close as possible to the panel surface to minimize shadows and maximize viewirg angle 6.5.5.16 $2 \%$.

56. Windows on dium-type counters should allow only one digit per drum to appear in the window at any one time 6.5.5.1b(3).

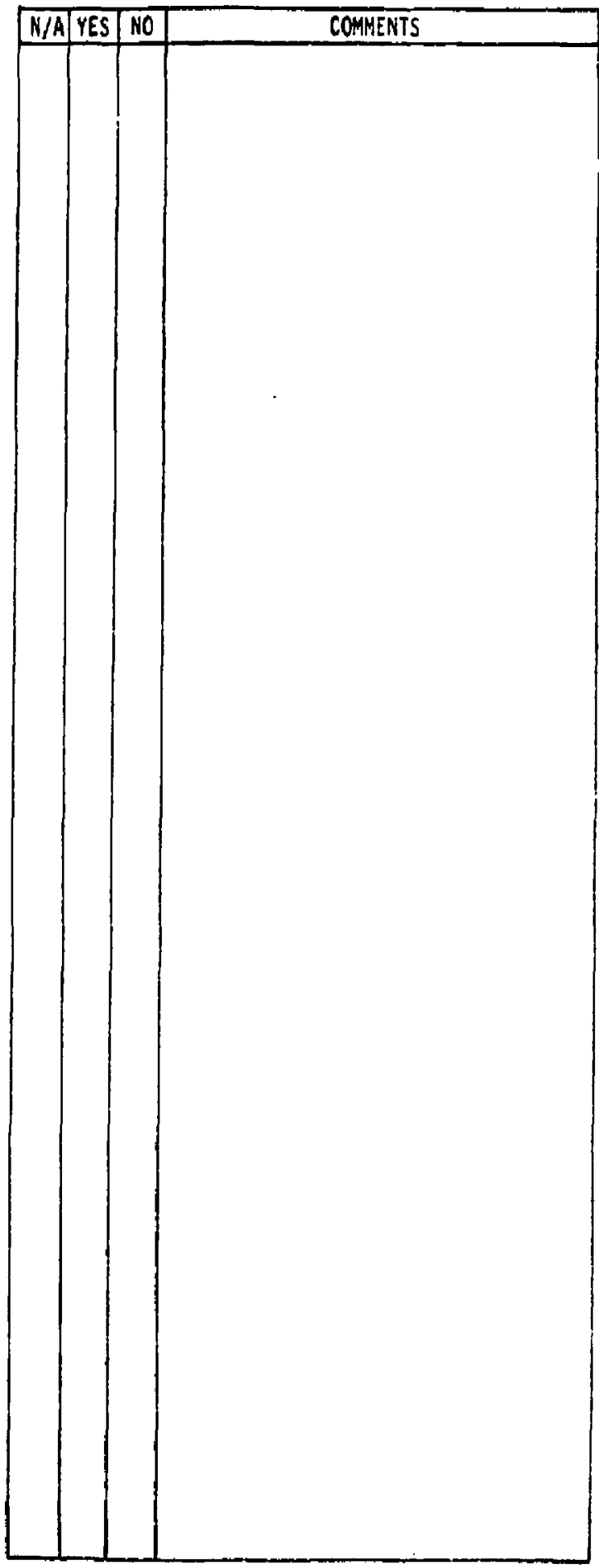


57. Numbers should change by snep action rather than through p:ontinuous movement. on drur,-type counters 6.5.5.:c(1).

59. Counter drums should move uf ward with increasing velues $-6.5 .5 .1 \mathrm{c}(2)$.

\section{ELECTRONIC COUNTERS}

59. Numerals on mulkidigit electronic counters should be oriented 0 sead horizontally from left to right 6.5.5.2a(1).

60. Simple, uniform character font style should be used on -lectronic counters (i.e., variable stroke widths, slanied characters, etc., should be ovojided) $-6.5 .5 .2 \mathrm{e}(2)$.

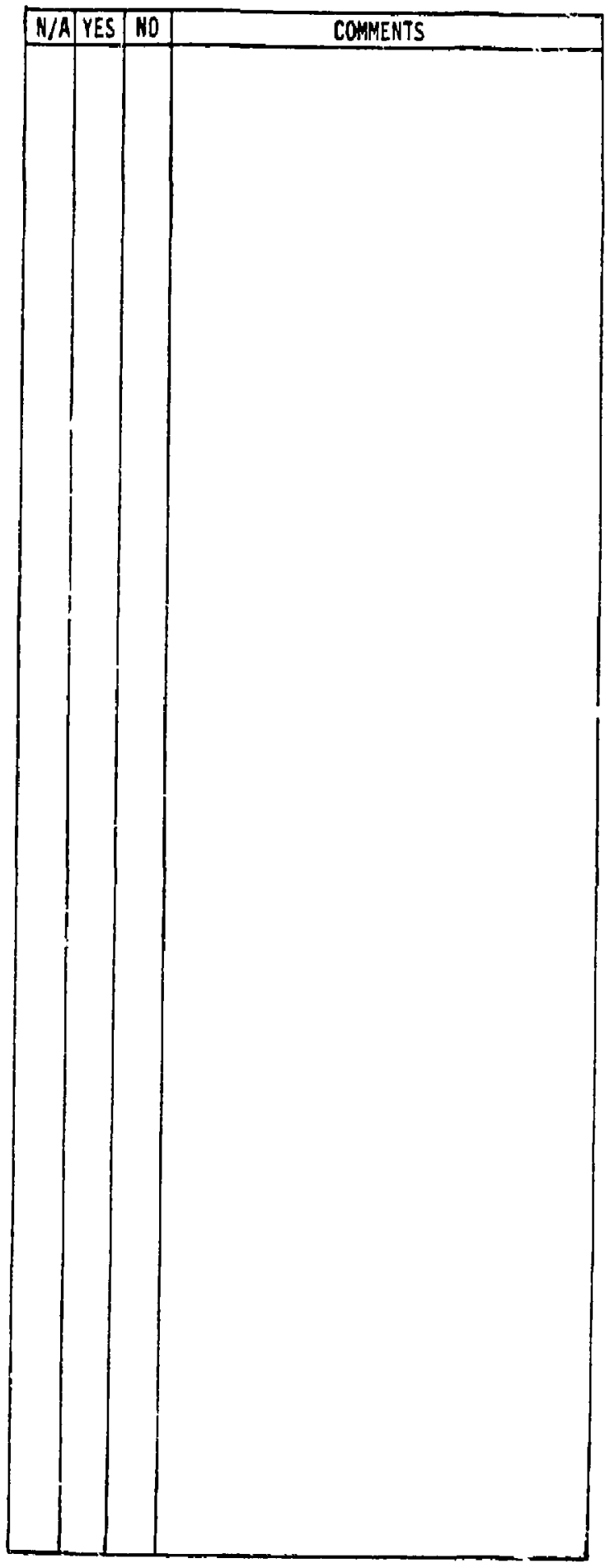


(Excerpt from: Greth, R.L. \& Block, C.A. (1983). Methodology investigation - Human factors engineering test procedure for Army aviation, Appendix C design checklist for maintainability. Fort Fucker, AL: U.S. Army Aviation Development Test Activity.)

Detailed Design Considerations YES NO N/A COAHENTS

1. Equipment uses standard parts to

the extent possible.

(NIL-STD-1472C, pard 5.9.1.1)

2. Specia! adjusting tools are securely mounted in resdily accessible location.

.(MIL-STD-1472C, para 5.9.1.3)

3. Equipment is replaced in modular packages. (MIL-STD-1472C, para 5.9.1.7)

4. Equipment can be rapidly and easily removed and replaced by one person, within we ight limitetions contained in Paragraph 5.9.11.3 of MIL-STD-1472C (ref 29). (MIL-5T0-14i2C, pari 5.9.1.3)

5. Number of inputs to and outputs from a unit are minimized by grouping functions. (MIL-STD-1472C, para 5.9.1.4)

6. Unitized functions sllow each $i$ tem to be checked and adjusted separately. (HIL-STD-14;2C, para 5.9 .1 .5$)$

7. Equiment is designed to facilitace rapid and positive fault detection and isolation. (MIL-STD-1472C, pard 5.9.7.6) 
8. Equfpment is designed for easy

assembly and disassembly.

(MIL-STD-1472C, para 5.9 .1 .7 )

9. Equiment can be removed, replaced, and repaired wearing personal and special purpose clothing and equiment, if applicable. (MiL-STD-1472C, para 5.9.1.8)

10. Similar components cannot be physically interchanged unless functionally the same.

(MIL-STD-1472C, para 5.9.1.9a)

11. Components cannot be improperly mounted. (HIL-STD-1472C, para 5.9.1.9b)

12. Coding, etc. is used for easy identification of components. (MIL-STD-1472C, para 5.9.1.9C)

13. Aligment pins, etc. are used for easy mounting of components. (HIL-STD-1472C, para 5,9.1.9d)

14. Cables and connectors are designed for easy identification, orientation, and alignment. (HIL-STD-1472C,

para 5.9.1.9e)

15. Parts are mounted so that a iuvie- !ever does not support an upper layer. (HIL-5TL-?4?2C. para 5.9.2.1)

16. Similar, but not functionally related, items are mounted with a standard orientation but are readily tentifiable and distinguishable.

(MIL-STD-1472C, para 5.9.2.2) 
Detalled Design Considerations

YES HO N/A CONMEHTS

17. Delicate ftems are loceted or guarded so that they aren't susceptible to damage during service, (MIL-STD-1472C, para 5.17 .2 .3 )

18. Waintenance controls comply with para 5.4 controls and

para 5.5 labeling of

MIL-STD-1472C (ref 29).

Refer to Sections 2.3 and 2.4 .

(MIL-STD-1472C, para 5.9.3)

19. Knobs are used for calibration controls when frequent adjustments must be made.

(MIL-5TD-1472C, para 5.9.3.1)

20. Screwdriver ad jus tments made without the aid of vision are designed to preclude screworiver slipping. (MIL-STD-1472C, para 5.9.3.2)

21. Reference scales or other feedback methods are avallable and visible for all adjustment controls. (MIL-STD-1472C, para 5.9.3.3)

22. Adjustment or calfbration controls with limited degree of motion have mechanical stops that prevent damage. (MIL-STD-1472C, para 5.9.3.4)

23. Sensitive adjustment points are guarded against inadvertent movement. (MIL-STO-1472C, para 5.9.3.5)

24. Hand or arm support is provided then adjustment is performed in a vibration or acceleration enviroment. (HIL-SID-1472C, pors 5.9.3.5) 
Detalled Design Considerations

YES NO N/A CONMENTS

25. Internal controis are not located close to dangerous vol tage, rotating machinery, or other hazards wi thout shieiding and labeling: (MIL-STD-1472C, para 5.9.3.6)

26. Structural members do not prevent access to or removal of items. (MIL-STD-1472C, para 5,9.4.1)

27. Replaceable ttens are not mounted so that they are difficult to remove. (MIL-STD-1472C, para $5.9,4.1)$

28. The removal of panels, cases, and covers is not blocked by structural members or other itens. (MIL-STD- 1472C, para 5.9.4.1)

29. Large, di ifficult to renove $i$ tems do not prevent convenient access to other items.

(MIL-STD-1472C, pora 5.9.4.2)

30. Check points, adjus tment points, test points, cables, etc. are accessible and visible during ma intenance. (MIL-STO-1472C, para 5.9.4.3)

31. Space exists for the use of test equi ment and otiner tools. (MIL-STD-1472C, para 5.9.4.3)

32. Fquipment requiring rear access is free to open or rotate the full distance and remain in the open position wi thout hand support. (BIL-STO-1472C, para 5.9 .4 .4 ) 


\section{Detalied Design Considerations YES NO NA COMMENTS}

33. Critical items requiring rapid mia intenance are rost accessible. (MIL-STO-1472C, para 5.9.4.5)

34. 1:ems requiring most frequent access, when criticality is not an issue, are most accessible. (MIL-STD-1472C, para 5.9.4.5)

35. High-failure-rate itens are replaceable wi thout having to remove other itens. (MIL-STD-1472C, para 5.9.4.6)

36. Mechanical items are removable with common tools.

(MIL-STO-1472C, para 5.9.4.6)

37. Access to equipment does not require removal of equipment ma intained by another technician. (HIL-STO-1472C, Dara 5.9.4.7)

38. Hechanical items can be lubri. cated without disassembly. (MIL-STD-1472C, para 5.9.5.1)

39. Extended fittings are provided for lubrication of difficult to access equipment. (HIL-STD-1472C, para 5.9.5.1)

40. Type and frequency of lubrication is specified by label near the lube port. (MIL-STD-1472C, para 5.9.5.2)

41. Lubrication chart of permanent construction 15 mounted at the operator station.

(MIL-5TD-1472C, para 5.9.5.2)

42. Cover and shield holes are large enough for mounting screw clearance wi thout perfect case aligment. (MIL-STD-1472C, para 5.9.6) 
Detalled Design Considerations YES NO N/A COMHENTS

43. Item orientation within fts case is obvious. (MIL-STD-1472C, para 5.9.7.1)

44. Cases lift from items, if possible. (MIL-STO-1472C, para 5.9.7.2)

45. Cases ara sufficlently larger than itens to minimize potentiat danage to items.

(HIL-STD-1472C, para 5.9.7.3)

46. Guides, tracks, and stops are provided for case removal and replacoment.

(MIL-STD-1472C, para 5.9.7.4)

47. Unsecured covers are obvious. (MIL-5TD-1472C, para 5.9.8.1)

48. Instructions for opening covers are permanently displayed, if not obvious.

(MIL-STD-1472C, para 5.9.8.2)

49. Bulkheads, brackets, and other units do not interfere with removal or opening of covers. (MIL-STD-1472C, para 5.9.8.3)

50. An access is provided for frequent ma intenance wich would otherwise require opening a cover, renoving a case, or dismounting an item.

(MIL-STD-1472C, pard 5.9.9.1)

51. Nonremovable access covers are sel f-supporting.

(4IL-5T0-1472C, para 5.9.9.2)

52. Accesses and covers are devoid of sharp edges.

(MIL-STO-14726, pard 5.9.9.2) 
53. Hecesses are labeled with namenclature for itoms reached through it, auxiliary equ f ment used with it, and procedures. (MIL-STD-1472C, para 5.9.9.3)

54. Accesses are labeled with warnIng signs of hazards beyond. (MIL-STD-1472C, para 5.9.9.3)

55. Access warning labels are 25\% larger than extended instruetions.

(MIL-STO-1472C, para 5.9.9.3)

56. Instructions on hinged doors are readable when the door is open.

(MIL-STD-1472C, pard 5.9.9.3)

57. Access openings for adjusting or handing interior ltems are large enough for the operation and provide an adequate view. (MIL-STD-1472C, para 5.9.9.4.1)

58. Access covers have grasp areas or other means for opening them. (MIL-STD-1472C, pard 5.9.9.4.1)

59. Dimensions for access openings conform to Figure 45 , MIL-STO-1472C (ref 29). (MIL-STD-1472C, para 5.9.9.4.1)

60. Allowance is made for the clearance of operator's gloved or mittened hand on externally located accesses. (MIL-5TO-1472C, pard 5.9.9.4.1)

61. Accesses are equipped with an interlock to de-energize hazardous equipment.

(MIL-STD-1472C, 5.9 .9 .4 .1 ) 
Detofied Desion Considerations YES WO N/A CONMENTS

62. Dpenings requiring visual access only are not covered, except where required for adequate system performance. (MIL-5TO-1472C, para 5.9.9.5)

63. Nuber of fasteners used is the minimum required given other requirements. (MIL-STO-1472C, para 5.9.10.1)

64. Fastener removal, if not handoperated, can be accomplished using standard tools. (MIL-STD-1472C, para 5.9.10.1)

65. Hinges and tongue-and-slot tatches are used.

(MIL-STO-1472C, para 5.9.10.2)

66. Captive bolts and nuts are used were necessary.

(HIL-STD-1472C, para 5.9.10.3)

67. Captive fasteners are used on cases and covers.

(HIL-STO-1472C, para 5.9.10.3)

68. Fasteners are of the same type and size.

(MIL-STD-1472C, para 5.9.10.3)

69. Where quick-opening fasteners cannot be used, the minimum number of the largest sc rews possible wlll be used. (MIL-STD-1472C, para 5.9.10.4)

70. Serews, bolts, and other fasteners that require more than $14 N-m$ (loft-1bs) torque have hex type external gripheads.

(MIL-STD-1472C, para 5.9.10.5.1) 
Detailed Design Considerations

YES MO N/A CONMENTS

71. Screws, bolts, and other fasteners

that require less than $14 \mathrm{~N}-\mathrm{m}$

(10ft-1bs) torque have hex type

internal, external, or combination

grip-heads.

(MIL-STO-1472C, para 5.9.10.5.2)

72. Internal grip-head fasteners are used only where a stralght or convex smooth surface is required. (MIL-STD-1472C, para 5.9.10.5.2)

73. Straight-siot or phillips type internal grip fasteners are not used except as wood fasteners or on standard commercial items.

(HIL-STD-1472C, para 5.9.10.5.2)

74. Identical screw and bolts heads are used on each panel or components. (MIL-STO-1472C, para 5.9.10.5.3)

75. Combination bolt heads (e.g., slotted and hex) ore used. (MIL-STO-1472C, para 5.9.10.5.3)

76. Nounting bolt heads and fasteners are readily accessible. (MIL-STD-1472C, pera 5.9.10.6)

77. Assembly and subassembly mounting fasteners require only one complete turn for disconnection, where practical. (MIL-STD-1472C, pard 5.9.10.7)

78. For machine screws and bolts, the number of tums and required force is no more than necessary. (MIL-STO-1472C, para 5.9.10.7)

79. Fastener requirements are posted on an instructional label or placard.

(MIL-STD-1472C, para 5.9.10.8) 
80. Rests and stands are provided when required and are part of the basic unit, rack, or consoie chassis. (MIL-\$TO-1472C, para 5.9.11.2)

81. All cables, hoses, and other accessories, etc., can be eastly removed or disconnected from equipment before handling. (NIL-STD-1A72C, pera 5.9.11.2)

82. Lifting and carrying weight ifinits conform to Table XXIV in HIL-STD-1472C (ref 29). (MIL-5TD-) 472C, para 5.9 .11 .3 .1 .1 and 5.9 .11 .3 .2 )

83. Items welghing more than oneperson lifts ore prominantly labeled with we ight and $11 f t$ limitation. (MIL-STD-1472C, para 5.9.11.3.1.2)

84. Korizontal p.sh and pull forces conform to Table XXV (or Figure 21) of MiL-STD-1472C (ref 29) (MIL-STD-1472C, para 5.9.11.4.1)

85. Vertical push and pull forces conform to Table XXVI (or Figure 21) of MIL-STD-1472C (ref 29). (WIL-STD-1472C, para 5.9.11.4.2)

86. Removable or carried units designed to be removed and replaced have handles or other suitable means for manipulating. (MIL-STO-1472C, pard 5.9.11.5.i)

87. Items have at least two handles, or one handle and one grasp ared. (MIL-5TD-1472C, pard 5.9.11.5.1) 
88. If possible, handles or grasp ireas are located relative to the center of gravity. (MIL-STD-1472C, para 5.9.11.5.2)

89. Handles or grasp areas have at least $50 \mathrm{~mm}(2$ 1r.) of clearance from obstructions. (MIL-STD-1472C, para 5.9.11.5.2)

90. Honfixed handles have a stop position so that the handle is perpendicular to the carrying surface.

(MIL-STD-1472C, para 5.9.11,5.3)

91. Nonfixed handles can be placed in Dosition with one hand.

(HIL-5TD-1472C, para 5.9.11.5.3)

92. A nonslip grasp surface is provided if an itun's bottom surface is used as a hanehold during removal. (HIL-STD-1472C, pare 5.9.71.5.4)

93. Handle dimensions conform to Figure 48 of MIL-5TD-1472C (ref 29).

(MIL-STD-1472C, para 5.9.11.5.5)

94. Handles used with bare hands have surfaces that are not electrical. ly or themally conductive.

(MiL-5TO-1472C, para 5.9.11,5.7)

95. Equipment items cannot be mounted improperiy.

(HIL-STO-1472C, para 5.9.12.1)

96. Common hand tools are used to replace fleid removable items. (MIL-5TD-1472C, para 5.9.12.2) 
Detalied Design Considerations

YES NO H/A CONHENTS

97. Cuidepins or other means are

used to assist in mounting.

(MIL-STO-1472C, pard 5.9,12.4)

98. An iten cannot be inserted in

the wrong position.

(MIL-STD-1472C, para 5.9.12.5)

99. Coding Identifies the correct

item for replacement and its

proper orientation.

(MIL-5TO-1472C, para 5.9.12.5)

100. Items frequently checked are mounted on rollout racks,

slides, or hinges.

(MIL-STD-1472C, nara 5.9.12.6)

101. Rol lout racks do not shift the center of gravity to cause the rack or console to fall.

(MIL-STD-1472C, para 5.9.12.6)

102. Racks and drawers have limit stops if frequent item checking is required.

(MIL-STD-1472C, para 5.9.12.7)

103. Limit stops can be easily overridden for item removal.

(MIL-STD-i472C, para 5.9.12.7)

104. If necessary, interlocks prevent damage to equipment when a rack or drawer is opened. (MIL-STD-1472C, para 5.9.12.8)

305. Hinged ftems have a brace to hold the equiment in th:e out position.

(MIL-STO-1472C, para 5.9.12.9)

105. sliding, rotating, or hinged equipment wi th rear access requirenents are free to open fully and stay open wi thout hand support.

(MIL-STO-1472C, para 5.9.12.10) 
107. Units are laid out so that a minimim of place-to-place movement is required during checkout.

(MIL-5TO-1472C, para 5.9.12.11)

108. Removal of each replaceable 1tem requires a minimum of openling or removing covers or panels.

(MIL-STD-1472C, para 5.9.12.12)

109. Cables containing individually insulated conductors with a cammon sheath are coded. (MIL-STD-14726, para 5.9.13.1)

110. Long conductors, bundles, or cables are secured to the equipment chassis with clamps. (MIL-STO-1472C, para 5.9.13.2)

111. Cables are long enough to al low each functioning unit to be checked in convenient place. (MIL-STD-1472C, para 5.9.13.3)

112. Tes: cables do not interfere with controls and displays. (MIL-STD-1472C, para 5.9.13.4)

113. Cables are readily accesstble for inspection or repair. (MIL-5TD-1472C, para 5.9.13.5)

114. Cables are protected fram damage.

(MIL-STD-1472C, para 5.9.13.6)

115. Cables routed through hales in metal use grommets or other means for damage protection. (MIL-STD-1472C, para 5.9.13.7) 
Detafled Design Considerations

YES NO N/A COMENTS

116. Cables are labeled to Indicate the equipment and connectors to wich they belong. (MIL-STO-1472C, para 5.9.13.8)

117. Quick-disconnect plugs are used as connectors. (MIL-STD-1472C, pard 5.9.14.1)

118. Plugs are keyed to preclude the insertion of the wrong plug in a receptacle. (HIL-STO-1472C, para 5.9.14.2)

119. Electrical connector markings conform to requirement 67 of MIL-STD-454 ( $r \in f$ 18). (MIL-5TD-1472C, para 5.9.14.3)

120. Electrical plugs and receptacies are identified by color, shape, or other equiment, means. (MIL-STO-1472C, para 5.9.14.3)

121. Plugs and receptacles have aligning pins or other similar devices.

(MIL-STD-1472C, para 5.9.14.4)

122. Aligning pins extend beyond the electrical pins. (MIL-STD-1472C, para 5.9.i4.5)

123. Aligning pins or mechanistis are oriented in the same position. (MIL-STD-1472C, para 5.9.14.6)

124. Aligning pin or mechanism position is shown by durable strips. arraws, or other indications. (MIL-5TD-1472C, pard 5.9.14.7)

125. Connectors are spaced far enoug.'. apart so that each can be grasped fimly.

(HIL-5To-1472C, pard 5.9.14.8) 
126. Space between connectors and idjacent obstructions is at

least $25 \mathrm{~mm}$ (1 in).

(MIL-STO-1472C, para 5.9.14.8)

127. Sequentially renoved and replaced connectors have a $25 \mathrm{~mm}$

(1 in) clearance in a swept area

of at least $270^{\circ}$ around it at

the start of a sequence.

(MIL-STD-1472C, para 5,9.14.8)

128. Connertors requiring high torque have space for the use of a connector wrunch.

(MIL-STD. 1472C, para 5.9.14.8)

129. Rear of plug connectors is accessible for testing and servicing.

(MIL-STD-1472C, para 5.9.14.9)

130. "Remove and replace" drawer modules haye connectors mounted on the back of the drawer that mate wi:h connectors in the cabiret.

(HIL-STOM1472C, para 5.9.14.10)

131. Electrical equipment replacement items have simple plug-in connectors.

(Mil-STD-:472C, para 5.9.14.11)

132. Disassembly of connectors for changing pin connections can be oone without special tools. (MIL-STD-1472C, para 5.9.14.12)

133. Adapters, if equired, can be hand-tightenec.

(M!L-STD-1472C, para 5.9.14.12)

134. Dusi covers are captive type. (MIL-STD-1472C, para 5.9.14.13) 
135. Test points for adjustment are

located close to the controls

and displays used in the

adjus tment.

(MIL-STD-1472C, para 5.9.15.1)

136. It is not necessary to remove subassemblies fram assemblies to reach test points.

(HIL-STD-1472C, para 5.9.15.2)

137. Marking and color coding of test points conform to

MIL-STO-415 (ref 17).

(HIL-STQ 1472C, para 5.9.15.3)

138. Storage space for leads, probes, spares, manuals, and special tools is provided within test equipment, handling case, or lid.

(MII.-STO-1472C, para 5.9.16.1)

139. Instructions for portable test equipment operation are on the eqipment face, in a lid, or in - special compartment.

(MIL-5TD-1A72C, para 5.9.16.2)

140. Portable test equipment instructions inciude a reninder to cal ibrate equipment, if necessary. (MIL-STD-1472C, pard 5.9.16.2)

141. There is an indication of power failure.

(MIL-STD-1472C, para 5.9.17.1.1)

142. Dispiays Indicate then equipment has falled or is out-oftolerance. (HIL-STO-1472C, para 5.9.17.1.2) 
143. Critical malfunctions are indfcated by an auditory alam for equipment not regulariy monttored.

(MIL-STD-1472C, para 5.9.17.7.3)

144. There is a positive indication of fuse or circuit breaker trip. (MIL-STD-1472C, para 5.9.17.2.1)

145. Fuses are readily accessible and do not require special tools for replacement.

(MIL-\$TO-1472C, para 5.9.17.2.2)

146. Circuit breakers are within easy reach of crewmembers.

(MIL-5TD-1472C, para 5.9.17.2.2)

147. The area of equipment secured by a fuse or circuit breaker is identified.

(MIL-STD-1472C, parz 5.9.17.2.3)

148. Fuse current ratings are permanently marked on the fuse holder. (MIL-STD-1472C, para 5.9.17.2.3)

149. "Spare" is marked adjacent to spare fuse hol ders.

(MIL-STD-1472C, para 5.9.17.2.3)

150. Fuse ratings are expressed in whole numbers and common fractions. (MiL-STO-1472C, para 5.9.17.2.3)

151. Fuse and circuit breaker labels are legible in the anticipated ambient 11 lumination. (MIL-STO-1472C, pard 5.9.17.2.3)

152. Circuit breakers controlling power are toggle bat or legend switch type controls.

(MIL-STD-1472C, para 5.9.17.2.4) 
Detailed Design Considerations

153. Printed circuit boards are easy to remove and replace.

(MIL-STD-1472C, para 5.9.18)

154. Feedback 15 provided wen the printed clicuit board is securely connected.

(MIL-STD-1472C, para 5.9.18) 


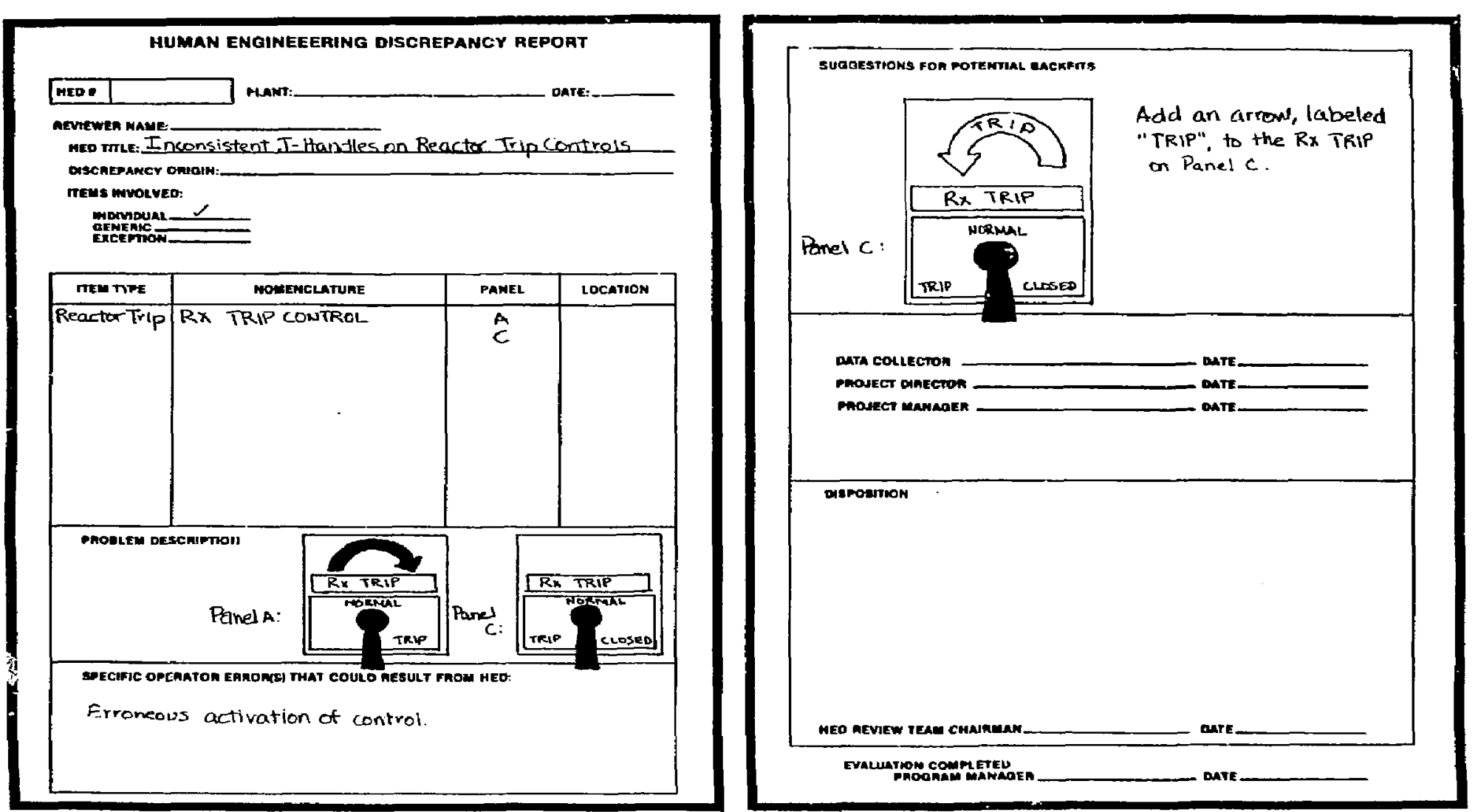

(Source: Essex Corporation, Systems Operability and Design Group, 1984.) 
EXHISTT 4-4

FXAMPLE OF AN HPE DISCREPANCY REPORT

(Source: Essex Corporation, Systems Operability and Design Group, 1981.)

\begin{tabular}{|c|c|c|c|c|c|}
\hline $\begin{array}{c}\text { nem } \\
\text { Number }\end{array}$ & Item Description & Location & Discrepaney & Priority & Recommended Brekfit \\
\hline 29 & $\begin{array}{l}\text { Tubine stress evaluator, ATT and low pressure } \\
\text { turbine valve vertieal meters }\end{array}$ & $870-6 B$ & $\begin{array}{l}\text { These should be on the 590-9 panel writhy } \\
\text { the other turb ine controls }\end{array}$ & 3 & $\begin{array}{l}\text { Idesilly these should be moved to the } 080 \\
\text { but given the design the omry way to } \\
\text { addreas is by externive training and } \\
\text { labeling }\end{array}$ \\
\hline 30 & $\begin{array}{l}\text { Trend recorder controls: } \\
\text { 1. Filter train A recorders } \\
\text { 2. Ssw loop A frow and press rec } \\
\text { 3. Filter train B recorders } \\
\text { 4. SSW Loop B now and press rec } \\
\text { 5. Hydragen analyzer ree }\end{array}$ & $\begin{array}{l}870-2 B \\
870-1 B \\
870-8 B \\
870-7 B \\
870-4 B \\
870-10 B\end{array}$ & $\begin{array}{l}\text { These controls are associnted with trend } \\
\text { recorders located to the left of the con- } \\
\text { trols In some cases the controlled } \\
\text { reeorders are separsted by an inter- } \\
\text { vening recerder. The visual association } \\
\text { of these controts is very dirficult to } \\
\text { make. }\end{array}$ & 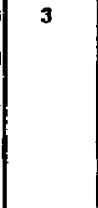 & $\begin{array}{l}\text { 1. Move controls direetly under the } \\
\text { recorders, or } \\
\text { 2. Use demarcation lines to provide } \\
\text { visual essociation }\end{array}$ \\
\hline 31 & $\begin{array}{l}\text { Unlabeied } 10 \text { position rotary control that should } \\
\text { be tabeled "Recombiner is seleet" }\end{array}$ & $\begin{array}{l}870-4 B \\
870-10 B\end{array}$ & $\begin{array}{l}\text { This control has } 10 \text { positions when oniy } \\
\text { three are used, aceording to operating } \\
\text { procedures }\end{array}$ & 3 & 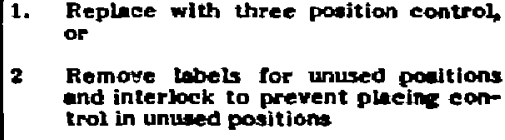 \\
\hline
\end{tabular}




\section{EXHEIT 1-5}

EXAMPLE OF AN OPERATHG EXPERIENCE REVIEW DATA FORM

Decumentallon hoviow

Purt A: Report Soroenine Summary

\begin{tabular}{|c|c|c|c|c|c|c|c|c|}
\hline \multirow[b]{2}{*}{$\begin{array}{l}\text { Typo of } \\
\text { noport }\end{array}$} & \multirow[b]{2}{*}{$\begin{array}{l}\text { Repoon } \\
\text { Numbor }\end{array}$} & \multirow[b]{2}{*}{$\begin{array}{l}\text { Roport } \\
\text { Dots }\end{array}$} & \multicolumn{5}{|c|}{ 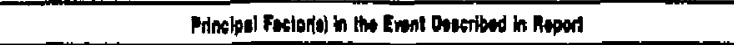 } & \multirow[b]{2}{*}{$\begin{array}{l}\text { C. Pinn } \\
\text { (ippelly) }\end{array}$} \\
\hline & & & 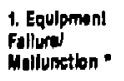 & $\begin{array}{l}2 \text { Proosdurs } \\
\text { Dofletioney }\end{array}$ & 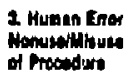 & 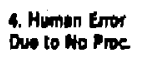 & 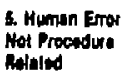 & \\
\hline & & & & & & & & \\
\hline & & & & & & & & \\
\hline & & & & & & & & \\
\hline & & & & & & & & \\
\hline & & & & & & & & \\
\hline *. & & & & & & & & \\
\hline & & & & & & & & \\
\hline & & & & & & & & \\
\hline & & & & & & & & \\
\hline & & & & & & & & \\
\hline & & & & & & & & \\
\hline & & & & & & & & \\
\hline & & & & & & & & \\
\hline
\end{tabular}

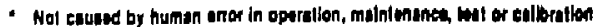


EXHIBTT 4-5 (continued)

Decumentation Rovlew

Part D: HFE Dlecrepency Summary

Documentation Reriow

Reviewers:

Dalo:

Type of Report (UOR, UIR, etc):

Report Number:

Report Date:

\section{Analysis and Summary of Roport}

1. Unit/work ares Involved:

2. Operating status when event occurred:

3. Result:

_ Incident without consequence

-. Personnel injury, contamination, or excessive radiation dosage

- Radioactlve release or contamination spread

- Equipment damage

__ Olf - nomal oquloment status without damage

__ Vlolation of Technical Specilication or other safety criteria

__ Reduced operational avallabllity;

— Tilp _ hrs

_ Shutdown _ hrs

_ Derated to __ $\%$, _ hrs

- Other (epecity) 


\section{EXHIBIT $4-5$ (continued)}

\section{Error Classification (check all that apply)}

\section{Operator Error}

Maintenance Error

Test/Calibration Error

Other (specily)

5. Error Description (check all that appiy)

Problem in monitoring $(\theta, 9$. tallure lo detect/properly identily critical condition, parameter out of rànge, faulty equiprnent lineup/condition; misreading of ol alarms, displays, indicalors)

Problem in control action (e.g., wrong control, wrong setting/alignment, accidental actuation, omission of control action)

Problem in communicationicoordination

Incorrect decision

Problem in timing 
6. Summary statement of the event:

7. HFE discrepancies that appear to have contributed to the event:

8. Immediate and lollow-up action taken to correct problem:

\section{Concluslons}

9. Does if appear that HFE discrapancies contributing to this event have been fully corrected? If no, explain: no no 


\section{EXAMPLE OF A QUESTIONNAIRE POR HFE \\ REVIEW OF CONTROL ROOM OPERABILITY}

(Source: K. Mallory, et al. (1980). Human engineering guide to control room evaluation, Volume I - Control room evaluation, Appendix III (NUREG/CR-1580). Washington, DC: U.S. Nuclear Regulatory Commission.)

\section{APPENDIX III \\ HUMAN ENGINEERING OPERATOR QUESTIONNAIRE}

Dote:

HFE Analyst - Briefing:

Unit:

Inferview:

Licensed Operalor

How Long?

or

Troinee

How Long?

A. Stoffing and Worklood

1. Please describe Tech. Spec, requirements for CR staffing.

a) If actual staffing diffors from Tech. Specs., please describe octual staffing.

2. In your opinion, under worst-case conditions, what is the moximum number of operators actually needed to effectively operate the control room during each of the following:

a. Vormal operations

b) Stortup/shutdowir

c) Tronsients/ernergency operations 


\section{EXHIBIT A-7 (continued)}

3. How many units do you presently operate?

a) If you operate two or more, ore they: (check one)

¿_jentical

__ nearly identical

_. mirror imoges of each other

__issimilar

b) If you operate two or more units, have you ever experienced any difficulties in shifting from one CR to another? yes no

4. Please describe your administrative or record keeping tasks (log entries, reading of parameters, etc.). 
d) Hove these responsibilities ever interfere with your operotionol duties, especially during off-normal conditions? yes no

5. Hove you observed any problems associated with shift turnover? yes no

6. Pleose describe any recommendation you may hove to improve shift furnover.

\section{B. Workspace Design}

i. Can the stotus of your plant be monitored from one centrol position? yes no

2. Are specific stations assigned to operators and wotch foremor? yes no 


\section{EXHIBIT 4-7 (continued)}

3. During normal or off-normal operations, do the actions or tosks of another operotor ever interfere with performance of your tosks? yes no

4. Hove you ever experienced any difficulty in reaching a requir ad control or seeing/reading a required display? yes no

5. Hove you ever experienced any problems locoting the correct control or disploy (for example, operating the wrong switch or inoccurately operating the correct switch)? yes - no

6. Are panels arronged within your $\mathrm{CP}$ in a manner which is logicol for normol and emersency operations? yes no

7. Are controls and displays partaining to systems or subsystems grouped logically and distinctively within eoch panel? yes no 


\section{EXHIBIT 4-7 (continued)}

B. Dues your panel lack important information, controls or displays, which would help you perfarm your job more effectively or sofely?

9. Are importont data, controls or displays, inoccessible, or difficult to access, secause of placemeni (for exomple, located in back panels out of operotor's view)? yes no

10. Does your $C R$ contain coritrols, displays or other equipment which is inoperative, not used, or unnecess $y$ for you to do an effective job? yes no

11. Do you find nimics or graphic/pictoriol panel arrangements, if used, helpful in per forming your job? yes N/A

d) If "no," pleuse describe why you fael they are not helpful and any recommendotions you may have to moke them more so. 


\section{EXHIBIT 4-7 (continued)}

12. Hove you ever inadvertently disturbed control settings (for example, accidentally bumping 0 switch)? yes no

13. Hove groups of controls or displays which look identical or very similar been marked or coded to permit easy discrimination between them? yes no

a) If "no," pleose describe areas where you feel marking or coding would enhance your ability to discriminate between companents.

14. Pleose describe the administrative procedure for adding operotorrecommended madifications to labeling, demarcation lines, mimics, or for adding guarding for certain controls, or otherwise modifying the panel.

15. Do you find operator-added modifications helpful? yes no 


\section{EXHBBT 4-7 (continued)}

d) If "no," please describe those modificotions which you find to be a hindronce.

16. Are major panels, sub-panels and panel segments cleorly and consistently labeled? yes no

17. Is the Control Room (CR) arranged to be effectively operated by the minimum shift required?

During narmol operations

During tronsients/emergency operotions

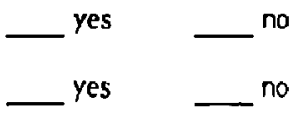

C. Workspoce Environment

1. Do CR features of an environmental nature, such as listed below, ever interfere with effective performance of your job? If "yes," please describe the noture and source of each problem and their effects on job performance.
a) Ventilation

_ yes no

b) Temperoture/humidity yes no 
c) Iflumination

yes

d) Noise levels

yes ${ }^{\text {no }}$

e) Excessive traffic through the $C R$

yes no

f) Other environmental foctors

_yes _no

2. Are there problems with time and distance involved in leaving $C R$ to prepare food or use facilities? yes no

D. Communicotions

1. Are there problems with communicotions procedures or equipment which interfere with receiving or transmitting required informotion in any of the following instonces? If "yes," pleose describe.

o) $\quad C R$ to field/ouxiliary operotors

yes $\quad$ no

b) Field to CR

yes _ـ no 
c) $C R$ to supervisor yes no

d) Between units $N / A$ yes no

e) CR to NRC _yes no

f) CR to others (please specify)

yes no

2. Are you oware of ony instences in which intro-control room (operotor-10operator) communicotions hove been lost or misheard due to distance or noise levels? yes no

3. Does the operation of communicotions equipment, or requirements for communicotions inferfere with operations: (Pleose describe if "yes.")

o) During normal operations

yes

b) During oft-normal operotions yes no 


\section{EXHIBIT 4-7 (continued)}

c) During transients/emergencies

4. Hove you experienced ony problems with using communications equipment in any of the following areas? (If "yes," pleose describe the problems.)

a) Location of the equipment

yes no

b) Operation of the equipment

_res

c) Ability to receive or transmit messages

(speech intelligibility)

__ yes _ no

d) Number of tronsmitters/receivers

yes

no

e) Foiled or braken equipment

yes no

\section{E. Annunciotor/Worning System}

1. Please describe your alorm annunciator system and its operation from incoming alarm to ocknowledge to condition cleored. 


\section{EXHIBIT 4-7 (continued)}

2. Does the onnunciator system in your $C R$ provide you with specific information about the noture of an abnormal event? yes no

3. Do alorm annunciators provide you with information obout the necessary oction 10 be token in response? yes no

4. Alarm onnunciotors located above the instrumentation of systems which they monitor? always frequently infrequently

5. Are alarm onnunciotors prioritized in any way? yes no

6. Please descrive any use of color coding used in the annunciotor system.

7. Do you have any problems reading annunciator messages from ony point in the Ci from which these messages must be read? yes no 


\section{EXHIBIT $4-7$ (continued)}

8. Are the auditory warning signals differentiated to provide meonings, such as priority olorms or lacolity of system components? yes no

3. Do "nuisance" or "false" alarms ever interfere with your performing your job effectively?

Under normal conditions

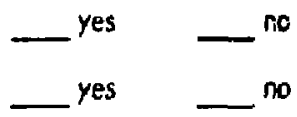

Under emergency conditions

o) If "yes," please identify frequent nuisonce alarms and the problems they present.

10. Are alarm acknowledge/silence/reset controls ovailable to the operator?

Are there suff:cient number yes no

Are they easily occessible from oll panels

yes ${ }^{\text {yes }}{ }^{\text {no }}$

11. Are olorm annunciators provided with a test capability?

For visuol/lamps

For audible

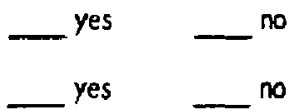

no

12. Do you have any recommendations which would enhance the operator usability of your annunciator system? 


\section{EXHIBIT 4-7 (continued)}

\section{F. Operator Protective Equipment}

1. Please describe the operotor arotective equipment ovailable in your $C R$.

2. Pleose describe the quantity and location of the equipment.

3. Does the face mask interfere with visibility? yes no

4. Does your protective breathing apparatus interfere with the following:
o) Operotor-to-operotor communicotions

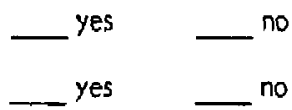
b) Use of communications equipment $\ldots_{\text {yes }}^{\text {no }}$

5. Have you ever encountered difficulty in performing required tosks os a result of weoring protective equipment? yes no

6. Do you feel sufficiently procticed in donning protective equipment so thot, if the need arises, you feel you could don it easily and quickly? yes no

7. Do you have any other comments or suggestions concerning the suitability of the ovoiloble protective equipment or its use? 


\section{EXHIBIT $4-7$ (continued)}

\section{G. Computers}

1. Pleose describe the functions performed by the computer to assist you in operating the system.

2. Do you find the computer useful and relioble?

yes

no

3. Do you feel that operotors are adequately trained to use the computer? _yes no

4. What changes or additions in computer usage would you recommend?

H. Procedures/Documentation

1. Do you find that your procedures documents are difficult to occess because of labeling, indexing or storoge? yes no 


\section{EXHIBIT $1-7$ (continued)}

2. Are your procedures sufficiently detailed to permil effective operotion of your CR during normol and emergency operotions?

3. Are there procedures which you find difficult to execute? yes

4. Pleose list the procedures which address operation of the most difficult or critical systems.

\section{Operotions}

1. Do you feel that too mony functions are performed automatically by the system in controlling abnormol event? yes no

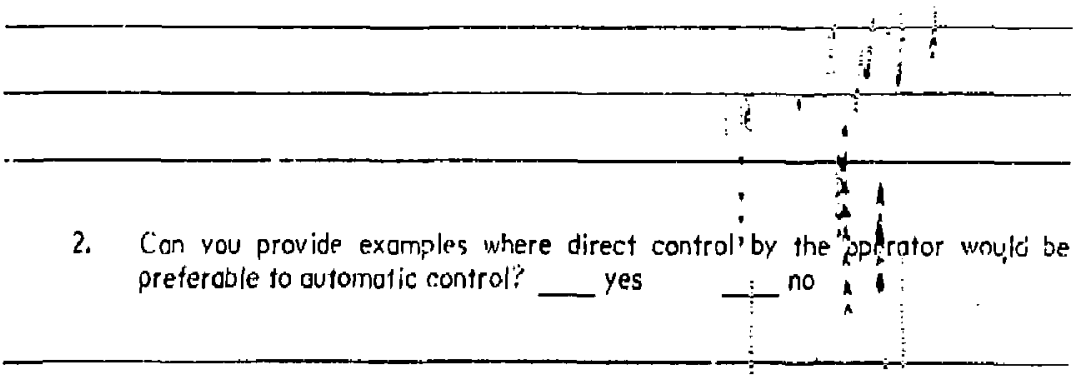




\section{EXHIBIT 4-7 (continued)}

3. Con you suggest examples where automotic cintrol would be preferoble, where not currently provided? yes no

4. Please describe any additional operotional problems you hove easperienced with the current panel design.

5. Please describe any recom:mendations you would make in design or procedure which would enhance the effectiveriess of the operator's job.

\section{J. Operator Work Scheduling}

1. Would you prefer a different system of shift scheduling? _yes no

a) Do you hove ony comments or suggestions for improving the effects of shift scheduling on the operator?

2. Have you ever experienced any negative effects in changing from one shift to another, in yourself or in other operators? yes no

o) If "yes," has this effected operoting abilities? yes no 
b) Any comments or recommendations?

3. How many overtime hours do you generally worls in a month?

a) Do you feel that extended shifts or overtime degrodes your duility to perform your job effectively? yes no

b) Hove you ever experienced ony problems in operating the plant os 0 result of working extensive overtime? yes no

c) Any comments or suggestions?

4. Are you oware of any operators who hove experienced personal problems as a result of working shifts and/or overtime? yes no

a) Any comments? 


\section{EXHIBIT 4-6 \\ EXAMPLES OF ITEMS POR A PERSONNEL, TNTERVIEW OR \\ SELF-ADMINISTERED QUESTIONNAIRE SURVEY \\ (Control Room Operating Personnel)}

1. Do you know of any areas on the board where toggle, lever, or pushbutton controls should 0 : replaced with rotary controls because of accidental activation?

YES NO N/A

If yes, please explain

2. Have you ever accideritally activated an adjacent control because it was positioned toc close to the one you wanted to manipujate?

YES NO N/A

If yes, please explain

3. Have you ever had difficulty activating a control

because an adjacem control was in the way?

YES NO N/A

If yes, please explain

4. Can you recall any controls that you are never required to used?

yS NO N/S

If yes, please explain

5. Are there any controls that are duplicated

unnecessarily?

YES NO N/A

If yes, please explain

6. Can you recall any knobs or handies of control switches that slip or are loose on their shafts?

YES NO N/A

If yes, please explain

7. Are there are controls that are difficult to adjust to the precise level you need?

YES NO N/A

If yes, please explain 


\section{EXHEBT 4-8}

\section{EXAMFLE OF A QUESTIONNAIRE FOK \\ HPE REVIEW OF MAINTANNABILITY}

(Excerpt from: Seminara, J.L., Gonzalez, W.R. \& Parsons, S.O. (1981). Human factors review of nuelear power plant maintainability (EPRI-NP-1567). Palc, Alto, CA: Electric Power Resear h Institute

\section{DIOGRAPHICAL DATA}

YOUR POSITION

YLARS OF POHFR PIANT EXPERIEHCE MUCLEAR FOSSIL

MILITARY REAATED EXPERIENCE

WORK EXTERIENCE (ELECT., MECH., I \& C, OPERATIONAL, ETC.)

PLANTS FORKED AT

AGE

REIGHT

WE1GHT

EDUCATION

SPECIAL MAINTENANCE OR I S C TRAINING

SPECIAL, REMARRE 


\section{PACITITIES}

1. Jow well has your workehop been integrated into the overall plant? should it have been loceted differently to help you get your job done wote easily?

2. To ainiwize the diutance that you wat cover, wat elemente of the plant should be located closest to your shop. Rank the following from "l" to " 10 ", with "l" representing the facility that should be closest to your shop.

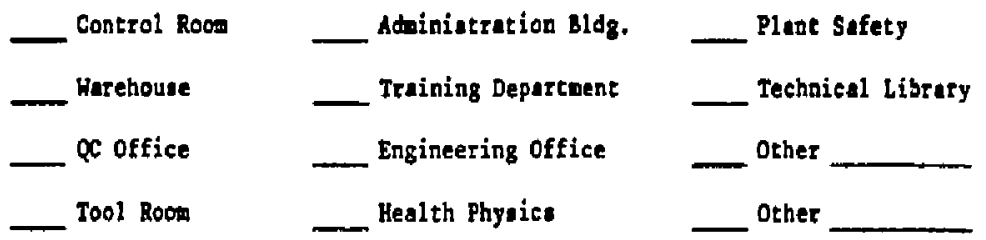

3. Bow do plant security requirementa and regulations affect your work? How wuch tize on the average per day is epent getting into the plant, getting pat security berriers with the plent, etc?

4. Are there ony problews getting auterials transported into the plant? Are there problems here due to security requiremento?

5. Has your plant been deaigned to minisize the equipment component a placed in contaninated arean, i.e., could one of the hardware which you waintain in contaninated area just as easily been put outaide the contaminated areas? 


\section{EXHIEIT $4-8$ (continued)}

6. Do fire proiection requirenenca affect your work? Can improvenente be ande in this area?

7. Is your workhop gized and arranged properly to allow efficient miatenance operationa? Are the electrical, mechanical, and I \& $C$ shops in the right relationthip to each other?

B. Is oufficient atorage cupability provided for parte and tools to avoid dange to component $\theta$ ? Is the design of atorage facilities adequate to prevent equipment demage?

\section{EWVIRONMENTAL CONSIDERATIONS}

9. Are all or most aystems that you wintain sheltered or are uore exposed to the element $B$ ? Have you encountered probleas in performing maintenance on harduare that is exposed to weather?

10. Some waintenance activities are typically conducted in high noibe environments. What problems, if eny, has this ereated in your toork? Cari you suggest improvements?

11. Is adequate illumination provided to allow you to conduct maintenance taskb? What ioprovesents can jou recosmend? 


\section{EXHBIT $1-8$ (continued)}

12. Doet your work require exposure to high temperatures and huaidity? Have all precaution been takan to ginimien the riskn to you and othera? Dose excessive body heat and huadity build up wen you are wearing protective elothing?

13. Hork in high radiation areas presente special probleas.

1. Have hardure aysteas in contaninated areas been designed so that they can be easily wintained by nen vearing eloves, reepiratore, heleets, etc.?

b. Are Bealth Phyrice procedures and apport adequate?

C. That precautions are taken to giniaize exposure tine and to svoid "bumiag up" wintenance persoanel? Do you "dry ran" takk vith cockups?

d. Are there any problen in turning over a job to another crev before it is completed becaure allowable tine in the conteainated area is linited?

-. That general inpropenents cen you reconend to ake it enier and/or enfer to conduct mintenence in conteminated aress?

f. Heve you experienced probleas vith contratot or ather outeide persounel working in high radietion areu? 
14. Bave you experienced probleas vith stew, abentos fibers, alippery ourfaces, etc. in the course of your vork? Can inprovenente be ouggested to mininize any dengers frow these sousces?

\section{ACCESSIBILITY}

15. Is adequate clearence provided around equipsent that you wintain to allow easy work notions and epace for work aida, tranoportation unita, and lifting devices? that apecific areat could atand iaprovetenta?

16. Are access openings designed so that people and conponento cen move through theo adequately? Can you cite sone good and bad examplea?

17. Are access openinge designed for proper visibility within?

18. Have stairs, ladders, and platforms been provided there necessary to allow resdy access to equipment that you mintain?

29. Rave equiparent cyotew been packaged or arranged oo that the potential for dange is ninimizec in tetoving and replacing defective parta? 
20. Are accen openinga in high-radiation areas designed to hllow for suited operation, including airpeks and respirators, when necessary?

21. If access to equipent that you wintain wre ideal or unrestricted, what percentage ravinga in asintenance time would you tatimate on the thole?

MVEMELT OF PERSONIEL AND EQUIPYEHT

22. Have aufficient elevators of the right type been provided to support mintenance activitiea?

23. Have cranes been positioned for maximum effectiveness? Does crane ocheduling limit you in any way, $i, e .$, are cranes available when you need them?

24. Have adequate provisions been ande for the utilization of hoists and rigging?

25. Are there adequate clearances for whecled vehicles when they are necessary to oupport mintenance activitiea? 


\section{EXHIBIT $1-8$ (continued)}

26. Are jou required to anhandle hervy iteas because it is not posible to effectively utilise lifting or tranuportation devicent low hesvy are the hesviest unit you acit lift conully and hou high off the ground?

27. Are portable units detigned with adequate handles and grap areat?

28. Deacribe a case or situation there equipant vat danged or alnoat damaged becaue of inadequate handling devices or tranupartation aids.

\section{EQUTPMENT DESIGN FOR MIMTEMNCE}

29. Sone equipment is exsy to disusemble for wintenance and others seen designed if if they were not aent to be taken apart. In general, hov weil have the syotens you typically anintain been designed? Examples of the best and worat cases, please.

30. Are all interchangeable unite, e.t., connectar pluth, phyically coded or keyed to that it is inposible to inere or replace wrons unit? 


\section{EXHIBIT 4-8 (continued)}

31. Is the equipaent designed so that replacing one umit does not require removal of other units for accese?

32. Are delicate companents apecially located or gaterded 80 thet they wiil not be dmaged when being handled or worked on, or when work is being perforaed on ad jacent componente? Arc there caseo where a piece of equipuent is dawaged in dissassetbly or reastembly?

33. It there equipment that requites excessive or recurrent asintenance? Are there obvious desiga changea that would correct this aituation?

\section{KALFUNCTIOH DIAGNOSIS}

34. Effective taintenance depends on accurate and timely diagnosis of probless. that probless have you experienced in diagnosing equipwent walfunctions or detecting enlfunction trenda? Do the operator a provide good aupport here?

35. To what extent is teat or diagnostic capability built into the syaterse being anintained? For example, do you have in-place vibration anitora? 


\section{EXHIBIT $4-8$ (continued)}

36. To wht extent do mintenance and I t $C$ personnel rely directly on eters, chart recorders, and other instrumentation in the control roon for determining arffunction trendy or diegnosing welfunctiona?

\section{CODING AND LABEIING}

37. Fave cablei, wires, controls, and plumbing lines been properly coded to perwit easy identification?

38. Ate access covers, valve controlb, ets., properly labeled with full identifying inf orwation?

39. Are appropriate labelo used for test points?

40. IIow engy if it to find what you re looking for in the plent? What could be done to better orient a neu wen in finding his way around and ovoiding "hot spots" or working on the wrong piece of equipment? 


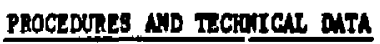

41. Are mintenence procedures sufficiently clear and detalled to penit erzorfree reintonance taskst are iaproveants is procedureo aeeded?

42. Are vendor-aupplied enintenance anauls and techaicel dete adequate to allow proper atintenance of oquipaene?

43. In general, is too much or too little ephasis beins placed on procedures and "doing thinge by the book"?

\section{TOMLS AND IEST EQUIPILET}

44. Have you experienced any probleas in heving the right tools available to do the job?

45. Heve the agstegn that you saintain been designed to mininize the nuber of opecial tools required?

46. Have you encountered any problew in having the right teat equipatat available to check out oyuter operationa? 


\section{BXHIBIT 1-8 (continued)}

47. Is adequate apace zenerelly provided for placing test equipant where needed for theckout purposes, e.8., are cousole units provided with traya on which test equipaent can be counted?

48. Have you experienced any opecinl problews in uning tools or test equipent in high-radiation, high-teaperature or high-huidity areas? What

recowendations can you axe to renedy these problens?

\section{COMNHICATIONS}

49. Have adequate provisions been wde to allow you to commicate with others in the course of your vork in all parts of the plant? that improvenents are needed?

50. Can you dencribe ense where the lack of effective comunications led to a problem or near preblem?

\section{SAFETY}

51. Has the equipsent that you mintain been designed to winiaize anfety hazards, e.8., tharp edges, electrical hazarda, projectiona to get onagged on, etc.? Do labels or placards identify all potential onfety hacards? 


\section{EXHBRIT $4-8$ (continued)}

52. Bas the equipaeat that you aniatain baen dasigned or inatalled to avoid dange through use or abuse, ect., viren that can be pinched by doors, cables wich project and can be tripped over, conponente that erike neturel footholda in resching upverds, or unite that mke convenient footreats?

\section{SPARES}

53. Are opare parto generalty available hen needed for uintaining plant syateas or teat equipuent?

54. Have you run into any probles detarninias the avalability of apares, identifying uhich opare part is needed, or in gaining eccess to spare parcs?

\section{ADMINISTRATIVE}

55. How wuch of your time is involved with paperwork (percent of average vork veek)? Is this a retsonable or uareanonable deand on your time?

56. How woth overtine $d$ - your an wort in w averate year? iRS. Joy auch of this or occurs during wajor outagent - Bave gou observed any problem due to excesaive or deands of the job? 
EXHIBIT $4-8$ (continued)

57. During aejor outages, are you required to wotk other that nornel day thifte? Bove you obuerved any probleas asoosioted with adjustmeats to offaoral thifte?

58. Then thift work is required, have you observed any problean in turning over a job from the day shift crew to the eving ohift crew for completion or vice veras? Are ahift tranaitions acconplithed woothly?

59. During major outages is the anintenance vork seheduled is an orderly wanner or could planaing be inproved? that kind of events have aborted outage schedules in the past? have planaing cools euch a PLAN-AL-LOG been helpful? Are computcrs used for outage planing and anageseat?

60. Do you have a syateatic preventive mintonace progros with fixed dates that woidg minecenary corrective mintenunce? Does the program need to be inproved! Are corrective and preventive anintenance schedules conputerised? How is the Preventive Haintenence progran anoged? 
EXHIBIT 4-8 (continued)

61. Is equipent atrvieing done on-libe to the grenteat extent posnible at opposed to shut-dow periods, e.g., lubrication, adjustuents, fillet replacenent, etc.? How could this oituation be inproved?

62. Are there problent in anitoring equipaent atatus through vioual inapectiont, vibration testing, perforing electrical/electrodic checkout testo, etc.?

63. How do you eotiante the time that it should take to do maintenance jobe and what controls are enployed in enauring axiaum productivity of persons. 1? Do waintenance foreses and/or supervisors personally inapect asintenance work?

64. That failure rate data do you have owallable to help guide preventive aintenance or outage naintenance work? Are reliability analyses conducted? are failure nodes and effects anolyes conducted? 


\section{MMNIRG}

65. During the aorwal work periods how wny wintenante people including supervisors are there in your shop? handle dotals work load?

Is this number auficient to

66. During wajor outages how any people are added to the work force in your shop? there are these additional peop.t obcained from?

67. How effective are the be additional people who are added to your organization? In what ways could their effectiveness be improved?

68. If you did not add extra people to cope vith ajor outages, hov wany additiona! in-house perastent exployees vould you have had to hirs to get the necessary mork accompliahed?

69. During a wajor outage how any total additional wintenance people are hired? What is the peak work force during the outage compared to your normal anning level? How long do your wa jor our age typically last? Can you enviaion improvesenta that would reduce the duration of major outage日? Ho much time would these improvemente anve?

\section{ORGWNIZATIONAL IFTEREACES}

70. Gintencace and I 6 C persopnel rely on control zoom operatora for diagnostic information, clearances to work on epecific plant ayetens, etc. How could your interaction vich operators be improved? How do you interact with Auxiliary operatore? 
71. Are there any problen in your relationohips with the engineering organizetion? In what vaye could your interface with engineering be inproved?

12. Nealth physics provides importent support to wintenance oparations. Are any inproventa needed in this relationthip?

73. In that wys could plant magewent be nore rebporsive to the nteds of maintenance pezsonel in order to perwit more efficient performace of mintenance activitien?

74. In wht wys could the union-anugeneat relationship be enhasced to perwit aore efficient mintenance operations?

75. That is the $Q$ orgenization' contribution to effective mintenance? Can the relationthip between aintenance and $Q C$ be improved to enture the highest: quality auintenance cork? 


\section{EXHIBIT $4-8$ (continued)}

76. Bow good a job does the Plant safety oreanization do is ensuring a safe work environent for asiatenace peraonnel?

77. To what extent does the purchasing organieation conoult with anintenonce personnel before buying ogatea components, test equipient, ecc., to ebsure that mintenance requiremente are being bet? Are there uny problew here?

78. To what extent are naintenance people consulted when your utility is planning or building a new plant? Are the gistakes of the pat being avoided in new plants? To what extent suct mintenance personnel reshape siant when it is turned over to the utility to facilicate anintenance?

79. In genersl, how good job are the A-Es doing in meeting the needs of maintenance people?

BD. In general, hou good a job ore mjor ustew vendora doing in designing hardware so that it veets the need of atintenance personnel? 


\section{EXHIBIT 4-8 (continued)}

\section{SLLCTIOH, ThInIG}

81. How pood a job does your utility do in oeleeting the right poople for wintenance (or I 6 C) jobs? that qualities and experieace are sought?

82. That treining program doen your utility provide for wintedence (or I \& C) pezonnels In this treining progran adequate to provide the skilla and knovledge needed for the job?

\section{HOUSERELPING}

83. Houskkeeping is a necenary part of anintenance mork. Are there efequate provisiors avaituble for conducting hausekeeping chores?

\section{CaITICAL DICIDESII}

4. Baned on jour experience, cite one exaple of an errot asde by a wintenance wh (or I \& technician) or a eccident or netr-aceident with serious or potentially uerious consequences. Describe the apecifies of the ease and indicate how the aituation could have been everted either through iar:oved tacility durito, better handlias equipatent, better prosedures, opeciol traíaiay, better equipent design, etc. 


\section{EXHIBIT 4-8 \\ EXAMPLE OF SULMARY OP \\ QUESTIONHAIRE RESPONSE DISTRIBUTION}

Department/Funetional Area:

Total Number of Respondents:

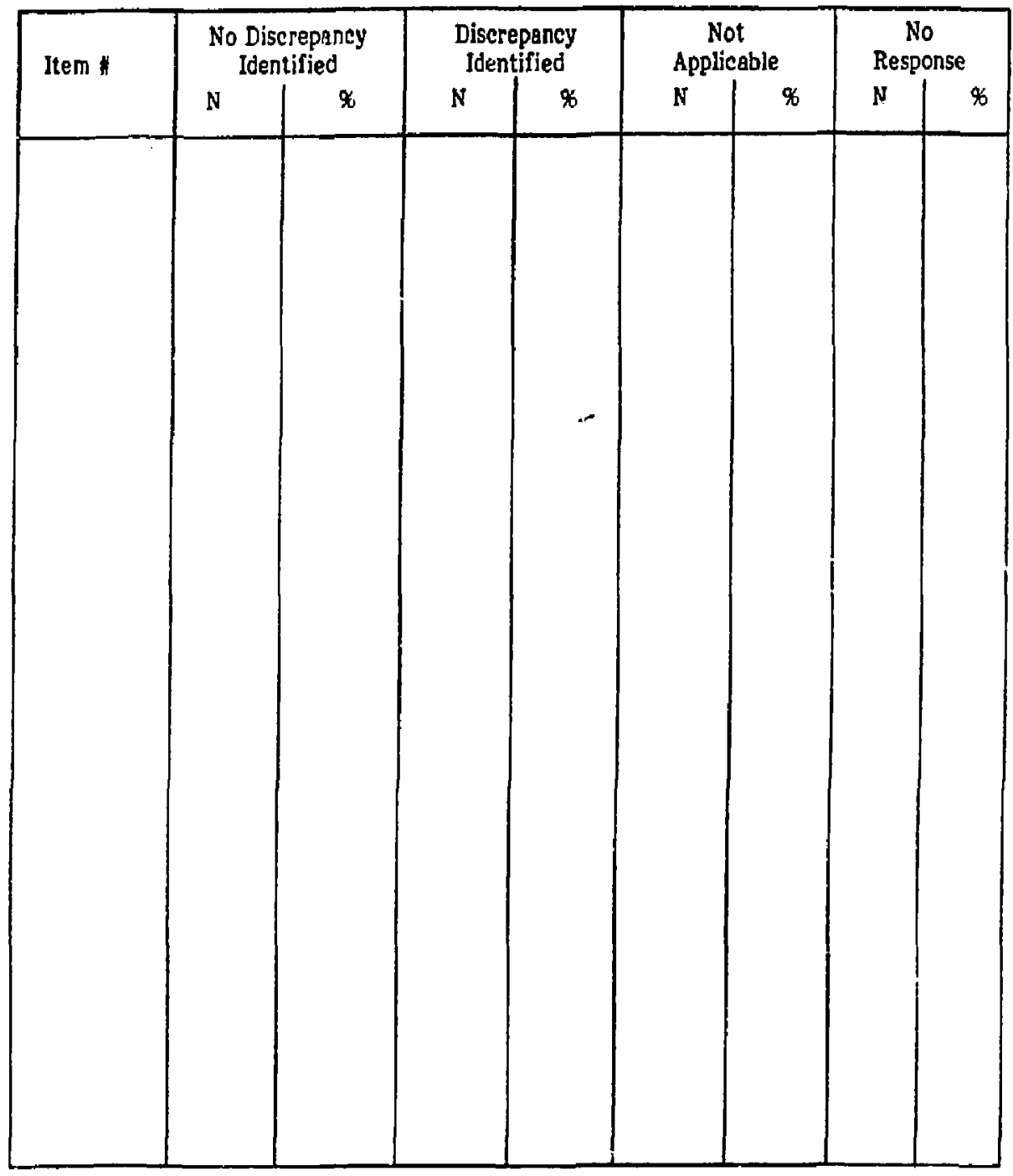


TOP 1-1-059

\section{DESIGN CHECKLIST}

\section{WABBLS, MANOALS, TAREFITGS}

\begin{tabular}{|c|c|c|c|}
\hline Dotulfod Design Considorations & |rEs|NO|N/A| & Commants & Leention \\
\hline 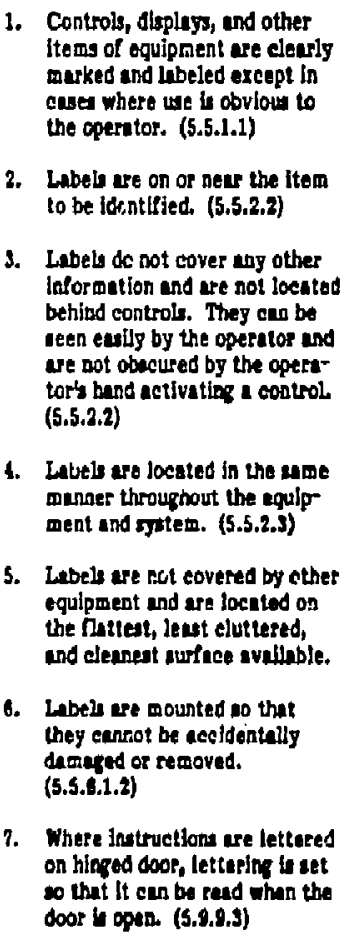 & & & \\
\hline
\end{tabular}

YES = Adequato NO - Inadaquate N/A = Not Appllieablo 


\section{EXHIBIT 4-8 (continued)}

85. Baned on your enintenence oxpurience at this plant, cite one ouple of a plant tyetes or unit of equiphent that lo not "humen engintered" or is pooriy deaigoed froe the mintenance son's atandpoint and wich hat or could lead to an etror, dasge to equipuent, or prosent a heeard to the an working r the syaten.

86. How think of a particular plant eysten or wit of equipant that is well "human engineered" or easy to anintain or wonicor eyoten atatus. Please describe the aystem or wit with ephasis on the features that ake it ropecilly good from the wioteiner's otandpoint.

87. This is the end of the interview. What questionk have I neglected to ank you? Are theze any enjor iapediaente or rosd blocke that keep you from doing the bet poroible erintenance job that we huved't covered? 


\section{EXHIBIT 4-11 \\ EXAMPLE OR A PERFORMANCE SEQUENCE SCENARIO}

(Source: Burgy, D. et al (1983). Task analysis of nuelear power plant sontrol room crews

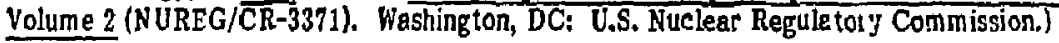

\section{Operating Sequence: Startup from Hot Shutdown}

Initial Conditions: The plant has been shut down to correct an equipment malfunction. The process of restart has begun. Plant pre-starting checks have been completed and the estimated critical position (ECP) has been calculated. The reactor is subcritical. No measurable thermal power is being produced. Reector coolent system (RCS) pressura is being controlled at 2155 psig. The turbine bypass valves are in automatic and controlling once-through steam generator (OTSG) pressure at 885 psig. OTSC level is being controlled at the startup operating level. Boron concentration is the proper concentration for startup. The rod groups are fully inserted. The Load Dispatcher has been notified of the plant condition.

Sequence Initiator: Permission has been received to take the reactor to $100 \%$ power.

Progression of Action: The crew withdrews the safety and regulating rod groups to take the reactor critical. Criticality is achieved within the limits speciffed in the ECP calcusation. The crew proceeds to take the reactor to the hot standby conditior. The crew then increases reactor power to $10 \%$, notifies the Load Dispatcher that the plant is coming on the line, parallels the generator an the grid, and proceeds to $100 \%$ power.

Final Conditions: The plant is operating at $100 \%$ power in the normal full power lineup.

Major Systems: Electrical Generation and Distribution System, Plant AC Auxiliary System, Integrated Control System (ICS), Main Feedwater System (FWS), Reactor Protectian System (RPS), Condenser System, Circulating Cooling Water System (CCWS), Power Conversion System (PCS), Control Rod Drive System (CRDS), Makeup and Purification System (MoP), Primary Sampling, Nuclear Instrumentation System (NIS), Auxiliary Feedwater (AFW), Main Turbine (MT), Generator and Exciter System, Reactor Coolant System (RCS), Pressurizer Level Control System (PZR-LCS), Condensate System, Extraction Steam and Heater Drain System, Heater Drains and Vents System. 


$$
=
$$


EXHIBFT 4-13 (continued)

Thak ANALras on. . Font

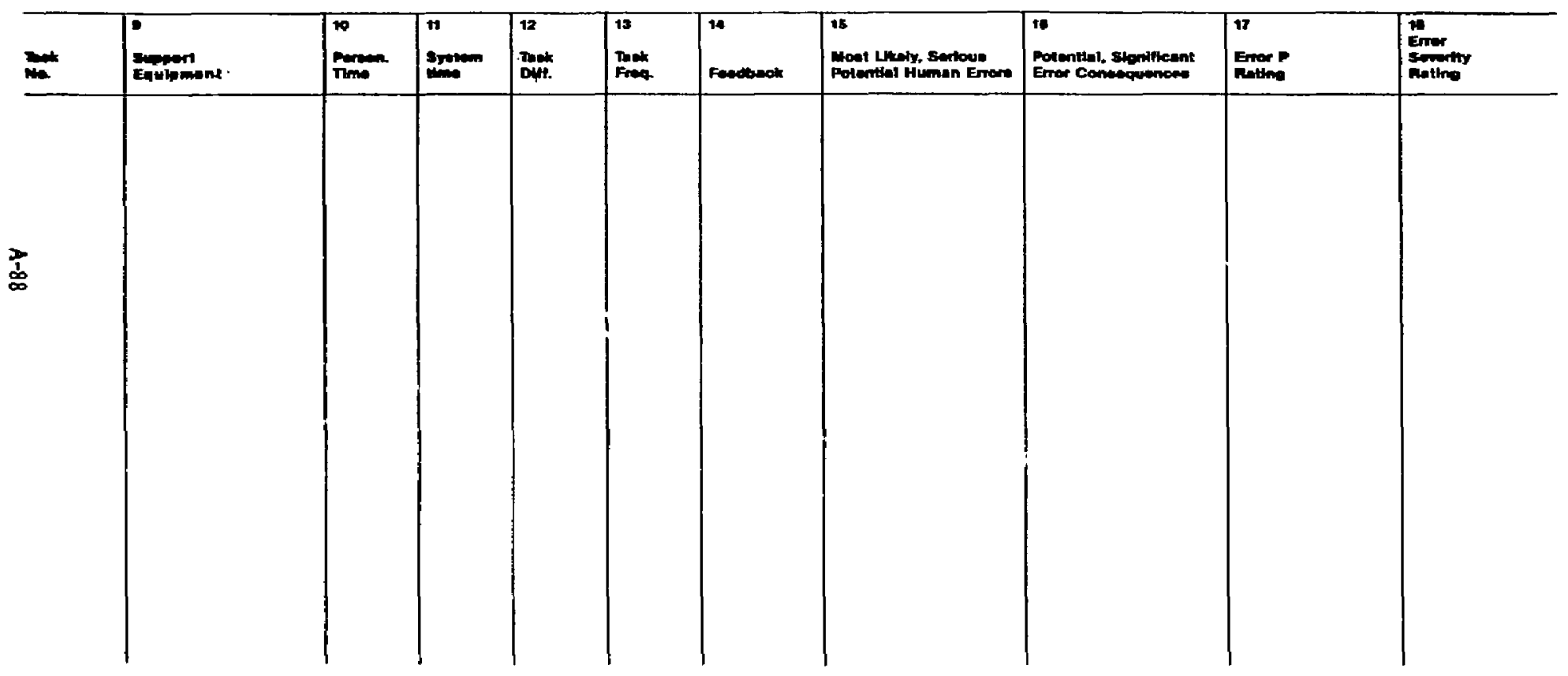




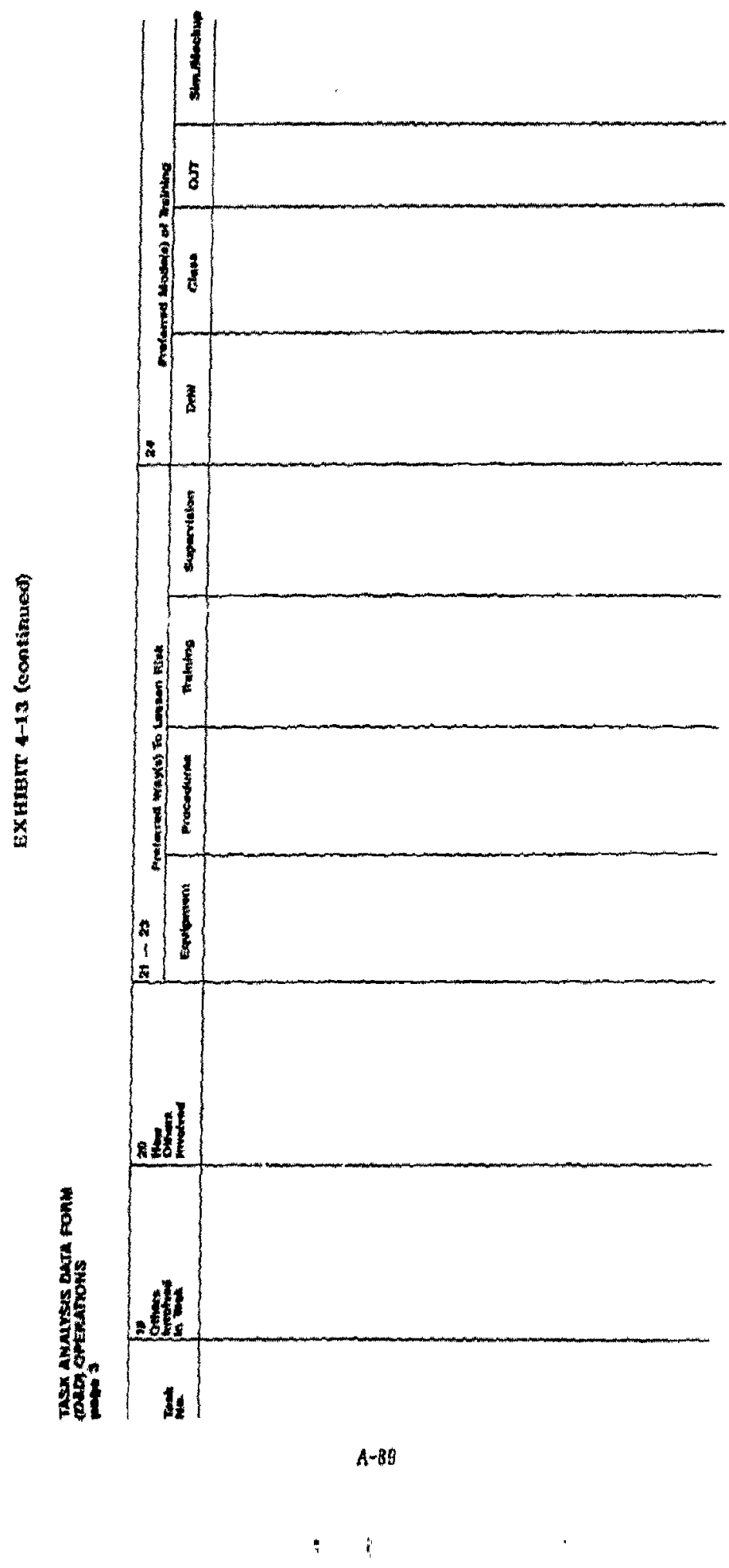




\section{EXHBrT 4-13 (eontinued)}

\section{Ther Amalvis: onta Fon:}

\section{Deps OFnutrows}

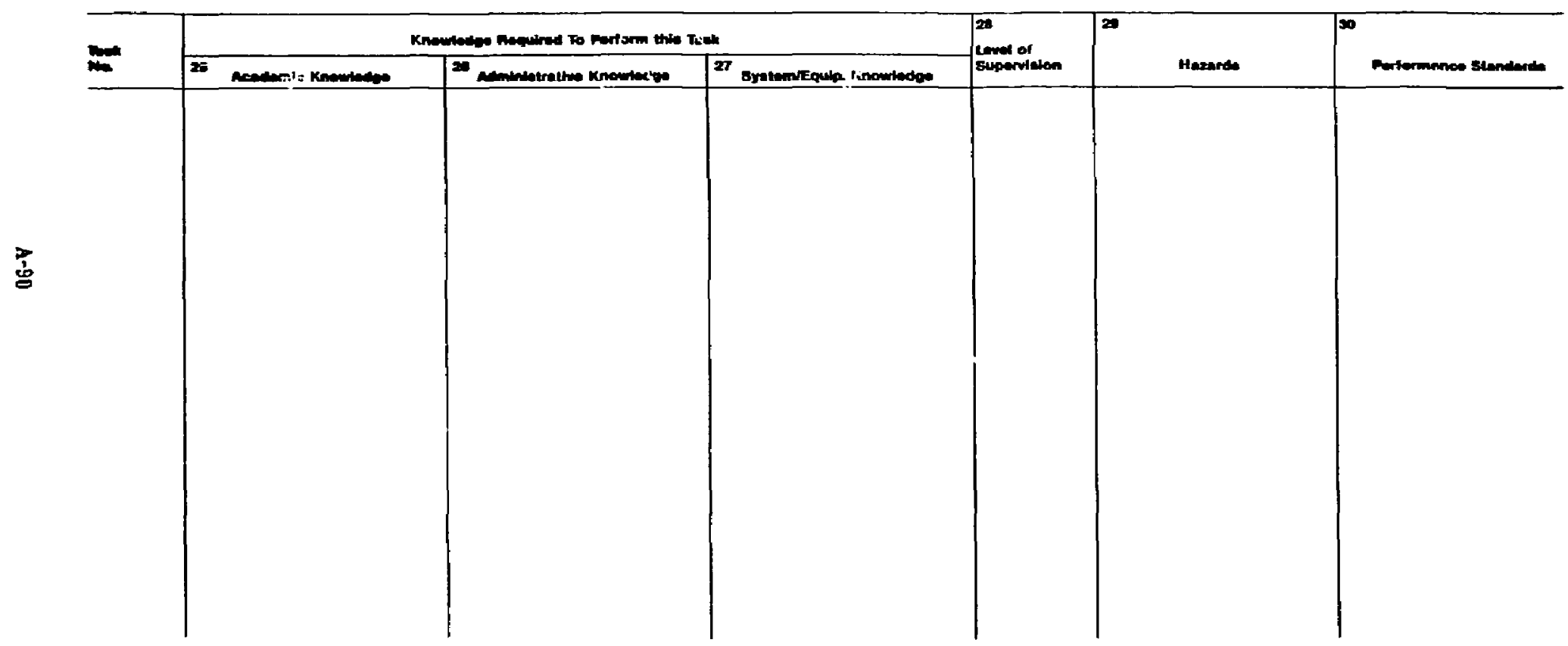




\section{EXHBT 4-14 \\ BXAMPLE OF A BAST FOR \\ WEIGHTING ERROR CONSEQUENCES USING THE RELATTVE \\ SAFETY SIGNIPICANCE OF SYSTEM PUKCTINS}

\section{Punction: Maintain Fuel Integrity}

Main Systems

High Pressure Safety Injection

Low Pressure Safety Injection

Accumula tor Safety Injection

Control Rod Drive

Emergency Bol'ation
Subsystem Examples

Electrical supply, pump cooling water

Electrical supply, first heat exchange system

Cooling Wate:

Electrical Supply

Function: Maintain Reactor Coolant system Integrity

Mein Systems

Reactor Coolent Pumps

PORV, Pressurizer Spray

Letdown System

Auxiliary Feeowater

Main Steam

Funetion: Maintain Reactor Building Integrity

Main Systems

Reactor Building Spray

Reactor Building Cooling Fans

Passive Reactor Building Cooling (Ine)

Hydrogen Monitoring and Control

Systems

Containment Isolation
Subsystem Fxamples

Electrical supply, cooling water, lubrication system

Electrical supply

Electrical supply

Steam, electrical supply

Valve control power

Subsystem Examples

Electrical supply, heat exchange systern

Cooling water system

Electrical supply

Electrical supply

Punction: Prevent Unmonitored Radioactive Rolease

Main Systems

Containment Purge

Waste Gas

Sump Systems
Subsystem Examples

Electrical supply

Electrical supply

Electrical supply 
EXHIBIT 4-14 (continued)

Punction: Prevent a Forced Outage

\section{Main Systems}

Most Equipment Protection

Such as Oil Systeris, Cooling

Systems

Alarm Systems
Subsystem Fxamples Electrical, heat exchange systems

Electrical

Punction: Prevent a Reactor or Turbine Trip or Reactor Runback

Main Systams

Feedwater, Condensate

Turbine Control System

Reactor Control System

Master Plant Controller
Subsystem Examples

Steam supply, control oil Control oil

Electrical power

Electrical, instrument air system

Function: Prevent Limiting Cunditions of Operation

Function: Prevent Lonf-Term Degradation of Equipment Misc. Systems

Function: Prevent Loss of Equipment Performance 
EXHIRIT \&-12

EXAMPLE OF A TASK-DESCRIPTTVE DATA FORMAT

(Source: Esser: Corporation, Systems Operability and Design Group, 1984.)

ACTION-INFORMATION REQUIREMENTS DETALS (AIRD)

shest ___ of unir:

REVIEWEA: DATE-

PLANT:

ERG NAME:

TASK NAHE:

NATUAE OF TASK

-

No.

imitiating cues

TERMINATING CUES:

REMARKS:

+
$\dot{1}$
0
0

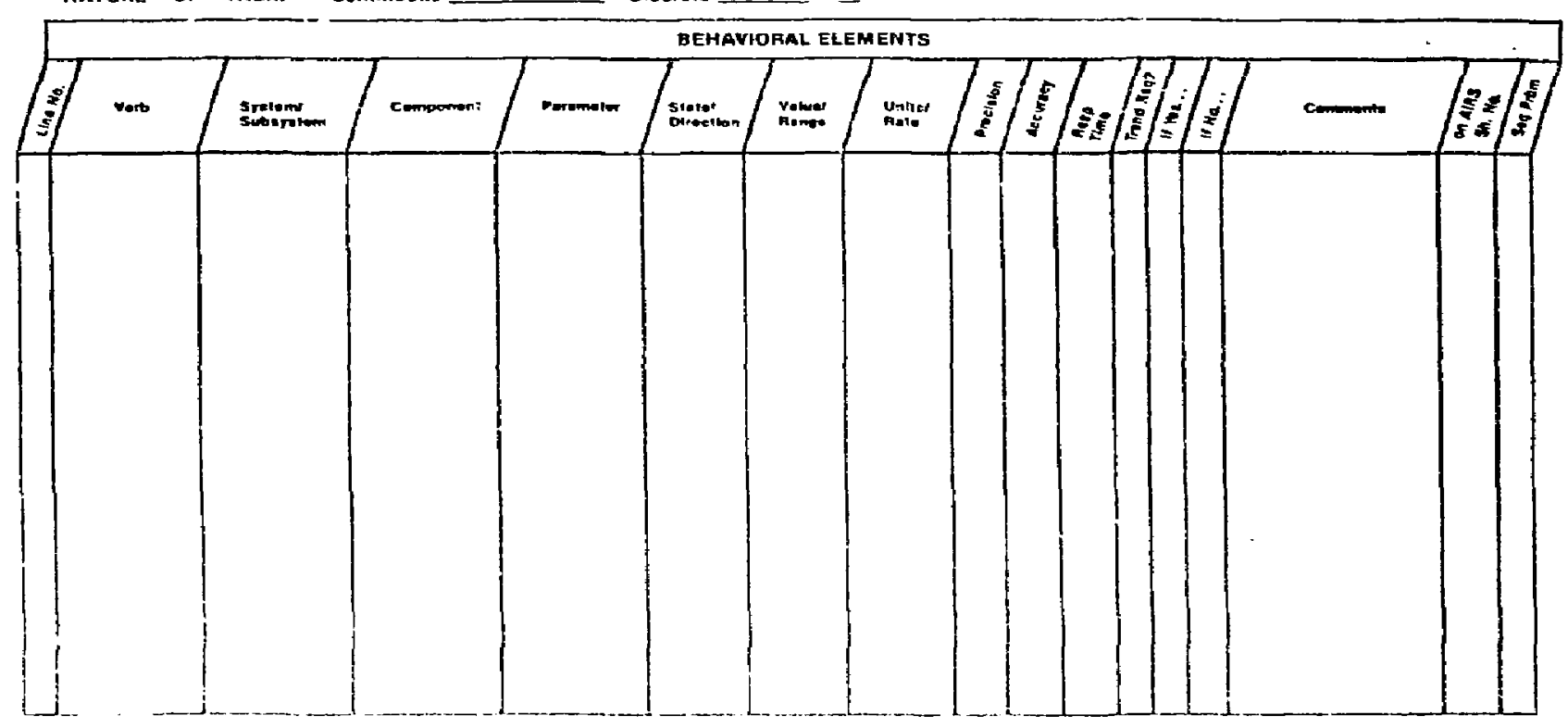




\section{EXHIBIT $4-15$ \\ EXAMPLE OF A CONSEQUENCE RATING SCHEME FOR DECONTAMINATION AND DECOMMISSIONING OPERATTONS}

(Source: Paramore, B., Banks, W.W., Veneziano, C., Gilmore, R.D., \& Coleman, S.R. (1983). A pilot task analyses of the Rockwell Size Reduction Facility, 234-52 Plutonium Finishing Plant. Richland, WA: Hanford Environmental Health Foundation.)

1 = No consequence to personnel safety or contamination control.

2 = Very minor severity.

- Minor personal injury without contamination with no loss of time from work (e.g., pinch/bruise, contusion, strain).

- Airborne contamination or other significant spread or buildup of contamination in sectioning room.

- Significant contamination of anteroom (up to $3,000 \mathrm{dpm}$ ) requiring no more than 4-hour cleanup.

3 = Minor severity

- Persona] injury resulting in loss of time from work but without contamination (e.g., broken finger or arm, sprained back muscle).

- Low-level skin contamination; no internal contamination.

- Dusting of contamination in clean area requiring no more than 2-day cleanup.

4 = Severe

- Slight internal deposition not requiring medical tres tment.

- Wound with implantotion requiring minor medical treatment.

- Contamination of clean erea requiring up to 2 weeks cleanup.

- Controllable environmental release (up to $100 \mathrm{dpm}$ ).

- Injury resulting in long-term disabilty.

$5=$ Very severe

- Fatality.

- Heavy internal deposition or wound with implantetion requiring extersive medical treatment.

- Spread of contamination reguiring more than 2-week cleanup.

- Contamination of building, resulting in shutdown of building operations.

- Large or uncontrollable environmental release. 


\section{FIGORE 4-1. DEFINITIONS OF TERMS IN SYSTEMS ANALYSIS APPROACH TO HFE REVIEW}

System (Subsystem): A whole which functions as a whole by virtue of the interdependence of its parts. Also, especially of man-machine systems, an organization of hardware, software, and personnel that work together in a patterned manner to accomplish some purpose.

System(s) Analysis: Examination of a system and its constituents to define their relationships and the ways in which they interact to achieve goal states.

Function (Subfunction): An activity (or a static role) performed by one or more system constituents (people, hardware, software) to contribute to a larger activity or goal sta te.

Funetion/Functional Analysis: The examination of system goals to determine what functions they require. Also, examination of the required funetions with respect to available manpower, technology, and other resources, to determine how the functions may be allocated and executed. In the context of HFE reviews, the identification of established functions and examination of how they are allocated and executed.

Task (Subtask): A set of human actions, related in time, that contributes to the accomplishment of a function.

Task Analysis: A process of identifying and describing units of work and analyzing the resources necessary for successful performance of those units of work.

Verification: The process of determining whether instrumentation, controis, and other equipment meet the specific requirements of the tasks performed by personiel.

Validation: The process of determining whether system functions can be accomplished given design, procedures, and allocation of task responsibilities. 
FIGURE 4-2. EXAMPLE OP A FUNCTONAL FLOW DLAGRAM

(Source: Geer, C.W. (1976). Analyst's quide for the analysis sections of MlL-H-46855 'D180-19476-1). Seattle, WA: Boeing Aerospace Company, Research and Engineering Jivision.)

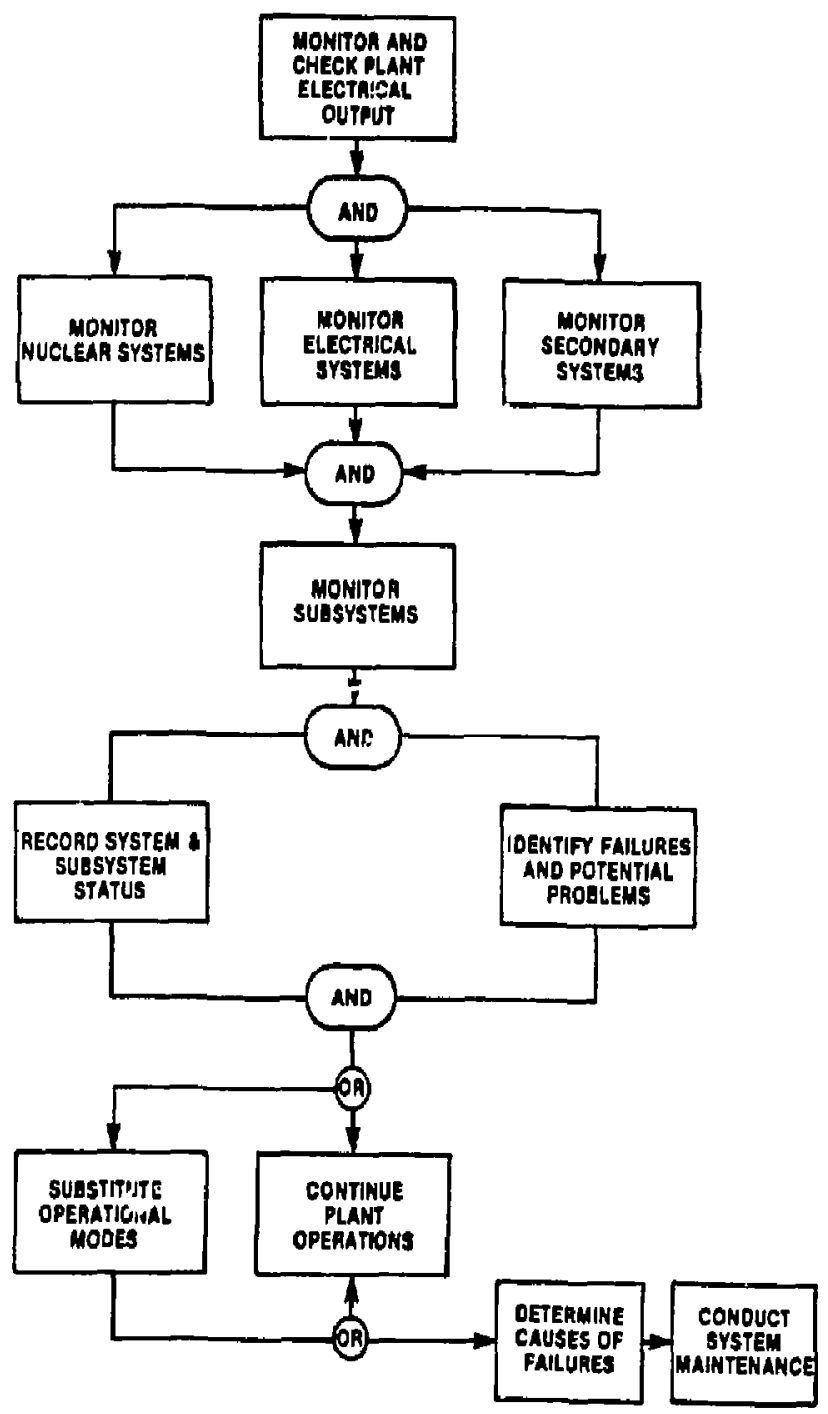


(Source: Seminara, J.L., et ai. (1979). Human factors methods for nucleer control room 'esign (EPRI-NP-1118-SY). Palo, Alto, CA: Electric Power Research Institute.)

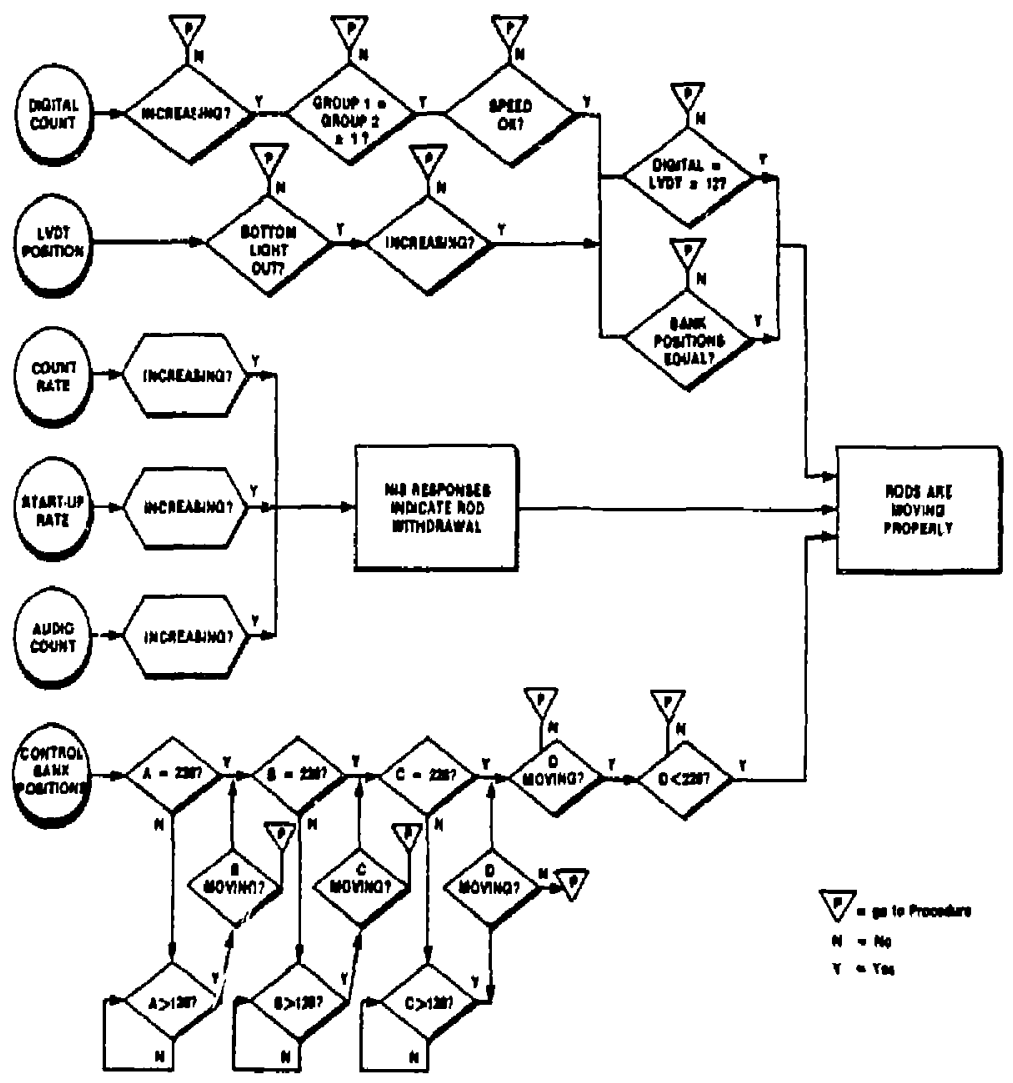


5.0 PROCEDURES REVIEW

REVIEW AIDS 


\subsection{HUMAN FACTORS ENGINEERING REVIEW}

\section{REFERENCES}

1. Bongarra, J.P., Jr. (1983). Human factors design guidelines for maintainability of Department of Energy (DOE) nuclear facilities (draft). Livermore, CA: Lawrence Livermore National Laboratory, Nuclear Systems Safety Program.

2. Bouchard, T.J., Jr. (1976). Field research methods: Interviewing, questionnaires, participant observation, systematic observation, unobtrusive measures, In $M$. Dunette (Ed.), Handbook of industrial psychology. Chicago: Rand McNally College Publishing Company.

3. Burgy, D., et al. (1983). Task analysis of nuclear power plant control room crews, Volume 1: Project approach and methodology, Volume 2; Data results (NUTEG/CR3371). Kashington, DC: U.S. Nuclear Regulatory Commission.

4. Departinent of the Army. (1975). Human factors engineering design for army material (MIL-HDB: 759). Washington, DCi Author.

5. Department of Defense. (1981). Human engineering design criteria for militery systems; equipment, and facilities (NiJL-STD 1472-C). Washington, DC: Author.

6. Department of Defense. (1966). Maintainability program requirements (MIL-STD470). Nashington, DC: Author.

i. Geer, C.K. (1976). Analyst's guide for the analysis sections of MIL-H-46855 (D18019476-1). Seattle, WA: Boeing Areospace Company, Research and Engineering Division.

8. Greth, R.L. \& Block, C.A. (1983). Methodology investigation - Human factors engineering test procedure for Army aviation. Fort Rucker, AL: L.S. Army Aviation Development Test Activity.

9. Kinkade, R.G, \& Anderson, J. (Eds.). (1984). Human factors guide for nuclear power plant control room development (EPRI-NP-3659). Palo Alto, CA: Electric Power Research Institute.

10. MeCormick, E.J. \& Sanders, M.S. (Eds.). (1982). Human factors engineering and design (5th Edition). New York: McGraw-Hill.

11. Perkins, J.C., Benel, D.C.R., \& Avery, L.W. (1983). U.S. Army Test and Evaluation Command test operations procedure: Human factors engineering, Part i - Test procedures (TOP 1-2-610). Aberdeen Proving Ground, MD: U.S. Army Test snd Evaluation Command (DRSTE-HF).

12. Seminara, J.L. (1982). Human factors methods for assessing and enhancing power piant maintainability (EPRI-NP-2360). Paio Alto, CA: Electric power Research Institute. 
13. Seminara, J.L., Eckert, S.K, Seidenstein, S., Gonzalez, W.R., Stempson, R.L., \& Parsons, S.0. (1979). Human factors methods for nuclear control room design (EPRI-NP-1118). Palo Alto, CA: Hlectric Power Research Institute.

14. Seminara, J.L., Gonzalez, W.R., \& Parsons, S.O. (1981). Human factors review of nuclear power plant maintainability (EPRI-NP-1567), Palo Alto, CA: Electric Power Research Institute.

15. Seminara, J.L., Gonzalez, W.R., and Parsons, S.O. (1977). Human factors review of nuclear power plant control room design (EPRI-NP-309). Palo Alto, CA: Electric Pawer Research Institute.

16. U.S. Nuclear Regulatory Commission. (1981). Guidelines for control room design reviews (NUREG-0700). Washington, DC: Author.

17. Van Cott, H.P. \& Kinkade, R.G. (Eds.). (1972). Human engineering guide to equipment design. Weshington, DC: U.S. Government Printing Office.

18. Woodsan, W.E. (1981). Human factors design handbook. New York: McGraw-Hill. 


\section{EXHIBIT 5-1 \\ BXAMPLES OF PROCEDORE-RELATED PERSONNEL ERRORS}

At Plant A, Unit 2, with the retator critical, the boron injection tank (BIT) was not operated in accordance with the station's procedures for periods of time in February and March 1982, so that

- Required BIT overpressure was not maintained and pressure control valve operability was not verified for the time periods noted.

- Required overpressure wes not verified and adjusted to normal on receipt of a low pressure alarm.

- Operators and supervisors failed to identify abnormal trends in logged date and failed to take appropriate corrective action.

- Required overpressure was reduced to zero on February 2, 1982, in accordance with a maintenance work request issued on January 24,1982 , without adequately detsrmining the effect on plant operation.

At Plant $B$, the reactor was operated in violation of Technical Specification Limiting Conditions for Operation during the period from May 14, 1980, to February 26, 1982. A particular valve serves two functions, containment isolation and vacuum breaking (between the reactor building and the supression pool). This valve was assembled incorrectly, so that it failed to properly perform either of its dual design functions. Inadequate maintenance procedures for reassembly and test of the valve caused the violation in the first place. Inadequate periodic functional test procedures allowed the condition to exist undetected for over 21 months.

At Plant C, from December 30,1982, to September 25, 1983, Unit 2 was in violation of its Technical Specifieations, because three suceessive quarterly tests for station battery operability had diselosed uncorrected violations of parameter limits. The licensee attributed the basic cause of the problem to inadequate procedures. The procedures included the limiting parameter values, but did not identify them as accept/reject values. Further, the procedures were vague about what was required of the tester if limits were exceeded. 


\section{BX HIBIT 5-2}

\section{EXAMPLE CHECELIST FOR TECHNICAL VERIPICATION}

Procedure Title:

Procedure Number:

Rev Number:

Date of Issue:

Rev Date:

Applicable Technical Documentation:

Evaluator(s):

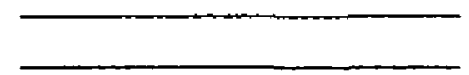

Date Evaluation Completed: 


\title{
EXHIBIT 5-2 (continued)
}

\begin{abstract}
INSTRUCTION
Itens 1 through 8 refer to information that should be provided in an introduction section, before the instructional steps. Check $Y E S$, NO or NA for each item. Make notes in the space below the item or on a copy of the procedure as necessary to explain a NO or NA check. Refer to the applicable technical documentation as necessary to ensure that the procedure is accurate and complete with respect to the requirements stated therein.
\end{abstract}

1. Does the procedure title clearly identify the situation to which the procedure applies?

$-{ }^{\text {YES }}-^{\mathrm{NO}}{ }^{\mathrm{NA}}$

2. If the procedure is for scheduled maintenance, test, or calibration, does the title correctly specify the frequency (e.g., monthly)?

$-\mathrm{YES}$-NO

3. If the procedure is for maintenance, test, or calibration, is the equipment to which it applies identified unmistakably in the title or in association with the title? (Unique identification number and/or nomenclature should be used. Location should be stated if necessery.)

$-{ }^{\mathrm{YES}}{ }^{\mathrm{NO}}{ }^{\mathrm{NA}}$

4. Is there a statement of purpose at the beginning, which clearly and correctly summarizes the actions detailed in the procedure and the final condition(s) to be accomplished?

- YES $-N O{ }^{N A}$

5. If the procedure is entered on the basis of plant/system/equipment symptoms, are the symptoms stated correctly, clearly, and completely?

- YES - NO ${ }^{\mathrm{NA}}$ 


\section{EXHIBIT 5-2 (continued)}

6. Are all prerequisjtes for use of the procedure stateo correctly and clearly? For example:

6.1 Other actions or procedures that must be completed before this procedure is used.

- YES _ NO _ NA

6.2 Plant, system, or equipment conditions that must exist before this procedure is used.

$-\mathrm{YES}{ }^{\mathrm{NO}}{ }^{\mathrm{NA}}$

7. Does the procedure provide complete and correct job planning information? For example:

7.1 Other documents (e.g., other procedures, drawings, manuals) needed to perform the procedure.

- YES _ NO _NA

7.2 Tools, equipment, and materials needed to perform the p.ocedure.

$-\mathrm{YES}{ }^{\mathrm{NO}}{ }^{\mathrm{NA}}$

7.3 Special requirements for personnel protective clothing and apparatus.

$-\mathrm{YES}-\mathrm{NO}-\mathrm{NA}$

8. Are general precautions which must be observed in performing the procedure stated correctly and completely?

${ }^{\mathrm{YES}}{ }^{\mathrm{NO}}{ }^{\mathrm{NA}}$ 


\section{EXHIBIT 5-2 (continued)}

\section{INSTRUCTION}

Items $9-46$ are criteria that apply tc tise instructional steps of the procegire. Evaluate each step with respect to each of these criteria. Refer to the applicable technical doeu!nentation to verify the accuracy and completeness of the s. ps. In a step does not meet a criterion, make a note of what is wrong on the prosedure. When all steps have been reviewed, complete the checklist item to show the findings, identifying the steps that do not meet a criterion.

9. Is provision made for documentating verification of simptoms actually observed?

- YES _ NO _ NA

10. If tris is an emergenicy prcceòre, are all required "immediate actions" stated in ih? first sectiun of instructional steps?

$$
\text { - YES _ NO N NA }
$$

11. Are "immediate actions" clearly identified as such?

$$
- \text { YES }-N O{ }^{N A}
$$

12. Are the actions required by the steps correct?

- YES $-\mathrm{NO}-\mathrm{NA}$

13. Are the actions required by the steps subject to misinterpretation?

_ YES _- NO _. NA

14. Is the sequence of steps correct/appropriate?

- YES _ NO 


\section{EXHIBIT 5-2 (continued)}

15. Are steps that must be performed in a particular sequence identified (e.g., by a note or a symbol such as an asteriski?

$$
\text { - YES _ NO }
$$

16. Do the steps include verification of automatic actions where necessary?

$$
\text { YES } \ldots \text { NO }- \text { NA }
$$

17. Are equipment and components identified correctly by unique number and/or nomenclature?

$$
\text { - }{ }^{\mathrm{YES}}{ }^{\mathrm{NO}} \text { - NA }
$$

18. Are equipment and component identificatior consisteat?

$$
- \text { YES }-N O-N A
$$

19. Are equipment and component locations stated when there might be uncertainty?

YES NO NA

20. Are all parameters to be observed identified correctly?

$$
\text { - YES _ NO }
$$

21. Is the terminology used to identify parameters consistent?

$$
- \text { YES }- \text { NO }- \text { NA }
$$


Procedure Number:

Revision Number:

\section{EXHIBIT 5-2 (continued)}

22. If performance of a step is conditional, are the conditions stated clearly and correctly?

$$
\text { _ YES _ NO NA }
$$

23. Are conditions of step performance stated quantitatively whenever possible?

- YES _ NO NA

24. Are acceptaice criterio and limits stated clearly and correctly?

$-\mathrm{YES}-\mathrm{NO}-\mathrm{NA}$

25. Are acceptance criterie and limits quantitative whenever possible?

$$
\text { - YES }-N O \text { - NA }
$$

26. Are quantitative acceptance criteria and limits stated as ranges rather than point values whenever possible?

$$
\text { _ YES _ NO _ NA }
$$

27. Is the user told what to do if acceptance criteria and limits are not met?

$$
-\mathrm{YES} \text { - NO }
$$

28. Are control anò elignment posit:ons specified correctly?

$$
\text { _YES _ NO _ NA }
$$




\section{EXHLBIT E-2 (continued)}

29. If there is a time criterion for starting or completing an action or series of actions is this stated clearly and correctly?

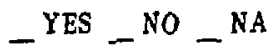

30. If an action must be performed later or repeated at an interval, is this made clear

- YES _ NO

31. Are all necessary cautions, warnings and notes that apply to individual steps or step series stated clearly and correctly?

$$
\text { - YES _ NO _ NA }
$$

32. Do cautions, warnings, and notes immediately precede the steps to which they apply asid appear on the same page?

- YES _ NO NA

33. Are the steps to which cautions, warnings, and notes apply identified correctly?

- YES _ NO $-\mathrm{NA}$

34. If calculations are necessary, is this stated?

$-\mathrm{YES}-\mathrm{NO}{ }^{\mathrm{NA}}$

35. Are current, accurate formulas and references such as eurves or lookup tables provided as neeessary for calculations?

$-\mathrm{YES}{ }^{\mathrm{NO}}{ }_{-\mathrm{NA}}$

36. Are instructions provided for all reasonable contingencies?

${ }^{\text {YES }}{ }^{\mathrm{NO}}{ }^{\mathrm{NA}}$ 
Procedure Number:

Revision Number:

\section{EXHIBIT 5-2 (continued)}

37. Where decisions are required, are the decision factors identified correctly and completely?

- YES _ NO

38. Where decisions are required, is the appropriate action path following each decision outcome identified?

$-\mathrm{YES}-{ }^{\mathrm{NO}}-\mathrm{NA}$

39. Are instructions to branch otier procedures correct and complete?

39.1 is the procedure correctly identified (by name, number, date of issue and Rev number and date as applicable)?

- YES $-N O{ }^{N A}$

39.2 Is the point of entry into the referenced procedure correctly stated?

$-\mathrm{YES}-\mathrm{NO}-\mathrm{NA}$

39.3 Are:instruetions given for return to the original procedure if necessery?

- YES - NO - NA

39.4 Review the action path defined by branching instructions. Will this path accomplish the desired results?

- YES _ NO _ NA

40. Art instructions to skip to another step within the same procedure c'srect and complete?

${ }^{\text {YES }}{ }^{\mathrm{NO}}-\mathrm{NA}$ 


\section{EXHIBIT 5-2 (continued)}

41. Are essential communications specified?

$-\mathrm{YES}{ }^{\mathrm{NO}}-\mathrm{NA}$

42. If corrmunication is required with personnel at a remote location, does the procedure correctly state where, with whom, and by what means?

$-^{\mathrm{YES}}$ NO $^{\mathrm{NA}}$

43. If the procedure is performed by more than one person, do the instructional steps clearly and cnrrectly indicate the division of responsibility?

- YES _ NO _ NA

44. Do the steps include hold points for independent quality control verifications where necessary and specify who is to perform the verifications (e.g., computations, alignments, tagouts)?

$$
- \text { YES }-N O{ }^{\text {NA }}
$$

45. If steps require that the actions of two or more people must be coordinated, is theie adequate guidance to ensure proper coordination?

$-\mathrm{YES}-\mathrm{NO}-\mathrm{NA}$

46. Are any steps omitted from the procedure?

$-\mathrm{YES} \ldots \mathrm{NO}-\mathrm{NA}$

47. Are all aids (such as decision now charts, worksheets, checklists) necessary for step performance provided?

$-^{\mathrm{YES}}-^{\mathrm{NO}}-^{\mathrm{NA}}$ 


\section{EXHIBIT 5 -2 (continued)}

48. Review any aids. Aie they technically correct and useful?

$-\mathrm{YES}{ }^{\mathrm{NO}}{ }^{\mathrm{NA}}$

49. Are all references to other documents correst and appropriate?

- YES $-{ }^{\text {NO }}-{ }^{\mathrm{NA}}$

50. Is the level of detail in instructional steps sufficient for all personnel who may use the procedure? *

$-\mathrm{YES}-\mathrm{NO}-\mathrm{NA}$

51. Are provisions for independent verification and signoff of accurate step completion adequate to prevent errors that could have significant consequences from going unnoticed?

- YES $-\mathrm{NO}$ - NA

52. Does the procedure or a related document (e.g., work request) identify any required follow-up actions such as a test, notifications, implementation of another procedure?

$$
- \text { YES }-\mathrm{NO} \text { - NA }
$$

* "specificity index" is provided at. the end of this checklist which may be used to evaluate level of detail more precisely. 
Procedure Number:

Revision Number:

\section{EXHIBIT 5-2 (continued)}

53. Specificity Index*: The level of specificity of a procedure may be evaluated by deterrining the percentage of steps in a selected sample that meet all of the following eriteria:

53.1 The action to be taken is specifically identified (open, close, torque, etc.).

53.2 Limits (if applicable) are expressed quantitatively ( 2 turns, 100 inch lbs., etc.).

53.3 The equipment or parts are identified completely (HPCI-MO-1\%, etc.).

Base the estimate on a sample of $20 \%$ of the steps in a given procedure or a minimum of 10 steps.

Do at least $90 \%$ of the steps evaluated meet the above criteria?

YES $-\mathrm{NO}{ }^{\mathrm{NA}}$

* Source: Brune \& Weinstein (May 1981) 


\section{EXHIBIT 5-3}

\section{EXAMPLE CHECKLIST POR PROCEDURE DESIGN VERIFICATION}

Procedure Tille:

Procedure Number:

nav Number:

Date of Issue:

Rev Date:

Evaluator(s):

\section{INSTRUCTIONS}

The checklist is designed to address major parts of the procedure in turn: cover, title page, table of contents, instructions (steps), and attachments. Items 4 through 10 , however, will require you to scan through all instruction and attachment pages to verify proper identification. Items 11 through 42 must be repeated for each instructional step or page of steps.

All items call for a "YES", "NO" or "NA" answer. "NO" indicates a discrepancy from a checklist criterion. Use the space below the item to identify the discrepancy (e.g., record the step numberis) and page number (s)l) and describe it in more detail as necessary. 


\section{EXHIBIT 5-3 (continued)}

\section{Identification}

1. Is there a cover page that shows all of the following information?

- Procedure title

- Procedure number

- Date of issue

- Revision number (if applicable)

- Revision date

- Approval signature and date

$-\mathrm{YES}-\mathrm{NO}-\mathrm{NA}$

2. Is there a table of contents that identifies and gives page references for the major sections of the procedure, as applicable (e.g., objective, prerequisites, job planning information, immediate actions, subprocedures, attachments)?

$-\mathrm{YES}-{ }^{\mathrm{NO}}{ }^{\mathrm{NA}}$

3. Is indention used in the table of contents to show subordination of parts of the procedure?

$$
\text { - YES }-N O
$$

4. I5 a descriptive title provided in the table of contents for all attachments?

_ YES _ NO

5. Do the headings/titles and page numbers listed in the table of contents match those in the procedure?

- YES $-N O{ }^{\mathrm{NA}}$ 
Procedure Number:

Revision Number:

\section{EXHIBIT 5-3 (continued)}

6. Does the procedure title appear in all caps, centered near the top of the first page of the procedure?

$$
\text { - YES _NO NA }
$$

7. Is the title of each major section within the procedure highlighted (e.g., underscored, with the first letter of each word capitalized)?

$$
\text { - YES _ NO _ NA }
$$

8. For each pege of the procedure, does the following identifying irs.jrmation appear in the upper right conner?

- Procedure number

- Date of issue

- Revision number (if applicable)

- Revision date (if applicable)

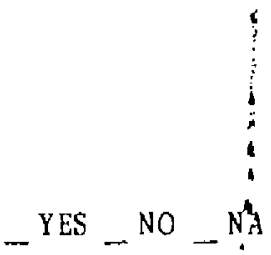

9. If this is a temporary procedure, is this shown in the identifying information on each page, with the expiration date?

$-\mathrm{YES}-\mathrm{NO}{ }_{-}^{\mathrm{NA}}$

10. Fur each page of the procedure, are the page number and total number of pages (page of I shown at the bottom of the page"?

$-\mathrm{YES}{ }_{-}^{\mathrm{NO}}-\mathrm{NA}$

11. Is the end of the procedure identifjed by END or FINAL PAGE following the last instructional step? 


\section{EXfIBIT 5-3 (continued)}

12. For each page of each attachment, is the following identifying information in the upper right corner?

- Procedure number

- Date of issue

o Revision number (if applicable)

- Revision date (if applicable)

- YES $-\mathrm{NO}{ }^{\mathrm{NA}}$

13. For each attachment, are the page number and total number of pages shown at the bottom of the page? (page _ of , referring to the pages in the particular attachment)

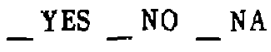

14. Do the attachments have the following information centered at the top of each page?

- Attachment number

- Attachment title

- Appropriate highlighting (e.g., underscored, with the first letter of each word capitsolized)?

- YES $-N O-N A$

\section{Instructional Step Format and Style}

15. Is there enough space between all numbered steps to separate them cleariy?

${ }^{\text {YES }}$ NO $^{\text {NA }}$

16. Do all of the written words of a given step or substep appear on the same page?

- YES _ NO _ NA 


\section{BXHIBIT 5-3 (continued)}

17. Are steps typed in upper and lower case letters rather than all upper case letters? ("All caps" should be reserved for use as a highlighting or emphasis technique.)

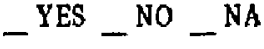

18. Ace margins sufficient, so that no information will be lost when the page is copied?

$$
\text { - YES _ NO }-\mathrm{NA}
$$

19. Is correct standard English spelling, grammar, and punctuation used?

$$
\text { - YES }-{ }^{\mathrm{NO}} \text { - NA }
$$

20. Are instructions written in short, concise, identifiable steps are opposed to multistep paragraphs?*

$$
\text { _ YES _- NO _NA }
$$

21. Are steps which have more than one action minimized?*

- YES - NO

22. If a step has more than two objects of action (e.g., the operator/technician is directed to close four valves), are they listed on separate lines rather than presented as a string in a sentence?

$$
- \text { YES }- \text { NO }
$$

\footnotetext{
* An index is provided at the end of this checklist which may be used to evaluate the complexity of the instructional steps more precisely.
} 


\section{EXXHIBIT 5-3 (continued)}

23. Are first-level steps highlighted by a short horizontal line to the left of the step number, to assist the operator in place-keeping?

$$
{ }^{\text {YES }} \text { NO }^{\mathrm{NA}}
$$

24. Do acronyms and abbreviations conform to fucility conventions?

$$
-\mathrm{YES}{ }^{\mathrm{NO}}-\mathrm{NA}
$$

25. Do symbols, if used, conform to facility conventions?

$$
-\mathrm{YES}-\mathrm{NO}-\mathrm{N}^{\mathrm{A}}
$$

26. When a specific component is referred to, is it identified in all caps, followed by the engineering number in parentheses?

$$
-\mathrm{YES}-\mathrm{NO} \text { NA }
$$

27. When a specific annunciator is referred to, is it identified in ull caps, followed by the alarm penel and window numbers in parentheses?

$-\mathrm{YES}-\mathrm{NO}-\mathrm{NA}$

28. Are conditional or critingency stens expressed such that the conditions are stated before the action which is to be performed? (For example, conditional/contingency instructions should be stated "IF _ , TlIEN do " not "do

$-\frac{\mathrm{IF}}{\mathrm{Y}} \overline{\mathrm{ES}}^{. " \mathrm{~N}}{ }^{\mathrm{NO}} \mathrm{N}_{\mathrm{NA}}$




\section{EXHIBJT 5-ŝ (continued)}

29. Are cenditional or contingency instructions easy to understand? For example, if two or more conditions mu-t be met before an action is perform d are they:
\&. Listed separately?
h. Listed ahead of the action statement?
c. Clarified by the appropriate logic terms?

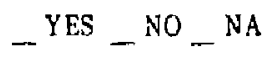

30. Are logic terms emphasized by using all cepitzl letters and underscuring? (For example IF. THEN, AND, OP)

_ YES _ NO _ NA

v1. Are conditional sters written to avoid multiple combinations of logic terms?

$-{ }^{Y} E S-{ }^{\mathrm{NO}}-\mathrm{NA}$

32. If calculations are equired, is adequate space provided to perform them?

Y YES NO NA

33. Are formulas for calculations provided when needed?

- YES $-\mathrm{NO}{ }_{-\mathrm{NA}}^{\mathrm{NA}}$

34. When deviation from a setpoint is allowed, is it given as a range or limiting value rather than as a percentage?

Y YES NO $^{\mathrm{NA}}$

35. Are cautions, warnings, and notes free of action instructions?

$-\mathrm{YES}-\mathrm{NO}{ }^{\mathrm{NA}}$ 


\section{EXEIBIT 5-3 (continued)}

36. Are cautions, warnings, and notes separate and easily distinguishable from instructional steps? (e.g., by headings and boxing)

$$
\text { _ YES _ NO }
$$

37. Are cautions, warnings, and notes easily distinguishable finm each other? (e.g., by headings and different boxing techniques such as asterisks, dashed lines, solio lines)

- YES _ NO _ NA

38. Do alignment instructions (e.g. valve alignment lists, electrieal alignment lists) meet the following criteria?

a. Each item individually specified.

b. Each item identified with a unique number or nomenclature.

c. Position specified.

- YES - NO

39. Are the titles and numbers of all referenced documents accurately identified, with procedure number given first, followed by title in all caps?

${ }_{-} \mathrm{YES}{ }^{\mathrm{NO}}{ }^{\mathrm{NA}}$

40. Is the operator/tecknician told where to enter and exit the referenced procedure?

$-^{\mathrm{YES}}$ NO $^{\mathrm{NA}}$

41. Is the operator/technician told whether it is necessary to reenter this procedure and, if so, when/under what conditions, and where?

$-\mathrm{YES}{ }^{\mathrm{NO}}{ }^{\mathrm{NA}}$ 
Procedure Number: Revision Number:

\section{EXHIBIT 5-3 (continued)}

42. Examine referenced material. Is the referenced material to have vasil easily incorporated into the procedure being verified?

$-\mathrm{YES}-\mathrm{NO}{ }^{\mathrm{NA}}$

43. If a graphic attachment or other attachment is cited in a step, does it appear at the end of the procedure, with the correct numerical identification and title, and in the correct order relative to other attachments? (They should be numbered and appear in the order in which they are cited.)

$$
\text { - YES } \ldots \text { NO }{ }^{\mathrm{NA}}
$$

44. Are all graphics identified as attachments?

$$
- \text { YES }-\mathrm{NO}-\mathrm{NA}
$$

45. Are all attachments. .

a. Deseriptively titled?

b. Clearly labeled?

c. Readable?

$-\mathrm{YES}{ }^{\mathrm{NO}}{ }^{\mathrm{NA}}$ 


\section{EXHLAIT $5-3$ (continued)}

46. For all flow charts...

a. Is the direction of yes/no paths consistent?

b. Are path and loop logic complete so there is no ambiguity about how to proceed?

47. Complexity index*: Evaluate the complexity of the instructions by determining the average number of actions per step that the user is directed to perform. Use all steps to calculate the average.

Is the average number of actions per step 1.5 or less?

$$
-\mathrm{YES}-\mathrm{NO}-\mathrm{NA}
$$

- Source: Brune \& Weinstein (195:) 


\section{EXHIBIT 5-4}

EXAMPLE CHECKLIST POR PROCEDURE VALIDATION EXERCISES

Procedure Title:

Procedure Number:

Rev Number:

Date of Issue:

Rev Date:

Observer:

Date of Velidation:

\section{INSTRTJCTIONS}

Answer "YES", "NO", or "NA" to each criterion statement. Use the space below each criterion statement to explain any "NO" answers. identify the part(s) or step(s) of the procedure that are involved. 


\section{EXHIBIT 5-4 (continued)}

1. Do the symptoms observable in the work station agree with what is said in $t^{1}, 2$ procedure?

- YES - NO - NA

2. Can the instructional steps be performed in the sequence indicated by the procedure?

$-\mathrm{YES}{ }^{\mathrm{NO}}{ }^{\mathrm{NA}}$

3. Can personnel readily locate all components referred to in the procedure?

$-\mathrm{YES}-\mathrm{NO}{ }^{\mathrm{NA}}$

4. Are system/eguipment responses and parameter values consistent with what is said in the procedure?

$-\mathrm{YES}-\mathrm{NO}-\mathrm{NA}$

5. To personnel omit any procedural steps?

$-\mathrm{YES}-{ }^{\mathrm{NO}}-\mathrm{NA}$

6. Do personnel perform steps that are not specified in the procedure?

$-\mathrm{YES}-\mathrm{NO}-\mathrm{NA}$ 
Procedure Number:

Revision Number:

\section{BXHIBIT 5-4 (continued)}

7. Can personnel perform the procedure without getting additional information from sources not identified in the procedure?

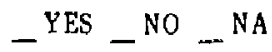

8. Ch personnel perform the procedure without getting help from others not identified in the procedure?

$$
- \text { YES }- \text { NO }
$$

9. If the proceciure is performed by more than one person...

9.1 Can they communicate without difficulty?

$$
\text { YES }-\mathrm{NO}-\mathrm{NA}
$$

9.2 Are essential communications specified in the procedure?

$-\mathrm{YES}-\mathrm{NO}-\mathrm{NA}$

9.3 Can their actions be coordinated without difficulty?

- YES $-\mathrm{NO}{ }^{\mathrm{NA}}$

9.4 Do they get in each others' way?

- YES 
Proceduro Number:

Revision Number:

\section{EXHIBIT 5-4 (continued)}

10. Can pr:sonnel perform the procedure effectivaly whila wearing protective gear (if required)?

$$
{ }^{\text {YES }} \text { NO }^{\mathrm{NO}}
$$

11. Do the physical characteristics of the procedure (e.g., size, binding, mounting) allow it to be used conveniently in the work setting?

$$
-\mathrm{YES}-\mathrm{NO} \text { - NA }
$$

12. Can other documentation, tools, and materials required by the prccedure be used conveniently in the work setting?

_ YES _ NO _ NA 


\title{
EXHIBIT 5-5
}

\section{SUMMARY OF REGULATORY GUIDANCE CONCERNING}

\author{
NEEDS FOR WRITTEN PROCEDURES
}

- Title 10 of the Code of Federal Regulations, Part 50, Appendix B ("Quality Assurance Criteria for Nuclear Power Plants and Fuel Reprocessing Plants") states that "Activities affecting quality shall be prescribed by documented instructions, procedures, or drawings of a type appropriate to the circumstances and shall be accomplished in accordance with these instructions, procedures or drawings. (They) shall include appropriate quantitative or qualitative acceptance criteria for determining that important activities have been satisfactorily accomplished" (10 CF R 50, revised as of January 1,1983, p. 456).

- For nonreactor facilities handling sufficient amounts of materials with critjcality potential - DOE Order 5480.1 (8-13-81), page V-9) requires that contractors shall "prepare and utitilize written procedures for the handling of fissionable materials, including storage, transfer and processing." More description of the activities and concerns to be covered by these procedures is given in Section V.9C of the Order.

- For reactor facilities - DOE Order 5480.1 (8-13-81, page VI-22) refers to "procedures, i.e., administrative, operating (normal and abnormal), maintenance repair, testing, quality assurance, and imergency", in the context of requirements for the "Contractor Independent Review and Appraisal System." (Independent and objective review of these procedures, and of changes thereto, is required.)

- For both nuclear and non nuclear facilities - DOE Order 5500.2 requires written plans and procedures for operational emergencies. The order identifies items that "should be considered in the preparation af emergency procedures." (It is noted that the list is not considered all-inclusive):

- Personnel evacuation and accountability

- Emergency notification

- Readiness actions

- Personnel monitoring and decontamination

- Medical emergency requirements

- Demage contral

- Reentry planning

- Damage assessinent.

Somewhat more specific guidance concerning procedural coverage at licensed reactor facilities is available in A merian National Standard N18.7-1976. ${ }^{5}$ This standard for $\mathrm{NRC}$-licensed reactors specifies that written procedures shall be provided for the lowing activities: 
- System operations (i.e., instructions for operation of individual systems related to the safety of the plant, including energizing, filling, venting, draining, starting up and shutting down, etc.)

o Integrated plant operations, including

- Startup

- Shutdown

- Power operation and load change

- Process monitoring

- Fuel handling (Specific procecures should be prepared for each receipt and shipment of fuel and for each refueling outage. General fuel handling procedures should prescribe preplanning and safety measures and should identify the specific procedures to be prepared for each outage.)

o Maintenance, including

- Preparation

- Performance

- Pos-maintenance checkout and return to service.

- Calibration and test

- Radiation control

- Chemical-redio chemical control

- Emergency operations

- Emergency Plan implementation and restoration to normel conditions following an emeigency

- Test and inspection 


\section{EXHIBIT 5-6}

EXAMPLE OP A CRTTERION CHECKLIST FOR ASSESSING

NEEDS FOR ADDITIONAL PROCRDORES

Functional Area/Department

Activity

Reviewerisi:

Date:

\section{INSTRUCTIONS}

Check YES or NO for each item. YES checks indicate potential reasons why a written procedure may be needed. The mix of results for each activity should be weighed on a case-by-case basis. As a rule of thumb, if three or more items are checked YES, a written procedure should usually be recommended. 


\section{EXHIBIT 5-6 (continued)}

1. The activity is long in terms of number of steps that must be performed.

- YES - NO

2. The activity reguires relatively complex decision-making or diagnosis.

$-\mathrm{YES}-\mathrm{NO}$

3. The activity is not performed very often (e.g., it is parformed no more than four times a year).

- YES $-\mathrm{NO}$

4. It could be necessary to perform this activity under conditions of high physiological or psychological stress.

- YES - NO

5. Proper execution of the activity is not self-evident from the equipment configuration.

$-\mathrm{YES}-\mathrm{NO}$

6. In error could occur in this activity that would be difficult to detect or recover.

YES 


\subsection{PROCEDUKES REVIEW}

\section{REPERENCES}

1. Brune, R.L. \& Weinstein, M. (198 1, May). Development of a checklist for evaluating emergency procedures used in nuelear power plants (N UREG/CR-1970, SAND8 [-7070). Washington, DC: U.S. Nuclear Regulatory Commission.

2. Brune, R.L. \& Weinstrin, M. (1980, May). Development of a checklist for evaluating maintenance, test, and calibration procedures used in nuclear power plants (NUREG/CR-1368, SAND80-7053). Washington, DC: U.S. Nuclear Regulatory Commission.

3. Serendipity, Inc. (1969), Project PIMO final report, Volume I: summery (AD-852 101). Alexandria, VA: Defense Logistics Agency, Defense Technical Information Center.

\section{Sources of Procedures Evaluation Methods/Checklists}

Brune, R.L. \& Weinstein, M. (1981, May). Checklist for evaluating emergency procedures used in nuclear power plants (NUREG/CR-2005, SAND81-7074). Washington, DC: U.S. Nuclear Regulatory Commission.

Brune, R.L. \& Weinstein, M. (1982, September). Procedures evaluation checklist for maintenance, test, and calibration procedures used in nuclear power plants (NUREG/CR-1369, SAND80-7054, Rev, 1). Washington, DC: U.S. Nuclear Regilatory Commission.

Fuchs, F., Engelschalh J. \& Imlay, G. (1981). Humen Engineering Guidelines Cor Use in Preparing Emergency Operating Procedures for Nuclear Power Plants (NUREG/CR-1999) Washington, D.C.: U.S. Nuclear Regulatory Commission.

Fuchs, F., Engelsehall, J., \& Imlay, G. (1981). Evaluation of emergency operating jrocedures for nuclear power plants (NUREG/CR-1875). Washington, DC; U.S. Nuclear Regulatory Commission.

Seminara, J.L., Gonzalez, W. \& Parsons, S. (1977). Human factors review of nuclear power plant control room design, Section 17: "Procedures" (EPRI NP-309). Palo Alto, CA: Electric Power Research Institute.

Toto, G. \& Lindgren, A.J. (1981). An independent assessment of DOE nuclear reactor facilities' procedures, operations, and maintenance (DOE/US-008). Washington, DC: U.S. Department of Energy. 


\section{Sources of Procedure Development Guidance}

Department of Defense. (1977). Technical writing style guide (MIL-HDBK-63038-2(TM)). Washington, DC: Author.

EOPIA Review Group. (1982). Emergensy operating procedures writing guideline (INPO 32-017). Atlanta, GA: Institute of Nuclear Powcr Operations.

Folley, J.D., Jr. \& Altman, J.W. (1956). Guide to design of electronic equipment for mainteinability, chapter on "Kecommended characteristi us for maintenance procedures and job instructions" (WADC-TR-56-218). Dayton, OH: Wrignt Air Development Center.

Morgenstern, M.H. et al. (1981). Guidelines for preparing emergency operating procedures (NUREG/CR- $\overline{1977}$, PNI-3713). Washington, DC: U.S. Nuclear Regulatory Commission.

Naval Air Systems Command. (1980). Technical manual writers guide (NAVAIR 00-25700). Warminster, PA: Author.

Serendipity, Inc. (1969). Project PlMo final report, Volumes IV-VIl (AD-852 104, 105, 106, 107). Aley.andria, VA; Defense Logistics Ageney Defense Teehnical Iniormation Center.

Taylor, D.F. \& Voss, T.J. (1982). A pilot evaluation of three alternative formats for emergency cotitrol ranm procedures. Transactions of the American Nuclear Society, $43,235-236$.

U.S Nuclear Regulatory Commission. (1982). Guidelines for the preparation of emergency operating procedures (NUREG-0899). Washington, DC: Author. 


\section{RXHIBIT 5-6 (continued)}

7. There could be significant consequences of an error made in performing this activity.

_ YES _. NO

8. Personnel may perform this activity who do not have a high level of skill/experience.

- YES - iNo

9. Personnel may perform this activity without close supervision or verification of correct performance.

_YES _ NO 
6.0 ORGANIZATIONAL INTERFACE REVIEW REVIEF AIDS 


\section{EXHIBIT 6-2 \\ ORGANLATIONAL COMMUNICATION SORVEY QUESTIONNAIRE}

This questionnaire is presented as an example of a comprehensive survey instrument that addresses many aspects of organizational interfaces thrat are relevant to the DOF facilities. Scoring of this survey is discussed in Section 6.0 of this Review Plan and Exhibit 6-1 of the Appendix provices the listing of communication indices and related questionnaire items to be used for scoring the questionnaire. 


\section{EXHIBIT 6-2}

Plant

\section{ORGANIZATIONAL COMMUNICATION SURVEY}

Drte:

1. What department do you work in?
1. Operations
2. Maintenance
3. $18 \mathrm{C}$
4. _ Quality Assurance
5. _- Heal th/Physics
6. _ Plant Management
7. __ Other (Please specify):

2. What is your current job category?
1. __ Auxiliary Reactor Operator
2. _L Licensed Operator (RO)
3. __ Senior Licensed Operator (SRO)
4. __ Technician
5. _ Mechanic
6. __ First Line Supervisor (e,g, shift supenisor, chief mechanicl
7. __ Secand Line Supervisor
8. _ Third Line Supervisor
9. __ Top Level Manager
10. — SRO and First Line Supervisor
11. _ SRO and Second Line Supervisor
12. _ Prolessional/Technical Staff
13. — Management Staff
14. __ Other (Please specify):

This is a series of questions about how people communicate at work. Imagine a typical week at work on your current job, and answer the questions accordingly. Please attempt to answer all the questions.

Most questions have seven point scales on which to answer. On these questions, please check the point that represents most closely how you feel. Read each question and scale carefully, For instance, to the question, "How rich do you want to be?" you might answer:
1 - Very Poor
2
3
4
5
6
7 Very rich

f.nswer each question for routine conditions except where outages are noted. 


\section{EXHIBIT G-2}

3. Do you have subordinates working for you? No

Yes How many?

4. How tree do you feel to discuss with your immediate superior (the person who most frequently gives you orders and directions) the problems and difficulties you have in your job without jeopardizing your position or having i: "held against" you later?

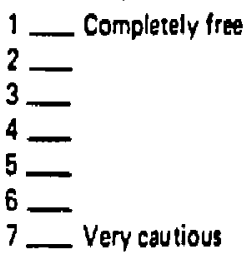

5. Immediate superiors at times must make decision which geem to be against the interests of their subordinates. When this happens to you to a subordinate, how much trust do you have that your immediate superior's decision was justified by other considerations?

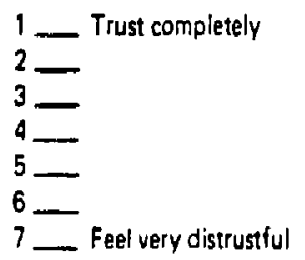

5. In general, how much do you feel that your immediate superior can do to further your career in the utility?

1 _ Much

2

3

4

5

6

1- Little

7. How much importance would your immediate superior's recommenuation have in any decision which would affect your standing in the utility such as promotions, transfers, etc?

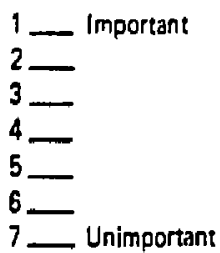

8. As part of your present job plans, do you want a promation to a higher position at some point in the future?

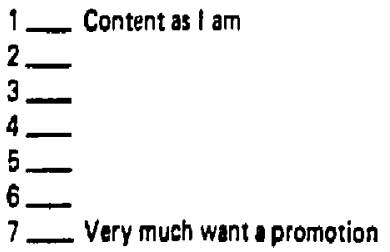




\section{EXHIBIT 6-2}

9. How important is it for you to progress upward in the utility"

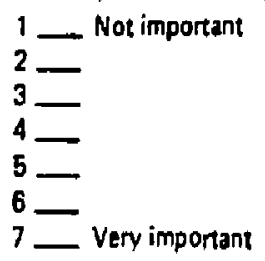

10. To what extent do you have confidence in your immediate superior regarding his general fairness?

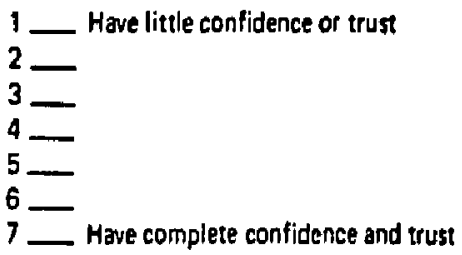

While working, what percentage of time do you spend interacting with the following individuals in your department?

Under Normal Conditions: Under Outage Conditions:
11. Immediate superiors

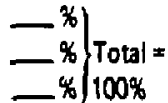
14. Immediate Superiors
15. Subordinates \%
12. Subordinates $100 \%$
16. Peers-others at your job level $\% 100 \%$

While vorking, what percentage of time do you spend interacting with individuals from the following departments (including vour own)?

\section{Under Normal Conditions:}

17. Operations

18. Maintenanca

19. $18 \mathrm{C}$

20. Quality Assurance

21. Health/Physics

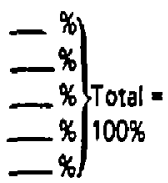

Under Outage Conditions:

22. Operationis

23. Maintenance

24. 18C

25. Quality Assurance

26. Health/Physics

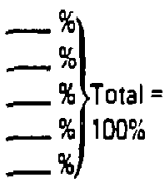

Of the total time you engage in communication while on the job, about what percentage of the time do you use the following methods to communicate?

27. Written

28. Face-to-face

29. Telephone

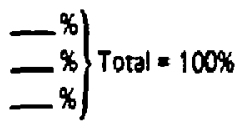

How would you rate the quality of the following in providing you the information you need to effectively perform your job:

30. Work Request/Job Order Forms

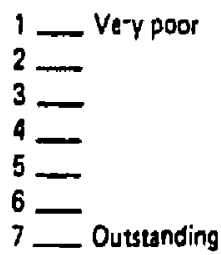

31. Policies

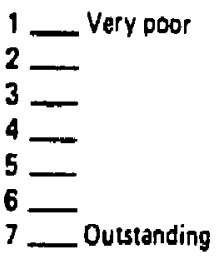

32. Procedures

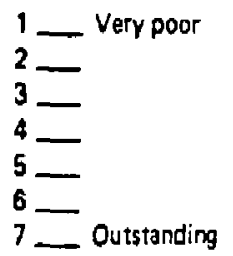




\section{EXHCBIT 6-2}

When receiving information from the sourtes listed below, how accurate would you stimate it usually is under normal plant conditions:

33. Imnediate Superiors

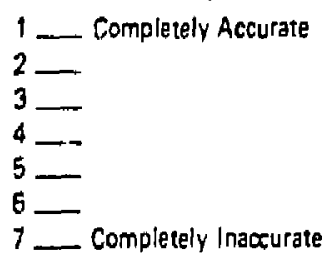

\section{Subordinates}

1 _ Completely Accurate

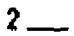

3

=

5

6

7 Completely Inaccurate

8 _Not Applicable
35. Peeis-Others at your Job Level

1 Completely Accurate

2

3

4

5

6

7 __Completely Inaccurate

When receiving information from the sources listed below, how accurate would you estimate it usually is during a plant ou tage:

36. Immediate Superiors

1 Completely Accurate

2

3

4

5

6

7 Completely Inaccurate
37. Subordinates

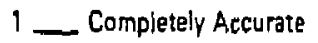

2

3

4

5

6

7
38. Peers-Others at your Job Level

1 Completely Accurate

2

3

4

5

6

7 Completely Inaccurate

8 Not Applicable

39. Do you ever feel that you receive more information than you can efficiently use?

$$
\begin{aligned}
& 1-\text { Never } \\
& 2- \\
& 5- \\
& 5-\text { Always }
\end{aligned}
$$

Of the total time you spend receiving information at work, what percentage is from
40. Immediate superiors
41. Subordinates
42. Peers-others at your job level
43. Other Sources (please specify

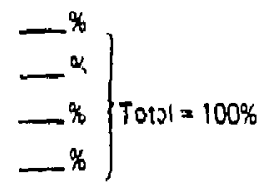

Of the total time you spend sending information, what percentage goes to:
44. immediate superiors
45. Subordinates
46. Peers-others at your job level
47. Other Sources Iplease specify

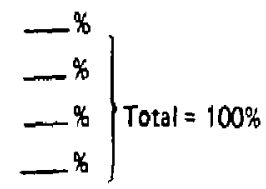




\section{EXHIBIT 6-2}

When transmitting information to the following people in your department, how often do you eummarize by emphasizing those aspects which are important and minimize those aspects which are unimportant?

48. Immediate Superiors

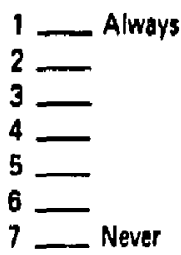

49. Subordinates

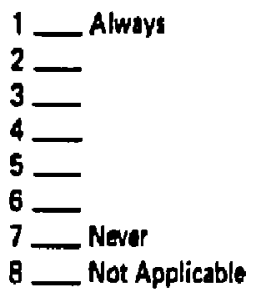

50. Peers-Others at Your Job Level

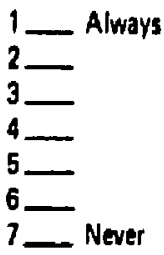

When transmitsing information to the following departments, how often do you summarize by emphasizing those aspects which se important and minimizing those aspects which are unimportant?

51. Operations

52. Maintenance

53. I\&C

54. Quality Assurance

55. Health/Physics

56. Plant Management

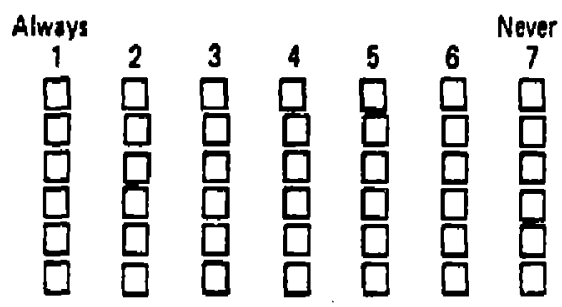

57. In a typical work week, approximately how often do you have less than the amount of information you could consistently handle for making the best possible work-related decisions? 1 - Very often

2

3

4

5

6

7 Not often

58. Sometimes at work you may receive more information than you can efficiently use. Other times, however, you may feel that you are not receiving all the information you need. How of ten during a week would you say this lack of intormation arises?
1 - Very often
2
3
4
5
6
7 - Not often

59. Is the total amount of information you receive in a typical work weak enough to meet the information requirtments of your job?
1
2
3
4
5
6
7 Too much
-
-
$\longrightarrow$ Not enough at all 
When transmitting information to the following people in your department, how often do you expand it by discussing in greater detail some aspects of the information?

60. To Immediate Superiors

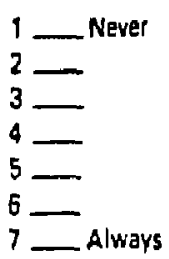

61. To Subordinates

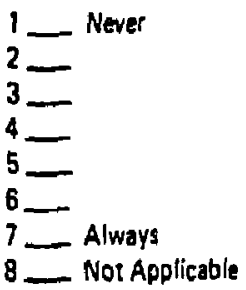

62. To Peers-Others at Your Job Level

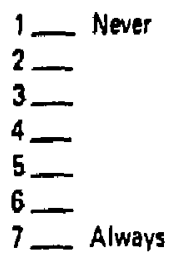

When transmitting information to the fellowing departments, how often do you expand it by discussing in greater detail some aspects of the inlormation?
Never
63. Operations
$\begin{array}{llll}1 & 2 & 3 & 4\end{array}$
Always
$\square \square \square \square \square \square \square$
64. Maintenance
$\square \square \square \square$
$\square$
$\square \square$
65. I\&C
66. Quality Assurance
67. HealthiPnysics
68. Plant Management

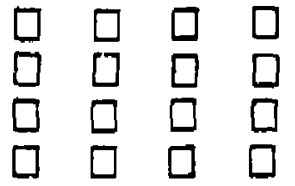
$\square$
$\square$
$\square$
$1]$

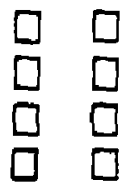

Of the iotal amount of information you receivt at work, how much du you pass on to:

69. Immediate Superiors

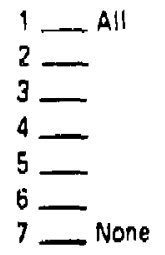

70. Subordinates

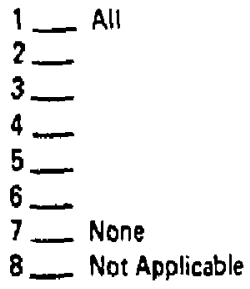

71. Peers-Others at Your Job Level

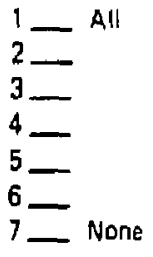

How desirable do you feel it is in your work group to interact frequently with:

72. Immediate Superiors

1 _ Very Desirable

2 -

3

4

5

6 - Completely Undesirable
73. Subordinates

1 _ Very Dessirable

2

3

4

5

6.

7 Not Applicable
74. Peers -Others at Your Job Level

$$
1 \text { - Very Desirable }
$$

2

3

4

5

6

7 Completely Undesirable Completely Undesirable 
75. While at work, we often receive the same information (such s directives, ratements of policy, changes in regulations, requests for reports, etc.) more than once. How often do you estimate the information you receive on the job is received more than once?

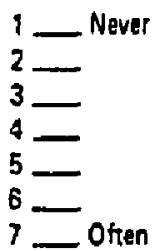

It is often necessary in our jobs not to pass to others some of the information which comes to us. About how often during a typical week do you withhold from the following people information which might be useful to them?

76. Immediate Superiors

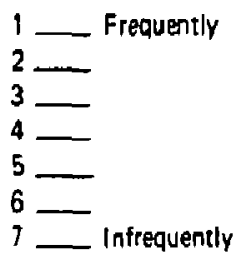

77. Subordinates

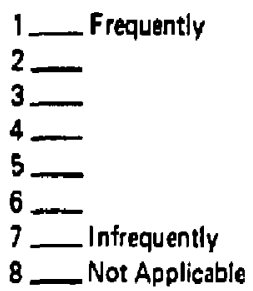

78. Peers-Others at Your Job Level

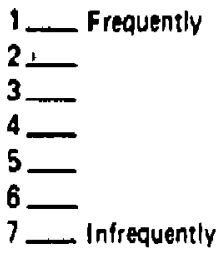

It is often necessary in our jobs not to pass to others some of the information which comes to us. About how often during a typical week do you withhold from the following departments infor. mation which might be uselul to them? Frequently

79. Operations

1

80. Maintenance

81. 180

82. Quality Assurance

83. Health/Physics

84. Plant Management
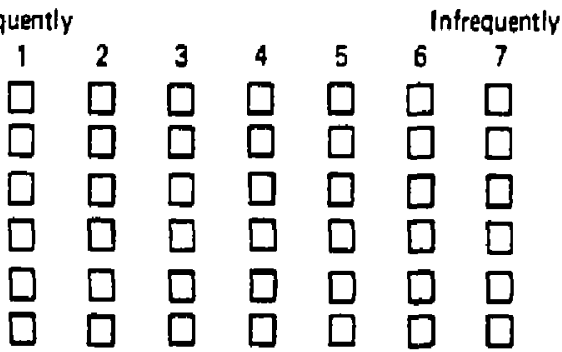

We often find it necessary to change the nature of inlormation le.g., use different words, shift emphasis, simplify, etc.) we pass on to others in our organizations. Of the fotal amount of information you raceive, how much of it must you axtively change in some way before you pass it on to the following people in your department:

85. Immediate Superiors

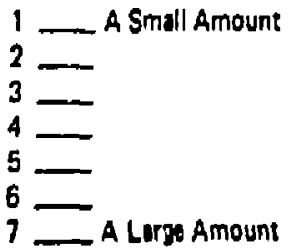

86. Subordinates

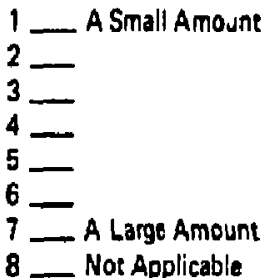

87. Peers-Others at Your Job Level

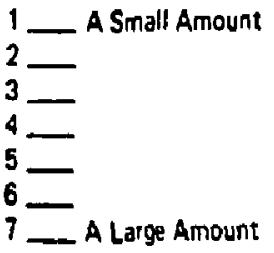




\section{ORGANIZATIONAL COMMONICATION INDICES AND THEIR \\ COMPONENT QOESTIONNAIRE TTEMS}

Listed below are the set of communication indices taken from the Organizational Communication Questionnaire $e^{4,5}$ and the related questionnaire items that make up each index. Questionnaire item numbers correspond to those numbers shown in Exhibit 6-2 of the Appendix.

\section{INDEX}

Trust

Influence

Mobility

Upward Direetionelity

Downward Directionality

Lateral Directionality

Quality of Work-Related Documentation

Accuracy
Summarization
Expansion
Getekeeping/Withholding
Information
Desire for Interaction
Redundancy
Changing Information
Satisfaction
Information Amount
Timeliness
Feedback

QUESTIONNAIRE

ITEM NUMBERS

$4,5,10$

6, 7

8,9

$11,14,41,44$

$12,15,40,45$

$13,16,42,46$

$27,28,29,30,31,32$

$33,34,35,36,37,38$

$48,49,50,51,52,53$, $54,55,56$

$60,61,62,63,64,65$. $66,67,68$

$69,70,71,76,77,78$, $79,80,81,82,83,84$

$72,73,74$

75

$85,86,87,88,89,90$, $91,92,93$

94

$57,58,59,95,96,97$,

98,99

100-110

111-120 


\section{EXEIBIT 6-2}

Of the total amount of information you receive, how much of it must you ectively change in some way before you pass it on to the following departments:

88. Operations

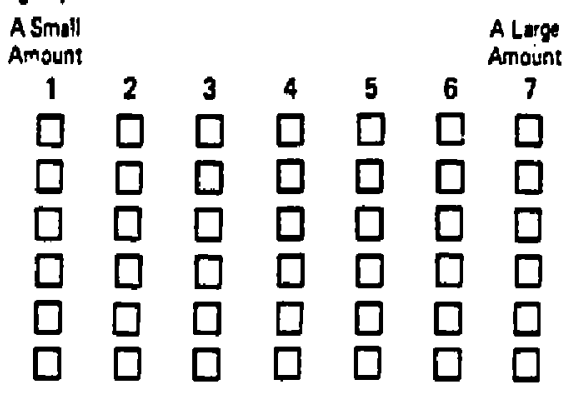

89. Maintenance

90. IaC

91. Quality Assurance

92. Health/Physics

93. Plant Management

94. Put a check under the face that expresses how you feel about communications in general, including the amount of information you receive, consats with your immediate superior and others, the accuracy of information available, etc.
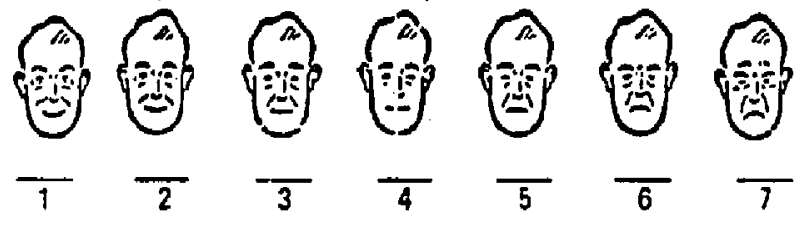

7

All organizations have reporting requirements. Please rate your satisfaction with the amount of information you give/send to others regarding the areas listed below.

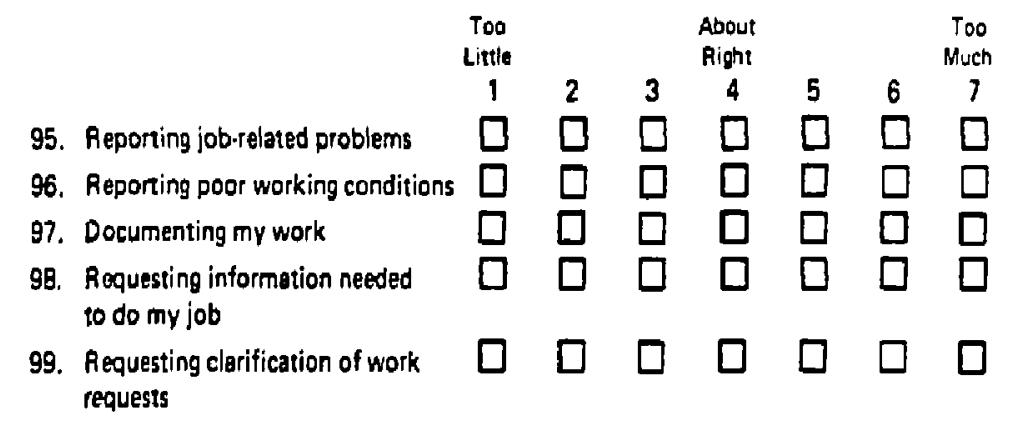




\section{EXHIBIT $6-3$}

CANDIDATE INTERVIEW QUESTIONS FOR THE ORGANIZATIONAL COMMUNICATION SORVEY

This set of interview questions was developed to tap critical incidents or real world examples of communication problems that employees have in their organization. The topic areas of the interview questions correspond to the major areas covered in the Organizational Communication Survey (Exhibit 6-2). These questions should be asked to a cross section of DOE facility personnel on an individual and confidertial basis. The interview responses should be reviewed to verify the questionnaire data findings and to provide examples of specific events where problems have occurred.

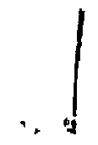




\section{EXHIBIT 6-3}

1. Do communication problems between functional areas lead to conflictug priorities for your facility or problems with advanced planning?

2. Do the official lines of communication in your facility allow for effective transfer of information up and down the chain of command? Why do you feel this is true?

3. Do the' official lines of communications break down? If so, where and when?

4. Do you sometimes receive inadequate information from other functional areas? Which areas do you have the most. problems with?

a. How is the information received from oth t functional areas inadequate?
(1) Incomplete
(2) Inaccurate
(3) Untimely
(4) Poorly written/transmitted

b. What type of information, in particular, is most inadequate jrom ther functional areas? (e.g., general letters of transmittal: work requests, foreeasts, etc.)

c. What suggestions do you have to help other functional areas improve on the adequacy of iniormation which they provide to you?

d. Do you ever experience work delays that are caused by poor communication between functional areas?

What types of delays? Please give an example. 


\section{EXHIBIT 6-3}

Are the activities in your furctional areas sensibly organized?

\section{IF YES:}

a. What factor(s) do you believe contribute most to the sensible organization of your functional area's work activities?

IF NO:

b. What is an example of work activities hut being sensibly organized?

c. What factor(s) do you believe ccultribute most to the lac: of sensibie organization of work activities?

d. What suggestions do you have to orgarize work activities more sensibly?

6. Does your supervisor provide support to help get work done on time?

a. What are some examples of when your supervisor has provided support to help you get your work done on time?

What are some examples of when your supervisor has not provided support?

b. What factor(s) ds you believe contribute mosi to your supervisor's lack of support in getting your job done on time.

c. What suggestions do you have that might help your superviso: to provide you with the support you need to get your work done on time? 
7. Can you think of any specific problems with work procedures and/or documentatic that cause confusion or increase the chance of performance errors? What are these? 
RXHIBTT 6-4

SAHPLE INTBRVET TALLY SHEET

INIERVIEW QUESTION:

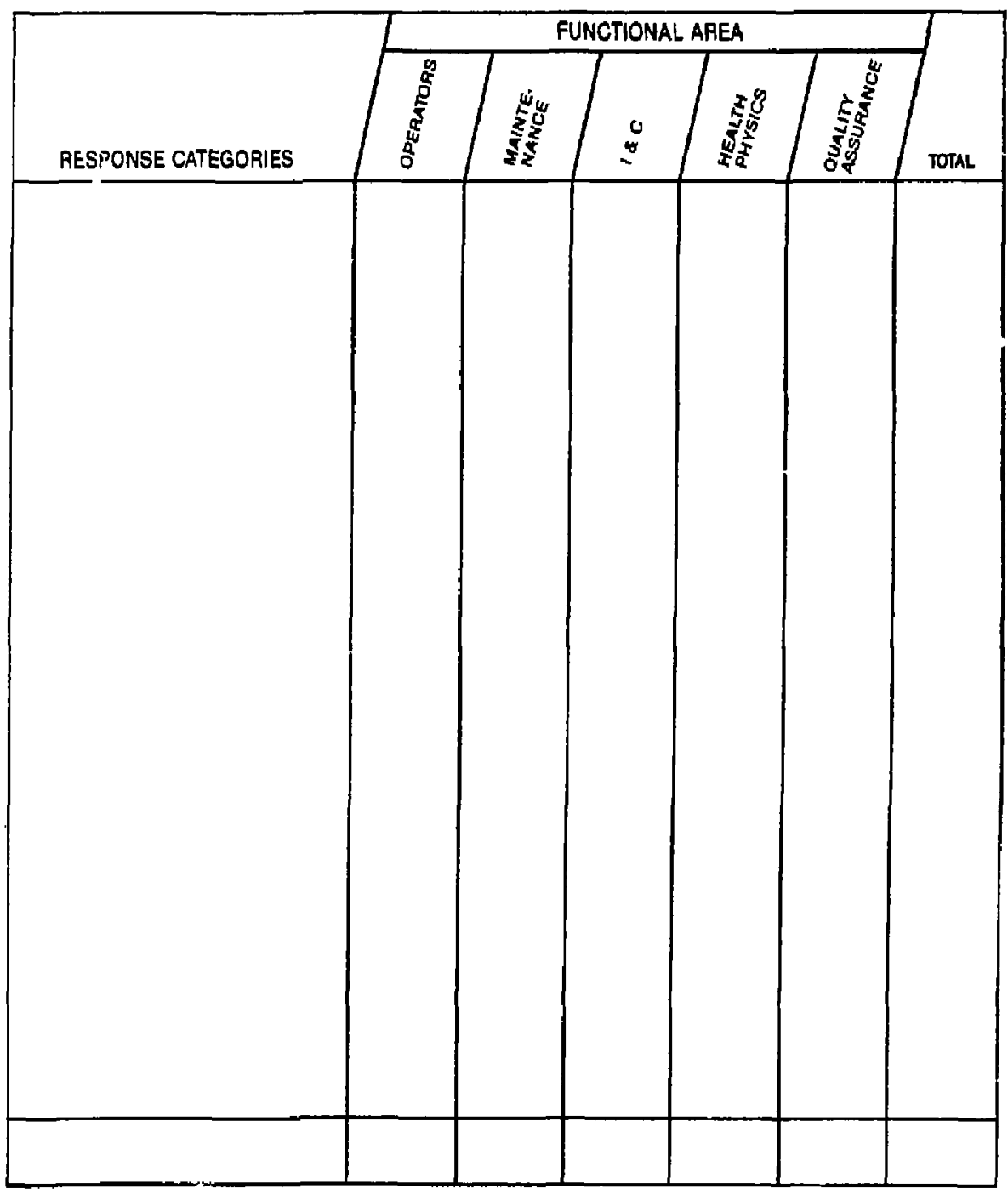

A-1 148 


\section{BXHIBTT 6-5}

SUMMARY RYALUATON OP CANDIDATE

ORGANIZATONAL INTEREACE SOLUTIONS

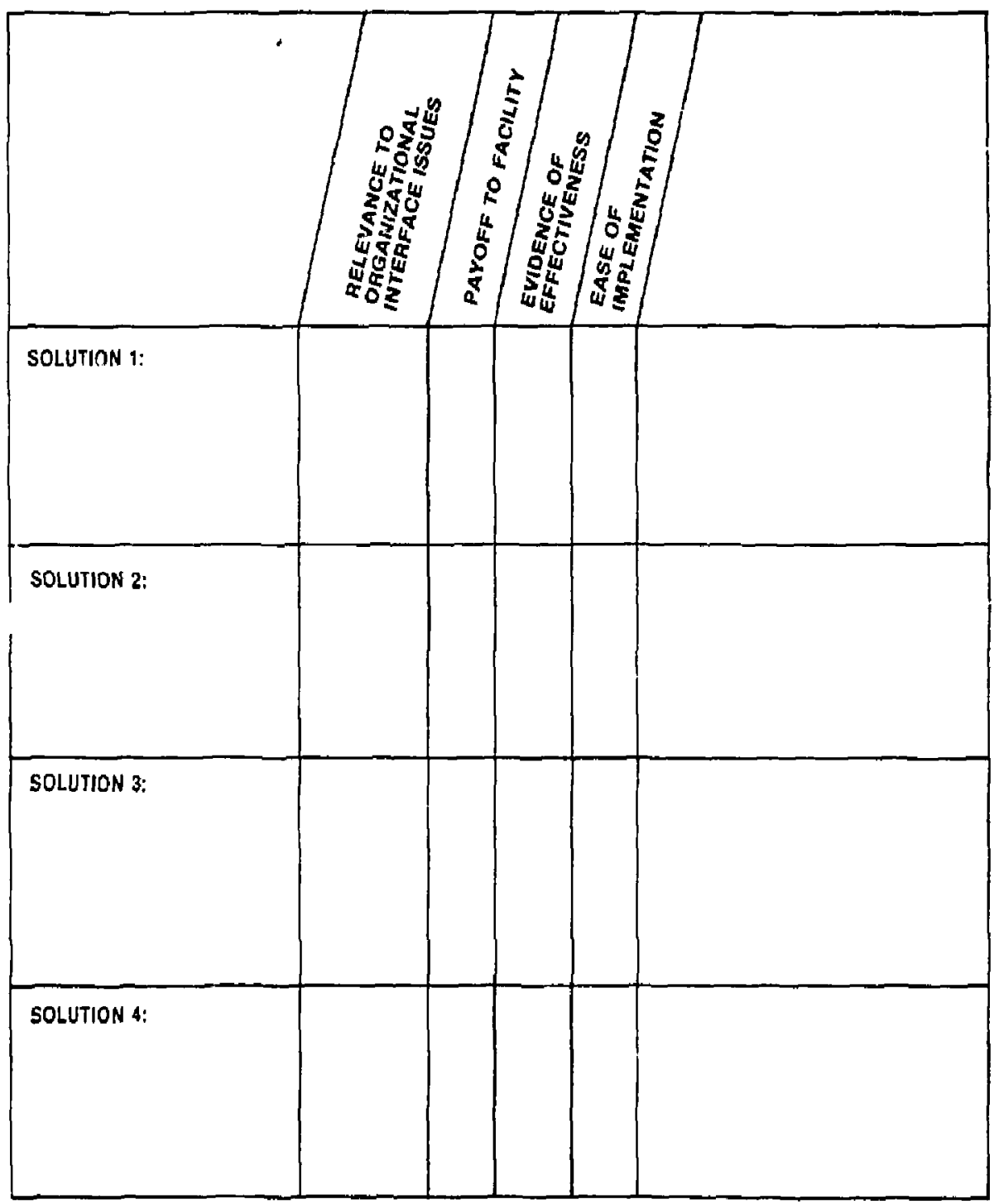

MAKE RATINGS FOR EACH

CRITERION ON A FIVE.POINT

RATING SCALE ( $1=$ LOW; $5=$ HIGH). 
FIGORE 6-1

MANAGEMENT/PLANT INTERPACE

$\%$ WHO HAVE PROBLEMS INTERFACINO WITH:
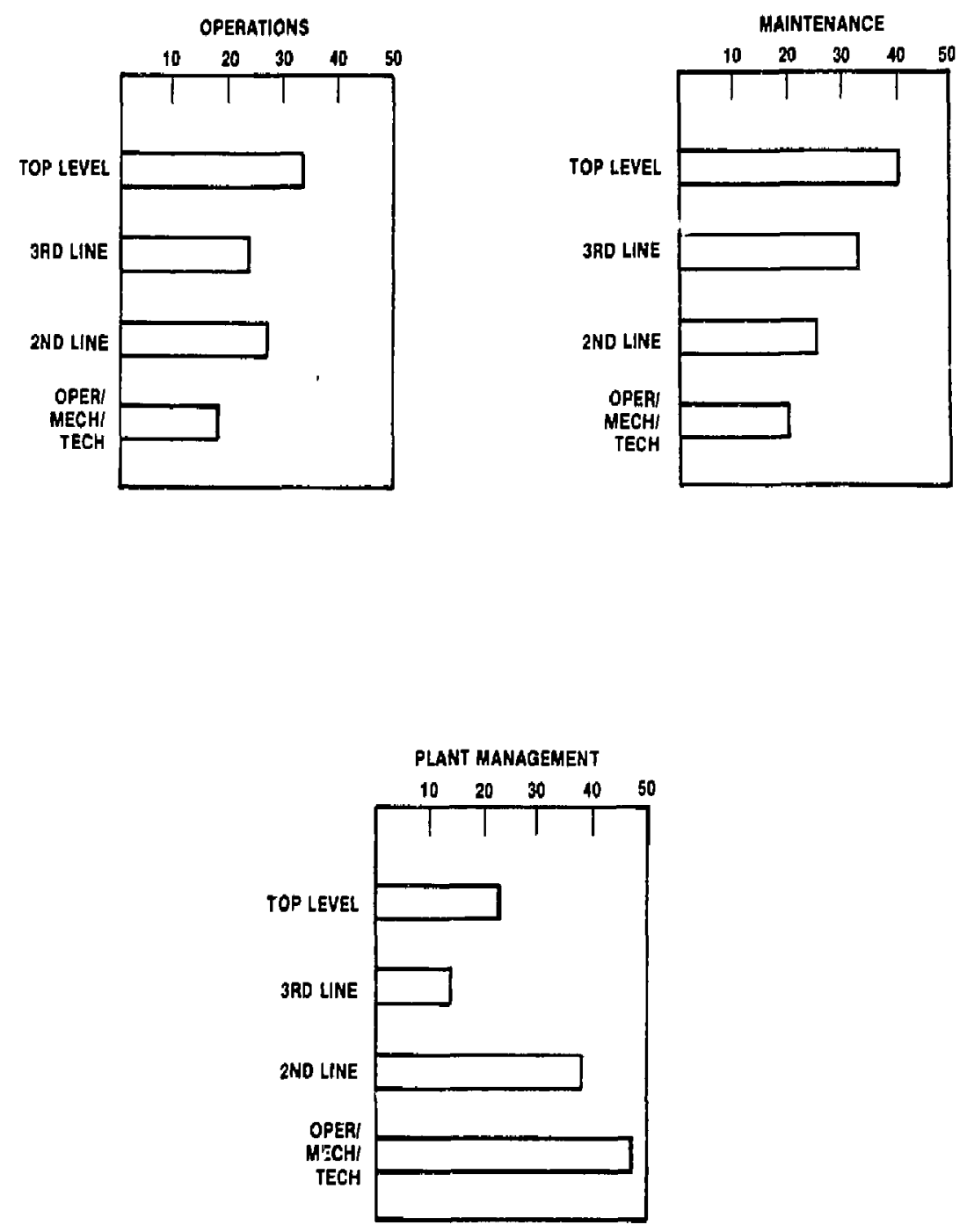
TABLE 6-1

TYPICAL CROSS SECTION OF DOR PACIITY PERSONNEL SELECTED FOR AN ORGANIZATIONAL COMMONICATIONS SURVEY

\begin{tabular}{|c|c|c|c|c|}
\hline Functional Area & $\begin{array}{c}\text { Operator/ } \\
\text { Technician/ } \\
\text { Mechanic } \\
\end{array}$ & $\begin{array}{c}\text { Line } \\
\text { Supervisors }\end{array}$ & $\begin{array}{c}\text { Department } \\
\text { Manggers } \\
\end{array}$ & $\begin{array}{l}\text { Top-Level } \\
\text { Manager }\end{array}$ \\
\hline Operations & 4 & 1 & 1 & \multirow{4}{*}{1} \\
\hline Maintenance & 4 & 1 & 1 & \\
\hline $18 \mathrm{C}$ & 2 & 1 & 1 & \\
\hline Healt? and Safety & 2 & 1 & 1 & \\
\hline $\begin{array}{l}\text { Quality Control/ } \\
\text { Quality Assurance }\end{array}$ & $\underline{2}$ & $\underline{1}$ & $\underline{1}$ & - \\
\hline Subtotals & 14 & 5 & 5 & 1 \\
\hline
\end{tabular}

Total: 25 persornel per facility receiving questionnaires. 
TABLE 6-2

DEPARTMENTAL COMMUNICATION PROBLEMS* BY PACDITY

COMMUNICATION

\begin{tabular}{|c|c|c|c|c|c|c|c|}
\hline & OPERATIONS & $\begin{array}{c}\text { MAINTEN- } \\
\text { ANCE }\end{array}$ & $18 \mathrm{C}$ & & $\begin{array}{l}\text { HEALTH } \\
\text { SAFETY }\end{array}$ & QANQC & $\begin{array}{l}\text { MANAGE. } \\
\text { MENT }\end{array}$ \\
\hline FACILITY & $\begin{array}{ll}\text { GATEK } & (3.6) \\
\text { REDUND } & (3.53\end{array}$ & $\begin{array}{ll}\text { AMOUNT } & 13 . \\
\text { REDUND } & 13 . \\
\text { TIMELIN } & 13 . \\
\text { MODAL } & 13 .\end{array}$ & $\begin{array}{l}\text { REDUND } \\
\text { MOOAL }\end{array}$ & $\begin{array}{l}(3.3) \\
\text { (3.3) }\end{array}$ & $\begin{array}{ll}\text { MODAL } & (\mathbf{3 . 1 )} \\
\text { REDUND } & (3.3) \\
\text { AMOUNT } & (3.7) \\
\text { TIMELIN } & (3.7) \\
\text { FEEDBACL } & (3.8)\end{array}$ & $\begin{array}{l}\text { OATEKEEP }(3.3) \\
\text { AMOUNT }(3.9)\end{array}$ & $\begin{array}{ll}\text { OVERLOAD }(2.0) \\
\text { TIMELIN } & (3.0) \\
\text { REDUND } & (3.0) \\
\text { MOBIL } & (3.0) \\
\text { GATEK } & (3.3) \\
\text { EXPÄNS } & (3.8)\end{array}$ \\
\hline FACILITY & $\begin{array}{lr}\text { AEOUND } & (3.0) \\
\text { INFLUEN } & (3.3) \\
\text { UNCERL } & (3.4) \\
\text { CHANG } & (3.6) \\
\text { FEEDBACK } & (3.6) \\
\text { TIMELIN } & (3.7) \\
\text { MODAL } & (3.8)\end{array}$ & $\begin{array}{ll}\text { REDUND } & 12 \\
\text { MODAL } & 13.8 \\
\text { OVERL } & 13 . \\
\text { UNDEAL } & 13 . \\
\text { TIMELIN } & 13 . \\
\text { AMOUNT } & 13 .\end{array}$ & $\begin{array}{l}\text { FEEDEACK } \\
\text { TIMELIN } \\
\text { UNDEAL } \\
\text { REDUND } \\
\text { AMOUNT }\end{array}$ & $\begin{array}{l}(9.3) \\
(3.4) \\
(3.7) \\
(3.7) \\
(3.7)\end{array}$ & MODAL & $\begin{array}{ll}\text { AEDUND } & (3.5) \\
\text { GATEK } & (3.9)\end{array}$ & $\begin{array}{ll}\text { ITECH STAT) } \\
\text { OVERLOAD }(3.0) \\
\text { UNDEAL } \\
\text { AEDUND } & (3.5) \\
\text { AMOUNT } & (3.5) \\
\text { AMO) }\end{array}$ \\
\hline FACILITY & AMOUNT $\quad(3.9)$ & $\begin{array}{ll}\text { REDUND } & (2 . \\
\text { EXPANS } & 13 . \\
\text { AMUINT } & (3 . \\
\text { MOCAL } & 13 . \\
\text { MAINT } & 13 .\end{array}$ & $\begin{array}{l}\text { AEDUND } \\
\text { AMOUNT }\end{array}$ & $\begin{array}{l}(3.7) \\
(3.7)\end{array}$ & $\begin{array}{ll}\text { UNDERL } & (2.9) \\
\text { TIMELIN } & (3.3) \\
\text { FEEDBACK } & (3.6) \\
\text { MODAL } & (3.7)\end{array}$ & $\begin{array}{ll}\text { AMOUNT } & (3.7) \\
\text { MODAL } & (3.8) \\
\text { FEEDBACK } & (3.5)\end{array}$ & $\begin{array}{ll}\text { REDUND } & (2.5) \\
\text { AMOUNT } & (3.7) \\
\text { INFLUEN } & (5.8)\end{array}$ \\
\hline
\end{tabular}

*Indices shown have mean scores less than 4.0 on a 7-point (low to high) rating scale. 
TABLE 6-3

JOB COORDINATION MEETING AGENDA/SUMMARY IIFORMATION PORM

\begin{tabular}{|c|c|c|c|c|c|c|c|c|}
\hline Work Request Process Funetions & $\mid \begin{array}{c}\text { Needs } \\
\text { Follow -up }\end{array}$ & $\begin{array}{c}\text { Missing } \\
\text { Job-Relcovant } \\
\text { lntormation }\end{array}$ & $\begin{array}{l}\text { Takes } \\
\text { Too Lorg }\end{array}$ & $\begin{array}{l}\text { Intormation } \\
\text { withneld }\end{array}$ & $\begin{array}{l}\text { Too Little } \\
\text { Peedhack }\end{array}$ & $\begin{array}{c}\text { Redundent } \\
\text { Information }\end{array}$ & $\begin{array}{c}\text { Duplication } \\
\text { of Effort }\end{array}$ & $\begin{array}{c}\text { Affected Departments/ } \\
\text { Comments }\end{array}$ \\
\hline 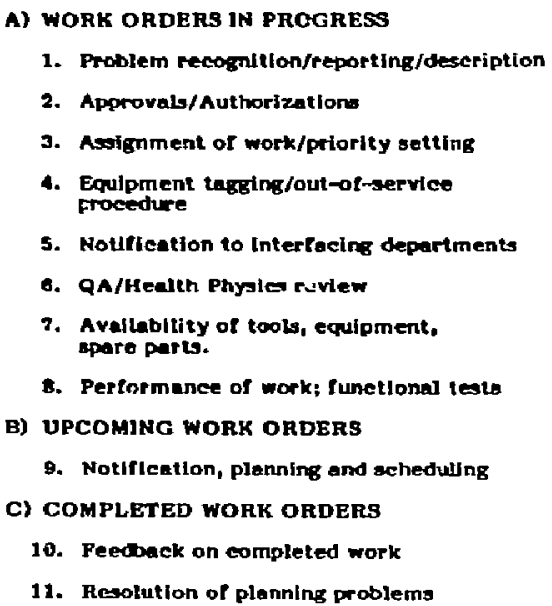 & & & & & & & & \\
\hline
\end{tabular}




\subsection{ORGANZATIONAL INTERPACE REVIEW}

\section{REPERENCES}

1. Seminarg, J. L., Parsons, S. O., Schmidt, W. J., Gonzalez, W. R., \& Dove, L. E. (1980). Human factors review of power plant maintainability (EPRI NP-1567SY). Paio Alto, CA: Electric Power Research institute.

2. Law, T. M. (Chairman) (1981, March). Workshop proceedings: Power plant maintenance and maintainability (EPRI NP-8-3-LD). Prepared by Pickerd, Lowe, and Garrick, Inc. Palo Alto, CA: Electric Power Research Institute.

3. Bauman, M. B., Pain, R. F., Ven Cott, H. P., \& Davidson, M. K. (1983). Survey end analysis of work structure in nuclear power plants (EPRI NP 3141). Palo Alto, CA: Electric Power Research Institute.

4. Roberts, K. H., \& O'Reilly, C. A., Ill. (1974). Measuring orgenizational communication. Journal of Applied Psychology, 59(3), 321-326.

5. Roberts, K. H., \& O'Reilly, C. A., III. Assessing Communication in Orgenization (supplementary notes to reference 6, describing the revised questionnaire used as the basis for the Organizational Communication, Questionnaire presented in this chapter. Berkeley, CA: University of Californie, School of Business Administration.

6. Bauman, M. B., Davidson, M. K., \& Van Cott, H. P. Enhancing plant effectiveness by improving organizational communication. To be presented at the 1984 Human Factors Society Annual Meeting, San Antonio, Texas, October, 23, 1984 .

7. Flannagan, J. (1954). The critical ineident technique. Psychological Bulletin, 51, $327-358$.

B. Selway, R. W. (1984). Quality Circles in Action. Presented at the Institute of Nuclear Power Operations Maintenance Superintendents Workshop, Atlanta, Georgia, April 23-25, 1984.

9. Olson, J., MeLaughlin, S. D., Osborn, R. N., \& Jackson, D. H. (1984). An initial empirical analysis of nuclear power plant organization and its effect on safety performance (NUREG/CR-3737). Washington, D.C.: U.S. Nuclear Regulatory Commission. 


\subsection{TRANING REVIEW}

REVIEW AIDS 


\subsection{TRALING REVIEW}

REVIEW AIDS 


\subsection{TRANING REVIEW}

\section{REFERENCES}

1. U.S. Department of Energy. (1983, June). Juidelines for job and task analysis for DCE nuclear facilities (DOE/EP-0095). Washington, DC: Author.

2. Memphis State University, Center for Nuclear Studies. (1984, January). Guidance Cor training program evaluation (DOE/EV/10782-T). Washington, DC: U.S. Department of Energy.

3. Institute of Nuclear Power Operations. (1985, February). Principles of training system development manual (INPO 85-006). Atlanta, GA: Author.

4. Institute of Nuclear Power Operations. (1985, February). Principles of training system developrient (supplement) (INPO 85-006 (Supplement)). Atlanta, GA: Author.

5. Heas, P., Selby, D., Hanley, M., and Mercer, R. (1983, September). Evaluation of training programs and entry level qualifications for nuclear power plant control room personnel based on the systents approach to trainirg (ORNL/TM-8848). Oak Ridge, TN: Oak Ridge National Laboratory.

6. Paramore, B., Banks, W.W., Venesiano, C., Gilmore, R., and Coleman, S. (1983, November). A pilot task analysis of the Rockwell size reduction facility, 234-5Z plutonium finishing plant. Richland, WA: Hanford Environmental Health Foundation.

7. U.S. Department of Energy (1985, November). Guidelines for Evaluation DOE NonReactor Nuclear facilities training prugrams. 


\section{WDEX}

\section{Page}

ASSESSMENT

Of Human Factors Discrepancjes

43-47

Of Needs For Addad Procedures

65-66

of Organizational Problems

$87-88$

Procedure for Prioritization

17

\section{CHECKLIST}

For Assessment

For Humen Factors Engineering Review

32-34 \&

A $-9-21$

For Maintainability Review

A-22-39

For Procedures Review

DEPARTMENT OF ENERGY

Humen Factors Program.

Office of Nuclear Safety

DISPLAYS

ERROR

Causes of

Consequence of $45-46,69$

Detection of 45

Factors 33

Potential For

45,69

Procedure Related

48, A-100 


\author{
Recovery From \\ Types of \\ Weighting Consequences or
}

FUNCTIONAL FLOW DIAGRAM

\author{
HUMAN \\ Error (see Error) \\ Interfaces
}

HUMAN FACTORS

Definition of

HUMAN RELIA IILITY

A. Function of

HURAN FACTORS ENGINEERING REVIEW

Assessment Of Human Factors Discrepancies

Checklist For

Criteria For

Discrepancy Report For

Key Terms In

Wethods For

Objectives of

Observation Checklist For

Operating Experience Review For

Phases of

Planning For
Page

45,69

1

A-91-92

A. -95

4

1

$1-2$

$19-47$

43-4?

A -84

21-22

A- $40-41$

A-94

24-02

20-21

32-34

25-32

19

22-24 
Questionnaire For

Reference List For

Review Aids For

Systems Approach To

HUNAN FACTORS REVIEW

M? anagement of

Participants In

HUNAN FACTORS REVIEW PLAN

Nøeds Assessment For

Questionnaires For

Selection Of Areas For

INTERVIEWS

LABELS

MAINTAINASILTTY

Chechlist For

Questionnaire For Review of

MAINTENANCE

\section{NEEDS ASSESSMENT}

Questionnaire Items For

OPERATING EXPERIENCE REVILW

Data Form For

Interview Form For
$11-17$

Page

A-47-63

A-97-98

A-8-21

$35-41$

6-10

$7-9$

27-32

$11-18$

15

33

A-22-39

A-64-82

A-3

$A-4-5$

$25-32$

A $-42-45$

A -46 


\section{INDEX (continued)}

ORGANIZATIONAL REVIEW

$\underline{\text { Page }}$

$71-87$

Assessment of Solutions $\quad 86-87$

Criteria For $\quad 72-75$

Methods For $\quad 76-82$

Objectives of 72

References For A-154

Review Aids For ; A-133-153

Solving Problems Identified By $\quad$ 82-85

PANEL

Design of $\quad A-2$

Laynut of $\quad 33$

PROCEDURES REVIELi: $48-70$

Assessment Or Needs For Added Procedure : $\quad 63-66$

Criteris For 49

Evaluation of Procedures Management 62-63

Methods For $\quad 50-66$

Objectives of 49

Performance Exercises $\quad 61$

Reierences For A-131-132

Review Aiơs For A-99-132

Trade-Offs in $\quad 49-50$

Validation Of Performance Effectiveness $58-61$

Verification of Adequacy $51-57$

QUESTIONNAIRE (S)

Critical Incident Items $\quad A-2-3$

Development of 12-14

Distribution of $14-15,31$ 
INDEX (continued)

For Humen Factors Engineering Review

$\underline{\text { Page }}$

27-31

For Procedures Needed

65

Items For

$12-13$

Pretest of

$13-14$

Scalar

A $-4-5$

Selection of Respondents

14

REVIEN METHODS (See Review Plan)

REVIEW PLAN

Applicability of

4

Comparison of Methods For

$41-42$

Organization of

4

Preparation Of Plan For

18

Selection of Review Options

$4-5$

\section{SURVEY}

For Human Factors Engineering Review

TASK ANALYSIS

Data Format For

TRAINING REVIEW

$88-90$

Criteria For

$39-90$

Method For

90

Objective of

89

References For

A- 156 
INDEX (continued)

$\underline{\text { Page }}$

VALIDATION

$\begin{array}{ll}\text { Of Man-Machine System } & 39-41 \\ \text { Of Procedures } & 58-61\end{array}$

VERIFICATION

Of Design Adequacy

38-39

Of Procedures Adeguacy

51-57 